Aus der Abteilung Thorax-, Herz- und Gefäßchirurgie

(Prof. Dr. med. Dipl.-Phys. F.A. Schöndube)

im Zentrum Chirurgie

der Medizinischen Fakultät der Universität Göttingen

\title{
In-vivo-Validierung einer neuen modifizierten HTK-Protektionslösung für Dünndarmtransplantate: eine experimentelle Untersuchung an einem Dünndarm-Transplantationsmodell der Ratte
}

\author{
INAUGURAL - DISSERTATION \\ zur Erlangung des Doktorgrades \\ der Medizinischen Fakultät der \\ Georg-August-Universität zu Göttingen
}

vorgelegt von

Ingmar Lautenschläger

aus

Buxtehude 
Dekan: Prof. Dr. med. C. Frömmel

I. Berichterstatter: PD. Dr. med. T. Stojanovic

II. Berichterstatter: Prof. Dr. med. A. Obed

Tag der mündlichen Prüfung: 23.05.2011 


\section{Inhaltsverzeichnis}

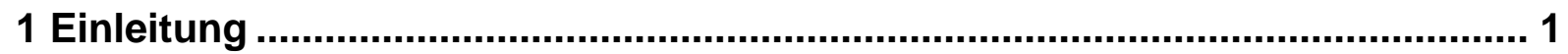

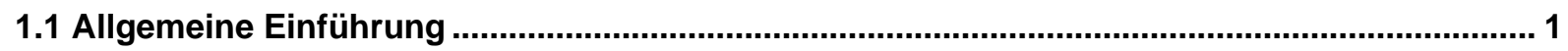

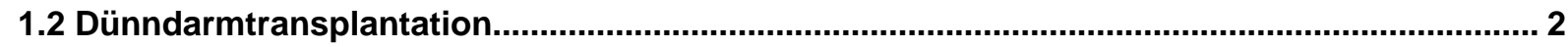

1.3 Phasen und Mechanismen der Transplantatschädigung.................................................... 3

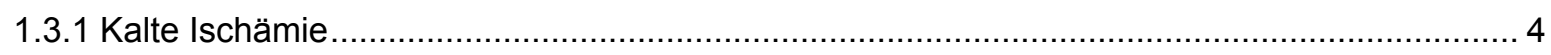

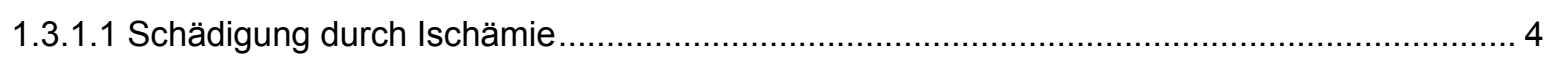

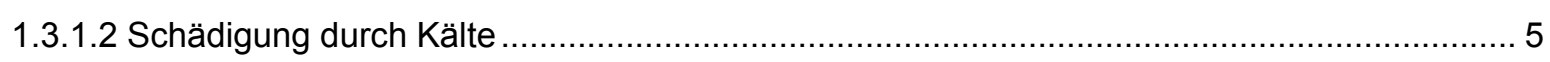

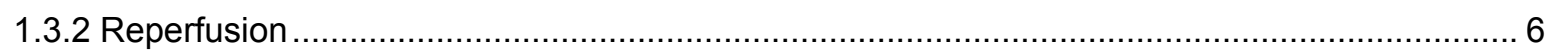

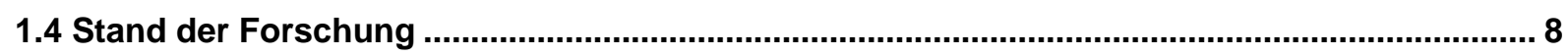

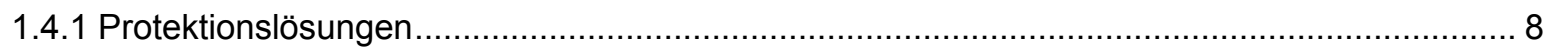

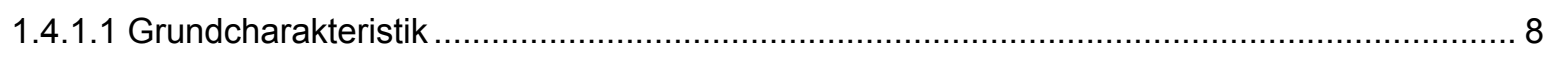

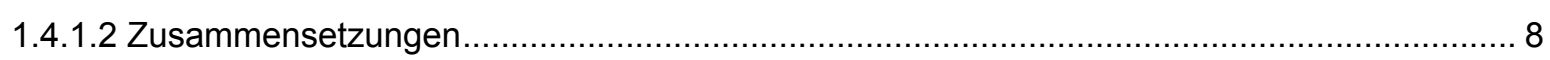

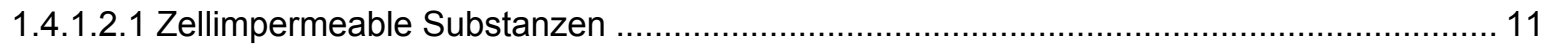

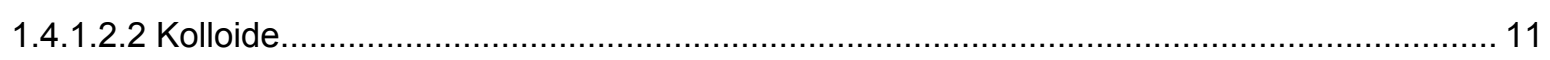

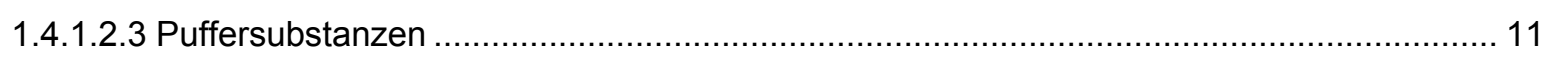

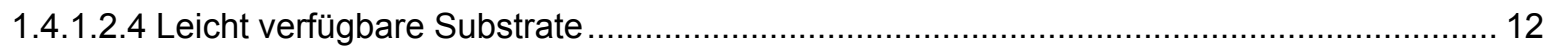

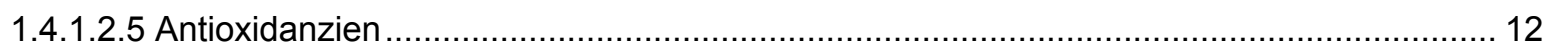

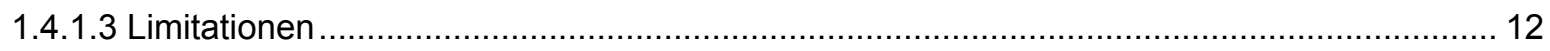

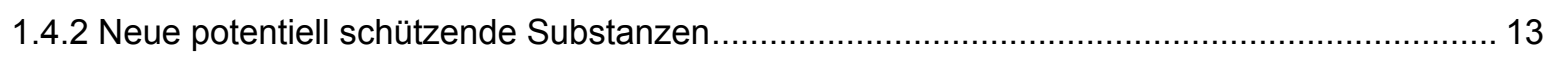

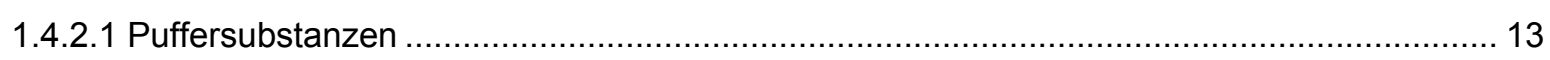

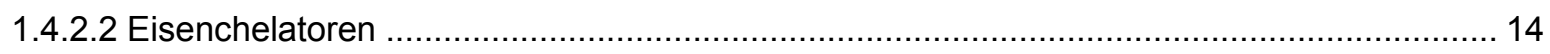

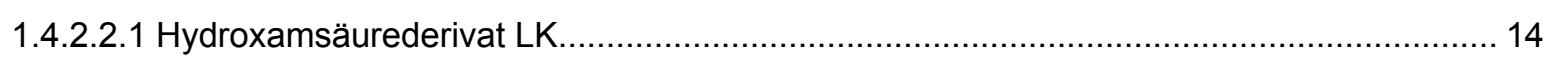

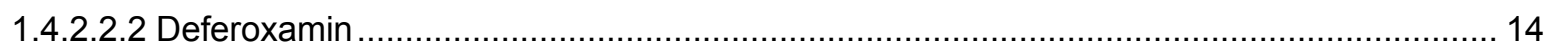

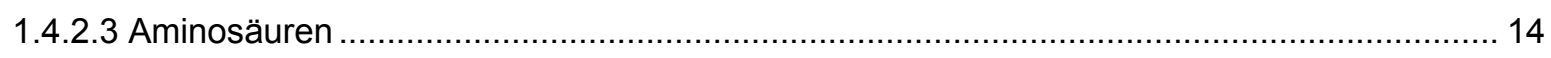

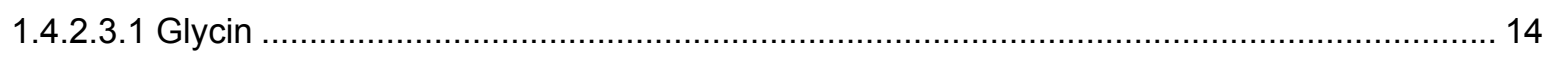

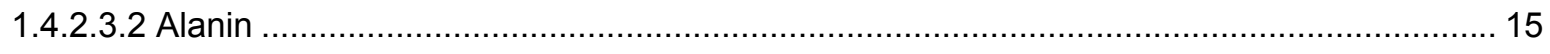

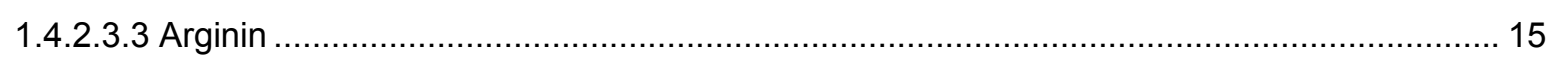

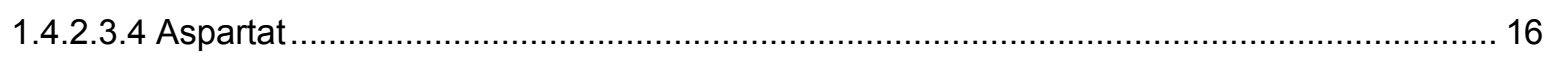

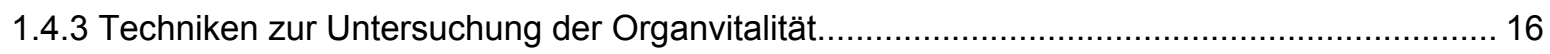

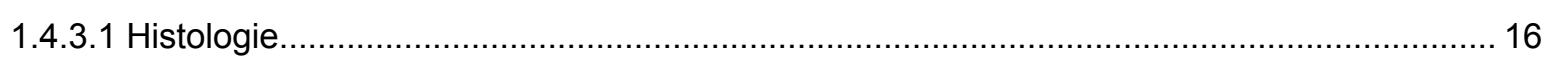

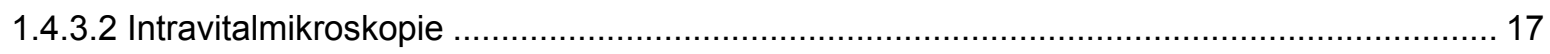

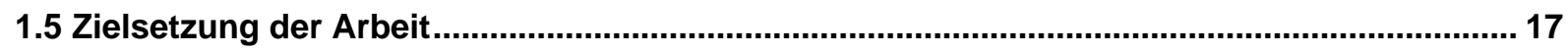

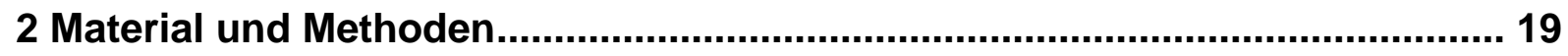

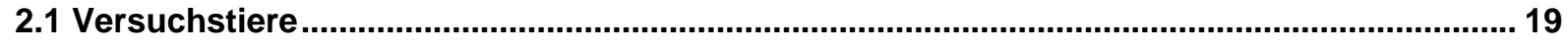




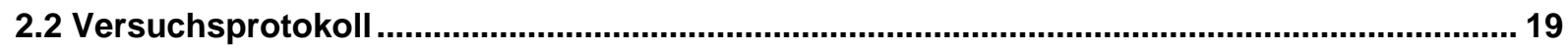

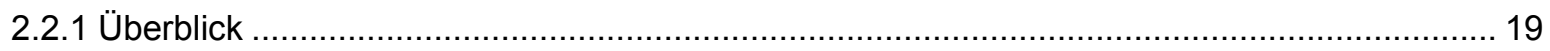

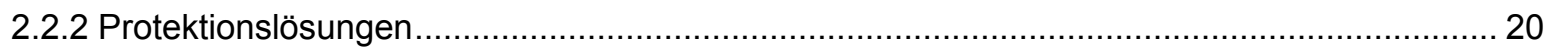

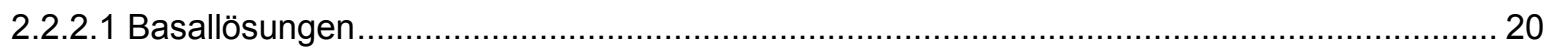

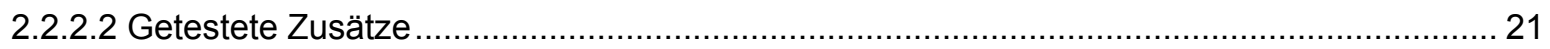

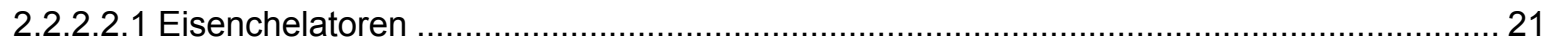

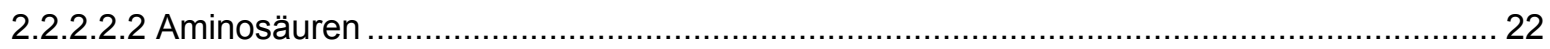

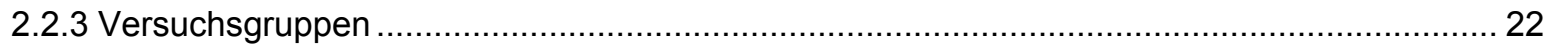

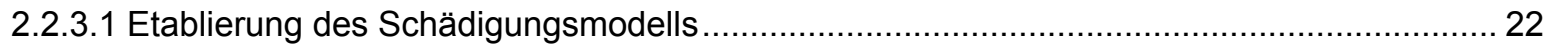

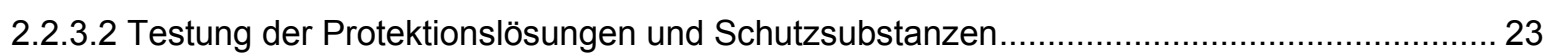

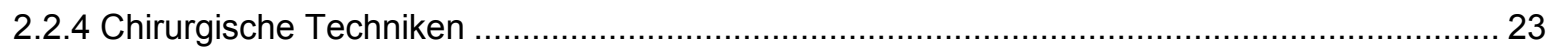

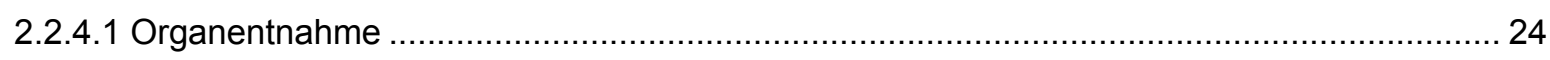

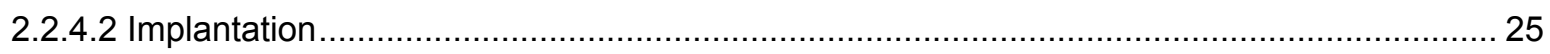

2.2.4.2.1 Kreislaufmonitoring und zentraler Venenkatheter............................................ 25

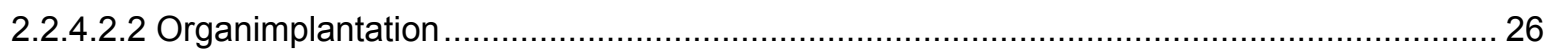

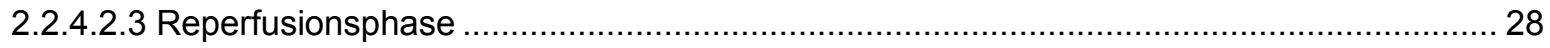

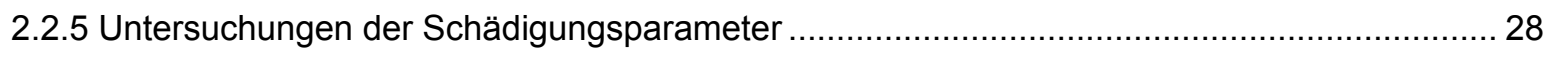

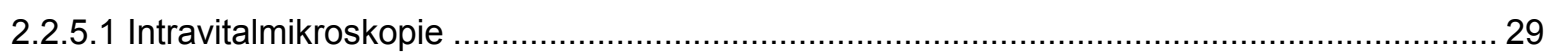

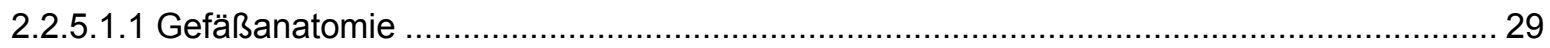

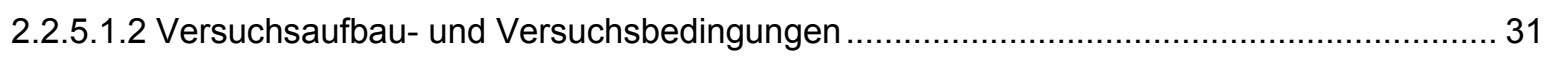

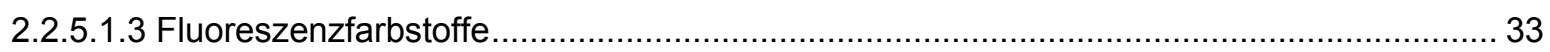

2.2.5.1.4 Technik und Aufbau der Videomikroskopiereinheit ............................................. 33

2.2.5.1.5 Dokumentation der Videomikroskopie ................................................................... 34

2.2.5.1.6 Durchführung der intravitalmikroskopischen Untersuchungen ................................. 35

2.2.5.1.6.1 Gewebeauswahl und Auslagerung ................................................................. 35

2.2.5.1.6.2 Arbeitsschritte der intravitalmikroskopischen Untersuchungen ................................... 36

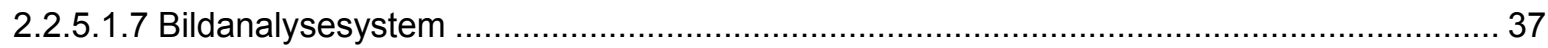

2.2.5.1.8 Durchführung der Bildanalyse zur Quantifizierung der Mikrozirkulation ........................ 37

2.2.5.1.8.1 Funktionelle Kapillardichte der Tunica muscularis (FKD muscularis $) \ldots \ldots \ldots \ldots \ldots \ldots \ldots \ldots \ldots \ldots . \ldots \ldots$

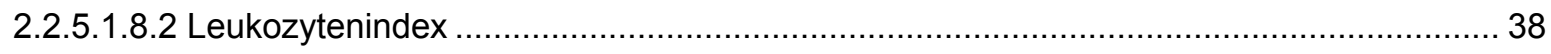

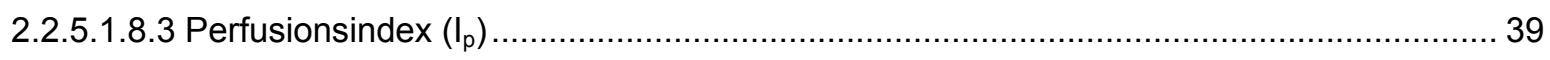

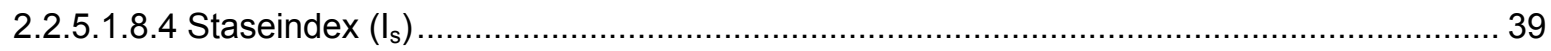

2.2.5.1.8.5 Funktionelle Kapillardichte der Tunica mucosa (FKD mucosa) ................................... 40

2.2.5.1.8.6 Blutkörperchenfließgeschwindigkeit (Red blood cell velocity $\left.\left(\mathrm{RBCV}_{\text {mucosa }}\right)\right) \ldots \ldots \ldots \ldots \ldots . . . . . . .40$

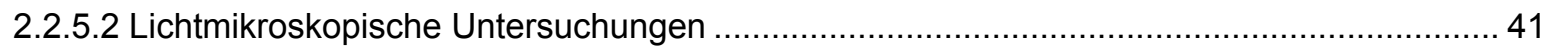

2.2.5.2.1 Histomorphologische Untersuchung der Transplantatschädigung ...............................4 41

2.2.5.2.2 Immunhistochemische Untersuchung der Transplantatschädigung ...........................42

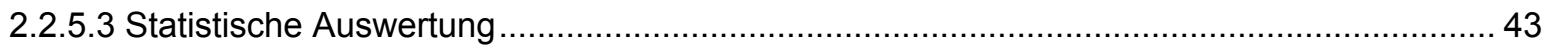

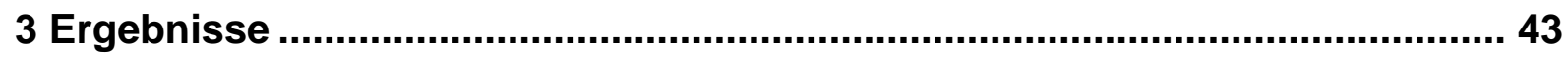

3.1 Ergebnisse der Etablierung des Schädigungsmodells ........................................................... 43 
3.2 Ergebnisse der Testung der Protektionslösungen und Schutzsubstanzen ...........................46

3.2.1 Ergebnisse der Untersuchung der Mikrozirkulation .................................................. 46

3.2.1.1 Funktionelle Kapillardichte der Tunica muscularis ................................................ 46

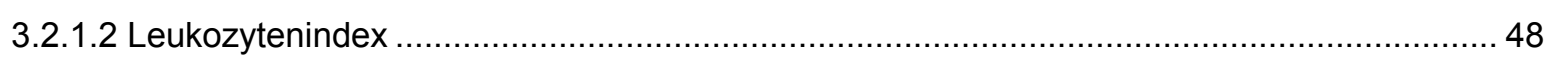

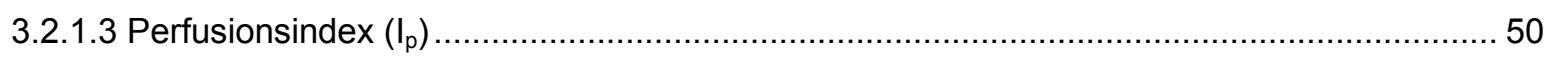

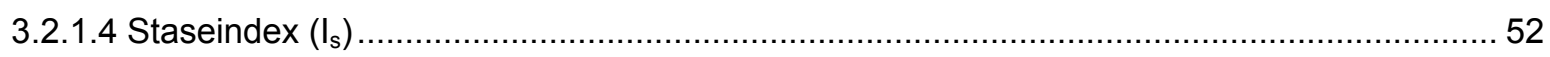

3.2.1.5 Funktionelle Kapillardichte der Tunica mucosa (FKD mucosa) ...................................... 54

3.2.1.6 Blutkörperchenfließgeschwindigkeit (Red blood cell velocity ( $\left.\mathrm{RBCV}_{\text {mucosa }}\right)$ ) ....................56

3.2.2 Ergebnisse der Untersuchung der Histomorphologie ............................................. 58

3.2.3 Ergebnisse der immunhistochemischen Untersuchung der Apoptose .................................61

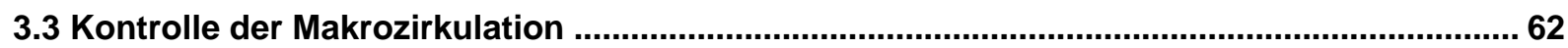

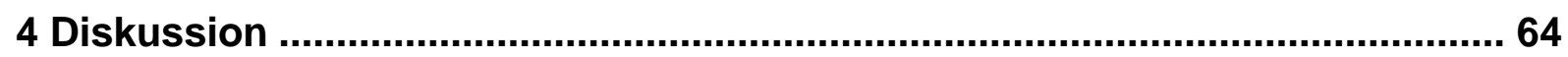

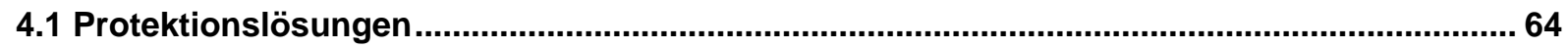

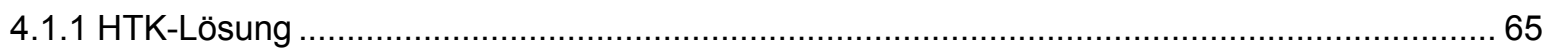

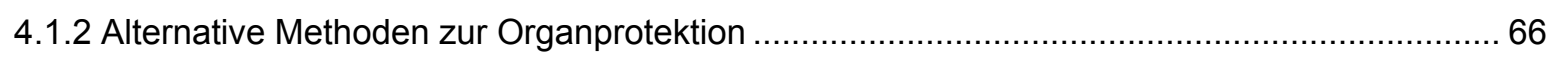

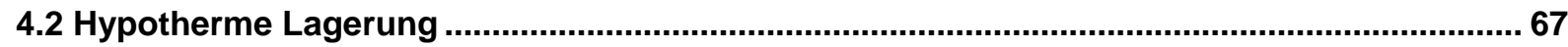

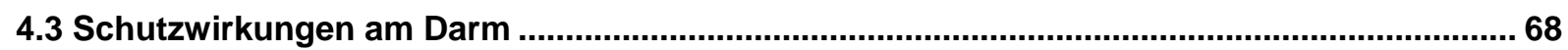

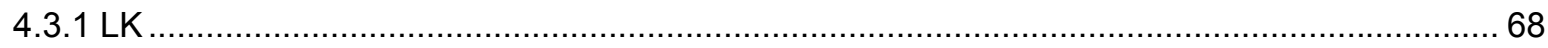

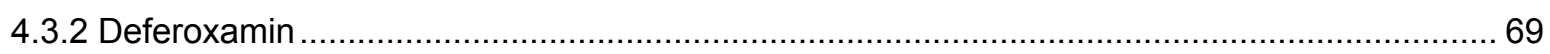

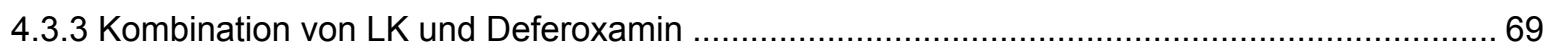

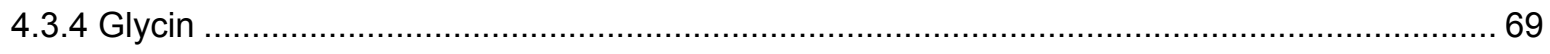

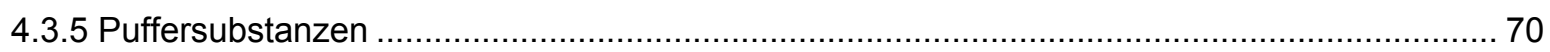

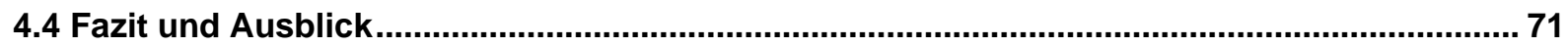

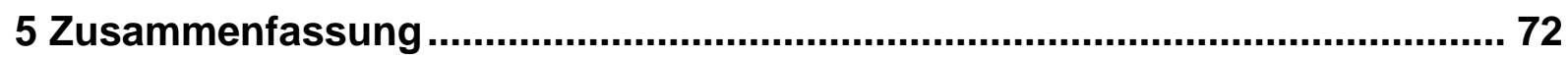

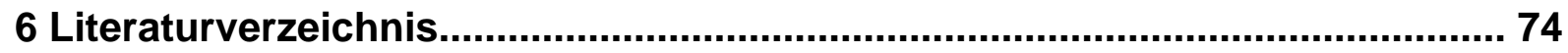

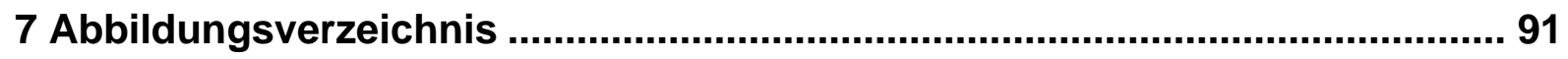

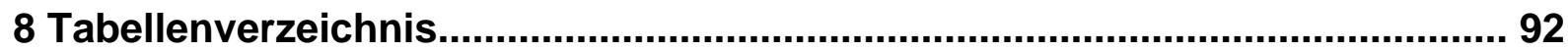




\section{Abkürzungsverzeichnis}

A Gesichtsfeld

ATP

$A_{\text {vil }}$

DES

FITC-Dextran

$F K D_{\text {mucosa }}$

$F K D_{\text {muscularis }}$

GLY

$\mathrm{H}_{2} \mathrm{O}_{2}$

HTK-Lösung

IL-1

$I_{p}$

$I_{s}$

$\mathrm{kDa}$

LEI

lkap

MAD

N36

$\mathrm{n}_{0}$

$\mathrm{n}_{\mathrm{g}}$

$\mathrm{n}_{\text {ges }}$

$n_{\text {irr }}$

$\mathrm{O}_{2}{ }^{-}$

$\mathrm{P}_{\text {dias }}$

$\mathrm{P}_{\text {sys }}$

$\mathrm{OH}$.

$\mathrm{RBCV}$ mucosa

ROS

TBS

TNF- $\alpha$

UW-Lösung
Fläche des Gesichtsfeld

Adenosin 5'-Triphosphat

Villusfläche

Deferoxamin, Desferal ${ }^{\circledR}$

Fluoreszein-Iso-Thio-Cyanat-Dextran

Funktionelle Kapillardichte der Tunica mucosa

Funktionelle Kapillardichte der Tunica muscularis

Glycin

Wasserstoffperoxid

Histidin-Tryptophan-Ketoglutarat-Lösung, Custodiol ${ }^{\circledR}$

Interleukin-1

Perfusionsindex

Staseindex

Kilodalton

Leukozyten-Endothelzell-Interaktion

Länge der nutritiv perfundierten Kapillaren

mittlerer arterieller Druck

neue, modifizierte HTK-Lösung

Anzahl der nicht perfundierten Villi der Mukosa

Anzahl der gut perfundierten Villi der Mukosa

Gesamtanzahl der Villi der Mukosa

Anzahl der irregulär perfundierten Villi der Mukosa

Hyperoxidanionen

diastolischer Blutdruck

systolischer Blutdruck

Hydroxylradikale

Red blood cell velocity, Blutkörperchenfließgeschwindigkeit

reaktive Sauerstoffspezies

Trispuffer

Tumor-Nekrose-Faktor- $\alpha$

University-of-Wisconsin-Lösung, Viaspan ${ }^{\circledR}$ 


\section{Einleitung}

\subsection{Allgemeine Einführung}

Ein irreversibler Verlust an enteraler Resorptionsfläche führt unweigerlich zu einem Kurzdarmsyndrom mit hoher Mortalität auf der einen Seite oder der Notwendigkeit der dauerhaften parenteralen Ernährung auf der anderen Seite. Die ursächlich häufigsten Pathologien für ein Kurzdarmsyndrom, die in ihrem Verlauf eine Dünndarmtransplantation erfordern können, sind bei Jugendlichen die Gastroschisis (21\%), der Volvulus (17\%) und die nekrotisierende Enterokolitis $(12 \%)$ und bei Erwachsenen die mesenteriale Ischämie (23\%), der Morbus Crohn (14\%) und das abdominelle Trauma (10\%) (Grant et al. 2005).

Diese Patienten sind auf eine stetige parenterale Ernährung über mehrere Stunden pro Tag angewiesen. Die totale parenterale Ernährung mündet auf Dauer in Komplikationen, die insbesondere den Gefäßzugang (Infektionen mit 0,34 Episoden I Katheterjahr und Katheter- oder Gefäßverschluss mit 0,071 bzw. 0,027 Episoden / Katheterjahr) (Richards et al. 1997) betreffen und zu metabolischen Störungen (Azotämie, Hyperglykämie, Hypertriglyzeridämie) (Maroulis und Kalfarentzos 2000) und hepatischen Dysfunktionen (Fettleberhepatitis, Cholelithiasis, Cholestase, Cholezystitis) (Angelico und Della Guardia 2000) führen. In der Folge besteht nicht nur die isolierte intestinale Dysfunktion, sondern es entstehen auch Organschäden an der Leber und anderen Organen. Nicht selten versterben die Patienten an Komplikationen, wie septischen Episoden oder Leberfunktionsstörungen, bevor sie transplantiert werden können (Fishbein et al. 2002). Die Dünndarmtransplantation ist für diese Patienten die einzige lebensrettende Therapie (Mangus et al. 2009).

Ziel der Dünndarmtransplantation ist die Beendigung der parenteralen Nährstoffgaben und vollständige Enteralisierung der Nahrungsaufnahme, um dadurch Komplikationen der totalen parenteralen Ernährung zu vermeiden und die Wiederaufnahme von häuslichen alltäglichen Aktivitäten zu ermöglichen. Dies ist bei über $80 \%$ der überlebenden Transplantatempfänger möglich (Grant et al. 2005), sodass gerade jugendliche Patienten von einer Transplantation langfristig profitieren würden. Die Altersverteilung der Transplantatempfänger zeigt mit einem Anteil von über $60 \%$ einen Schwerpunkt bei den jüngeren Patienten im Alter von $\leq 18$ Jahren (Grant et al. 2005). 
Auch wenn in den letzten Jahren die Überlebensraten und die Lebensqualität von transplantierten Patienten deutlich verbessert werden konnten, handelt es sich bei der Dünndarmtransplantation noch immer nicht um eine Standardtherapie (weltweit ca. 180 bis 200 Dünndarmtransplantationen pro Jahr) (Beath 2006, Mangus et al. 2009). Die Ergebnisse bezüglich der Mortalität und des Transplantatversagens bei der Dünndarmtransplantation (1-Jahres Transplantat-/Patientenüberlebensraten ab 1998 weltweit $65 \% / 77 \%$ (Grant et al. 2005)) sind durch neue pharmakologische Substanzen und Protokolle für die immunsuppressive Therapie auf aktuell etwa $80 \%$ gestiegen (Vianna et al. 2008) und denen für die Lebertransplantation näher gekommen.

Die Herausforderung der Dünndarmtransplantation liegt dabei insbesondere in der hohen immunogenen Last des Dünndarmes, der großen endo- und epithelialen Fläche sowie der Mukosabarriere. So führt eine Störung dieser Komponenten zu einer Perfusionsstörung im Dünndarm, einem Verlust der Mukosabarriere mit der Folge der bakteriellen Translokation und Sepsis. Diese ist eine der wesentlichen Todesursachen der Transplantatempfänger (Bond et al. 2005, Grant et al. 2005).

\subsection{Dünndarmtransplantation}

Nach abgeschlossener Hirntoddiagnostik wird der Dünndarm des Spenders vor der Explantation mittels selektiver Darmdekontamination und "Immunonutrition" auf die bevorstehende Preservation und Transplantation vorbereitet (Braun et al. 2007). Im Anschluss erfolgt die kalte Konservierung in einer geeigneten Protektionslösung (z.B. University-of-Wisconsin-Lösung (UW-Lösung) oder Histidin-Tryptophan-KetoglutaratLösung (HTK-Lösung)). Die Hypothermie reduziert die Stoffwechselrate auf etwa die Hälfte bei jeder Temperaturreduktion um $10{ }^{\circ} \mathrm{C}$, sodass bei $4{ }^{\circ} \mathrm{C}$ im Vergleich zu 37 ${ }^{\circ} \mathrm{C}$ noch ca. 10-12\% des ursprünglichen Metabolismus ablaufen (Belzer und Southard 1988). Wie für viele andere Organe, z.B. Niere und Leber (Pedotti et al. 2004) sowie Herz, Lunge und Pankreas (Karam et al. 2005), wird dieses Prinzip auch in der aktuellen klinischen Praxis bei der Dünndarmtransplantation (Braun et al. 2007, Ghanekar und Grant 2001) genutzt. Die Kaltlagerung bei 0 bis $8^{\circ} \mathrm{C}$ und Konservierung bis zur Implantation reduziert sowohl den Sauerstoffverbrauch als auch den Ablauf der schädigenden Prozesse infolge des Sauerstoff- und Energiemangels (verminderte oxidative Phosphorylierung und ATP-Produktion). 
Nach der Frei-Präparation des Dünndarmes erfolgt die vaskuläre Applikation von kleinen Mengen (ca. $500 \mathrm{ml}$ ) der Protektionslösung, da eine übermäßige Spülung des Gefäßbettes und des intestinalen Lumens die Mukosa schädigen kann. Um einen nachlastfreien Abfluss des Perfusates zu gewährleisten, wird zuvor die Vena portae im Leberbett abgetrennt (Braun et al. 2007). Das Explantat wird danach in der Phase der kalten Ischämie bei ca. $4{ }^{\circ} \mathrm{C}$ gelagert und zum Empfänger transportiert. Als erster Schritt der Implantation wird die Kontinuität des Gefäßsystems wieder hergestellt. Hierzu erfolgt die Anastomosierung der Arteria mesenterica superior des Transplantates an die infrarenale Aorta abdominalis des Empfängers. Der venöse Gefäßanschluss wird zwischen der Vena mesenterica des Transplantates und der Vena portae des Empfängers hergestellt (Braun et al. 2007). Die Rekonstruktion der luminalen Passage erfolgt oral mittels End-zu-End-Anastomose. Das aborale Ende des Transplantates wird für die lleostomie benutzt. Proximal des lleostomas erfolgt die distale Anastomose zwischen dem Transplantat und dem Rest des Eigendarmes (Braun et al. 2007). Der distale Anschluss an das Darmlumen des Empfängers ist dabei jedoch stark von der Anatomie des Situs abhängig und kann variieren. Eine intraoperativ eingelegte Trilumensonde dient der luminalen Dekompression und ermöglicht einen frühzeitigen Beginn der enteralen Ernährungstherapie (Braun et al. 2007).

\subsection{Phasen und Mechanismen der Transplantatschädigung}

Zu jedem Zeitpunkt während der Dünndarmtransplantation, wie bei der Vorbereitung der Organentnahme, der Explantation mit Präparation und Perfusion, der Kaltlagerung und dem Transport sowie bei der Implantation und Reperfusion, kann das Organ Schaden nehmen. Die kritischen Phasen der gesamten Transplantation sind insbesondere die Ischämie und die Reperfusion. In der Literatur finden sich unterschiedliche Angaben zur Ischämietoleranz von Spenderdünndarm. Einige Arbeiten fordern, dass die kalte Ischämiezeit grundsätzlich nicht mehr als 6 Stunden betragen sollte (Braun et al. 2007), andere sehen nach einem Zeitintervall von 8 bis 12 Stunden noch zufriedenstellende Ergebnisse (Asfar et al. 1994). Unstrittig ist, dass die Phase der kalten Ischämie einen Risikofaktor für den späteren Verlust der Transplantatfunktion darstellt (Furukawa et al. 1997). Bei der Schädigung der Spenderorgane durch die hypotherme Lagerung werden in der letzten Zeit 
pathophysiologische Effekte über reaktive Sauerstoffspezies (ROS) (Peters et al. 1998, Salahudeen et al. 2000) und Eisen (Huang und Salahudeen 2002, Kerkweg et al. 2002) diskutiert.

\subsubsection{Kalte Ischämie}

Der Zustand eines Organs bei hypothermer Lagerung mit aufgehobener Durchblutung wird als kalte Ischämie bezeichnet.

\subsubsection{Schädigung durch Ischämie}

In der Phase der Ischämie zwischen der Organentnahme und der Implantation ist das Gewebe einer hypoxischen Schädigung ausgesetzt. Da der Darm als stark oxidativ stoffwechselaktives Organ sehr empfindlich auf Hypoxie reagiert, gilt die Handhabung von Dünndarmtransplantaten per se als eine Herausforderung. Eine Deckung des Energiebedarfes des Gewebes alleine durch anaerobe Glykolyse ist nicht möglich, da im Organ keine Kohlenhydratspeicher vorhanden sind. Nach Verbrauch der energiereichen Substrate, z.B. dem noch vorhandenen ATP, laufen verschiedene schädigende Prozesse überwiegend parallel, zum Teil jedoch auch sequenziell $a b$. Je weiter die Zellschädigung fortschreitet, desto eher sind die Prozesse netzartig miteinander, mit sich selbst verstärkender Rückkopplung, verwoben (de Groot und Rauen 2007):

Der intrazelluläre Energiemangel führt $\mathrm{zu}$ einer stark reduzierten Aktivität transmembranöser lonentransporter, wie z.B. der $\mathrm{Na}^{+}-\mathrm{K}^{+}-$ATPase, und über den konsekutiven Einstrom von Natriumionen und Wasser nach intrazellulär zur Zellschwellung (Jamieson et al. 1988, Massberg und Messmer 1998). Die Permeabilität der zellulären Membranen ist erhöht und es kommt zum parallelen Anstieg des intrazellulären Kalziumgehaltes. Dies betrifft insbesondere die Endothelzellen (Gute et al. 1998, Mazzoni et al. 1989). Nach etwa 4 Stunden Ischämie sind $95 \%$ des zellulären ATPs aufgebraucht und unter den anaeroben Bedingungen werden noch 2 mol ATP im Gegensatz zu sonst im aeroben Stoffwechsel üblichen $38 \mathrm{~mol}$ ATP pro mol Glukose produziert. Aus der Glukose entsteht hierbei Laktat, was zu einer Azidose führt. Das Ausmaß der Azidose ist entscheidend für die pathophysiologische Wirkung auf das Gewebe. Während eine milde Azidose ( $\mathrm{pH}$ 6.9-7.0) protektive Effekte über die Hemmung der 
Phosphofruktokinase als geschwindigkeitsbestimmender Schritt in der Glykolyse entfaltet und somit das Fortschreiten der Azidose verlangsamt, kann eine schwere Azidose über die Destabilisierung von Lysosomen und Mobilisierung von schweren Metallen, z.B. Eisen (Baicu und Taylor 2002) und der folgenden Aktivierung von Hydrolasen wie z.B. Proteasen und Phospholipasen (Bonventre und Cheung 1985) für die Zellen im Gewebeverband deletär sein. Wichtige Funktions- und Strukturproteine, wie z.B. Proteine des Zytoskeletts, werden so geschädigt. Die vorgeschädigten zellulären Membranen werden zunehmend durchlässiger. Über den Zusammenbruch des mitochondrialen Membranpotentials und die Kalziumakkumulation in der mitochondrialen Matrix kann der mitochondriale Permeabilitätsübergang resultieren (de Groot und Rauen 2007). Über die mitochondrialen Poren kann noch vorhandenes ATP aus dem Zytosol in das Mitochondrium gelangen und über die mitochondrialen ATPasen verbraucht werden, was den ATP-Gehalt der Zellen weiter kritisch vermindert (de Groot und Rauen 2007). Hält die Phase der Hypoxie lange an, so werden die kompensatorischen Synthese- und Reparationsmechanismen der Zelle überlastet und es kommt zum Zelltod durch vorwiegend nekrotische Veränderungen. Diese Mechanismen sind im Prinzip sowohl für den Zelltod durch warme als auch kalte Ischämie gleichartig beschrieben (de Groot und Rauen 2007).

\subsubsection{Schädigung durch Kälte}

Die kälteinduzierte Schädigung von Säugetierzellen wurde lange Zeit einem veränderten Zellmetabolismus und einer veränderten lonenhomöostase, insbesondere einer erhöhten intrazellulären Natrium- und Kalziumkonzentration, zugeschrieben (Hansen et al. 1994). Reaktive Sauerstoffspezies (ROS) wurden für die Erklärung des Kälteschadens lange nicht beachtet. In den letzten Jahren häuften sich jedoch Hinweise auf eine Beteiligung von ROS (Rauen und de Groot 2004, Rauen et al. 2007 b) bei der Kälteschädigung verschiedenster Säugetierzellen (Ratten-, Schweine-, Kaninchen- und Humanzellen) (Rauen und de Groot 2002). Eine signifikante Schädigung von z.B. Leberzellen durch die in der Kälte entstehenden ROS beginnt ab $15{ }^{\circ} \mathrm{C}$ und hat bei 4-8 ${ }^{\circ} \mathrm{C}$ ein Maximum (niedrigste getestete Temperatur war $-2{ }^{\circ} \mathrm{C}$, unpublizierte Ergebnisse und mündliche Mitteilung von Kerkweg 2004). Ebenso in den Nierenzellen hat dieser Mechanismus eine zentrale Bedeutung. Hier scheint der intrazelluläre, chelatisierbare und redoxaktive 
Eisenionenpool, der sich bereits nach 90 Minuten der Kühlung mehr als verdoppelt (Rauen et al. 2000), eng mit der hypothermen Schädigung und kälteinduzierten Apoptose verknüpft zu sein (Rauen und de Groot 2002, Rauen et al. 2000). Die Apoptose beginnt während der Wiedererwärmung nach einer subletalen Schädigung durch Kälte. Über welchen intrazellulären Mechanismus das freie, labile Eisen die Schädigungen bedingt, ist jedoch noch unklar.

\subsubsection{Reperfusion}

In der Phase der Reperfusion setzt die Durchblutung des Spenderorgans durch den Empfängerkreislauf schlagartig wieder ein. Blutzellen, Sauerstoff und Substrate stehen für den aeroben Stoffwechsel wieder zur Verfügung. Die Reperfusionsphase ist durch die veränderte Mikrozirkulation, als auch die immunologischen Schäden (aktivierte Endothelzellen, Granulozyten und Makrophagen als Folge der Hypoxie und der intrazellulären Kalziumerhöhung) gekennzeichnet (de Groot und Rauen 2007):

Im vorgeschädigten Gewebe kann der Verlust von Flüssigkeit aus dem Intravasalraum, die lokale Hämatokriterhöhung und die erhöhte Blutviskosität infolge der Gewebeazidose zur kapillären Obstruktion führen und die Wiederdurchblutung verhindern. Dies wird als „no reflow“-Phänomen bezeichnet (Ames et al. 1968). Die vom „no reflow“-Phänomen betroffenen Gewebeareale werden folglich nicht suffizient durchblutet und unterliegen der lokalen warmen, ischämischen Schädigung.

Doch auch in den wieder durchbluteten Arealen setzt sich die Gewebeschädigung fort. Das als „reflow paradox" bezeichnete Phänomen ist dabei durch immunologische Abläufe, wie die gesteigerte Leukozyten-Endothelzell-Interaktion (LEI) in den postkapillären Venolen, geprägt (Menger et al. 1992). Die LEI und konsekutive Auswanderung der Leukozyten durch das Endothel in das Interstitium hängt von der Adhäsion von Leukozyten und den Scherkräften des Blutstromes am Endothel ab (Eppihimer und Granger 1997). Das durch OP-Trauma (Explantation, Spülung, Implantation) und kalte Konservierung vorgeschädigte und damit im immunologischen Sinne aktivierte Endothel des Transplantates exprimiert verstärkt Adhäsionsmoleküle (Springer 1990) an seiner Oberfläche. Gleichzeitig begünstigen lösliche Faktoren, wie Interleukin-1 (IL-1), Tumor-Nekrose-Faktor- $\alpha$ (TNF- $\alpha$ ) und freie Radikale (z.B. Hyperoxidanionen $\left(\mathrm{O}_{2}^{-}\right)$und Hydroxylradikale $(\mathrm{OH} \cdot)$ ), die in der Reperfusionsphase entstehen, eine Endothel- und Leukozytenaktivierung. Diese 
stören wiederum die endotheliale Integrität und perpetuieren die Schädigung. Die Adhäsion von Leukozyten an der Endotheloberfläche wird dadurch erhöht. Die Extravasation der Leukozyten beginnt mit dem Rollen von Leukozyten am Endothel, dann folgt die Adhäsion der Leukozyten an einem Ort und resultiert in der Extravasation der Leukozyten durch die Gefäßwand ins Interstitium (Diapedese) (Eppihimer und Granger 1997). Makromoleküle und weitere Entzündungszellen können in der Folge den Intravasalraum leichter verlassen und verstärken ein interstitielles Ödem (Menger et al. 1992).

Zusätzlich zur Leukozytenextravasation kommt es auf molekularbiologischer Ebene zu weiteren zentralen Schädigungsprozessen:

Das postischämische Endothel und die darunter liegende Gewebematrix setzen chemotaktische, lösliche Faktoren z.B. Interleukine, TNF- $\alpha$, plättchenaktivierenden Faktor und Leukotriene frei und es entstehen schädigende ROS aus dem wieder verfügbaren Sauerstoff (Menger et al. 1992). Wichtige ROS sind Wasserstoffperoxid $\left(\mathrm{H}_{2} \mathrm{O}_{2}\right), \quad \mathrm{O}_{2}^{-}$und $\mathrm{OH} \cdot$. Sie werden als Mediatoren des Ischämie- und Reperfusionsschadens (McCord 1985) als auch des kälteinduzierten Zellschadens (s.o.) angesehen. An der Produktion der ROS sind verschiedene Enzymsysteme bzw. Pathomechanismen beteiligt: Über das Enzym Xanthinoxidase, welches in der Ischämiephase durch eine Kalzium-abhängige proteolytische Reaktion aus der Xanthindehydrogenase hervorgeht (McCord 1985), wird die Produktion von $\mathrm{O}_{2}^{-}$und $\mathrm{H}_{2} \mathrm{O}_{2}$ im reoxygenierten Gewebe vermittelt. Weiterhin konnte gezeigt werden, dass ein anderes Enzymsystem, die mitochondriale und zytosolische SuperoxidDismutase, die Bildung von $\mathrm{OH}$ - aus $\mathrm{H}_{2} \mathrm{O}_{2}$ katalysiert und darüber DNA, Membranen, Lipide und Proteine schädigt (Salahudeen et al. 2000). Schon in der kalten Ischämie kommt es in einigen Zelltypen wie z.B. Endothelzellen und Hepatozyten zum Anstieg des intrazellulären Eisenionenpools (Rauen et al. 2000). Ursache hierfür könnte die Ruptur von eisenhaltigen Lysosomen oder eine Schädigung von Mitochondrien sein (Lemasters 2004). Das freigesetzte Eisen führt zum mitochondrialen Permeabilitätsübergang, dem ein Zusammenbruch des mitochondrialen Membranpotentials folgt. Der Endpunkt dieser Schädigung ist Nekrose oder Apoptose (Lemasters 2004). Das freie, redoxaktive, chelatisierbare Eisen trägt zudem in der Reperfusionsphase über die Fentonreaktion zur Bildung von $\mathrm{OH}$ bei (Lemasters 2004). 


\subsection{Stand der Forschung}

\subsubsection{Protektionslösungen}

Die anaerobe Kaltlagerung ( 0 bis $4^{\circ} \mathrm{C}$ ) von Organen in Protektionslösungen ist unkompliziert, standardisiert durchzuführen und im klinischen Alltag praktikabel. Die Zeit für den Organtransport, sowie die chirurgischen Eingriffe kann so überbrückt werden. Dabei hat die kalte, ischämische Lagerung nicht nur Vorteile (siehe Abschnitt 1.3 Phasen und Mechanismen der Transplantatschädigung), worauf sich die Anforderungen an die Protektionslösung gründen (Belzer und Southard 1988).

\subsubsection{Grundcharakteristik}

Organprotektionslösungen sollen der durch Hypothermie induzierten Zellschwellung, der durch Sauerstoffmangel hervorgerufenen intrazellulären Azidose und dem interstitiellen Ödem, welches während der Organspülung entstehen kann, entgegenwirken. In der Reperfusionsphase soll eine Protektionslösung die Schädigung durch freie Sauerstoffradikale mindern und gleichzeitig, über das Angebot von geeigneten Substraten, zur Regeneration der ATP-Speicher beitragen (Belzer und Southard 1988). Essentielle Komponenten einer Protektionslösung sind damit impermeable Substanzen und/oder Kolloide, Puffersubstanzen mit adäquater Kapazität, Substrate für den oxidativen Zellstoffwechsel und Antioxidanzien.

\subsubsection{Zusammensetzungen}

Innerhalb der letzten 40 Jahre wurden verschiedene Protektionslösungen mit diversen Elektrolyt-, Puffer-, zellimpermeablen Substanz- und Kolloidzusammensetzungen für die Organprotektion entwickelt. Zur Übersicht und Einordnung der vorliegenden Arbeit wurde eine Tabelle mit den Zusammensetzungen der geläufigen Lösungen, ihrem Entwicklungsjahr und der Referenz in der Fachliteratur (Pubmed-Identifizierungs-Nummer) erstellt (Tab. 1). Multimodale Konzepte der Protektionierung sind verbreitet und werden z.B. in der HTK- und der UW-Lösung genutzt: niedriger Natriumgehalt und wenig/kein Kalziumgehalt (HTK+UW), hohe Pufferkapazität (HTK), Kolloid (UW). Die Schutzeffekte dieser Lösungen scheinen jedoch mit speziellen Aminosäuren und unter Verwendung von Eisenchelatoren noch weiter ausbaubar (de Groot und Rauen 
2007). Einige Lösungen enthalten neben den genannten Substanzgruppen noch weitere Zusätze (z.B. ROS-Fänger) (Tab. 1). Die Formulierung einer neueren Protektionslösung (Polysol) hat einen polypragmatischen Ansatz (Bessems et al. 2005 b). Die grundlegenden Ziele der Protektionsbehandlung mit zügigem Auswaschen des Gefäßbettes des Organs um 1. Kühlung, 2. Entfernen des Blutes und 3. Equilibrieren des Gewebes mit der Perfusionslösung zu erzeugen, sind bei allen Protektionslösungen gleich (Maathuis et al. 2007). 


\section{Tabelle 1: Übersicht Protektionslösungen}

\begin{tabular}{|c|c|c|c|c|c|c|c|c|c|c|}
\hline Protektionslösung & $\mathrm{C}-3$ & $\mathrm{HOC}$ & HTK & EC & UW & PBS & CEL & Unisol & IGL-1 & Polysol \\
\hline \multicolumn{11}{|l|}{ Ionen (mM) } \\
\hline $\mathrm{Na}+$ & 10 & 80 & 15 & 10 & 30 & 125 & 100 & 62,5 & 120 & 135 \\
\hline $\mathrm{K}_{+}$ & 115 & 80 & 10 & 115 & 125 & - & 15 & 70 & 25 & 5 \\
\hline $\mathrm{Ca} 2+$ & - & - & 0,015 & - & - & - & 0,26 & 0,05 & 0,5 & 2 \\
\hline $\mathrm{Mg} 2+$ & 30 & 35 & 4 & - & 5 & - & 13 & 15 & 5 & 4 \\
\hline $\mathrm{Cl}-$ & 15 & - & 50 & 15 & - & - & 41,5 & 30,1 & - & - \\
\hline [SO4]2- & 30 & 40 & - & - & 5 & - & 1,2 & - & - & - \\
\hline \multicolumn{11}{|l|}{ Puffer (mM) } \\
\hline [H2PO4]- & 15 & - & - & 15 & 25 & 13 & - & 2,5 & 25 & 21,74 \\
\hline [HPO4]2- & 42,5 & - & - & 42,5 & - & 56 & - & - & - & - \\
\hline [HCO3]- & 10 & - & - & 10 & - & - & - & 5 & - & - \\
\hline Hepes & - & - & - & - & - & - & - & 35 & - & 20 \\
\hline Histidin & - & - & 198 & - & - & - & 30 & - & - & 6,3 \\
\hline Gesamtpuffer & 67,5 & - & 198 & 67,5 & 25 & 69 & 30 & 42,5 & 25 & 48,04 \\
\hline \multicolumn{11}{|l|}{ Impermeable Substanzen (mM) } \\
\hline Mannitol & - & 185 & 30 & - & - & - & 60 & 25 & - & - \\
\hline (Glukose) & 25 & - & - & 195 & - & - & - & 5 & - & 11,1 \\
\hline Ribose & - & - & - & - & - & - & - & - & - & - \\
\hline Saccharose & - & - & - & - & - & 140 & - & 25 & - & - \\
\hline Trehalose & - & - & - & - & - & - & - & - & - & 5,3 \\
\hline Raffinose & - & - & - & - & 30 & - & - & - & 30 & 3 \\
\hline Citrat & - & 55 & - & - & - & - & - & - & - & - \\
\hline Glukonat & - & - & - & - & - & - & - & 70 & - & 94,99 \\
\hline Laktobionat & - & - & - & - & 100 & - & 80 & 30 & 100 & - \\
\hline \multicolumn{11}{|l|}{$\overline{\text { Kolloide }(g / L)}$} \\
\hline HES & - & - & - & - & 50 & - & - & - & - & - \\
\hline DEX [40kDa] & - & - & - & - & - & - & - & 6 & - & - \\
\hline PEG [35kDa] & - & - & - & - & - & - & - & - & 1 & 20 \\
\hline \multicolumn{11}{|l|}{$\overline{\text { ROS-Fänger (mM) }}$} \\
\hline Allopurinol & - & - & - & - & 1 & - & - & - & 1 & 1,2 \\
\hline Glutathion & - & - & - & - & 3 & - & 3 & - & 3 & 3 \\
\hline Tryptophan & - & . & 2 & - & - & - & . & - & - & - \\
\hline \multicolumn{11}{|l|}{ Andere Substanzen (mM) } \\
\hline Adenosin & - & - & - & - & 5 & - & - & - & 5 & 5 \\
\hline Glutaminsäure & - & - & - & - & - & - & 20 & - & - & - \\
\hline Ketoglutarat & - & - & 1 & - & - & - & - & - & - & - \\
\hline Adenin & . & . & - & - & - & - & - & - & - & 5 \\
\hline Pyruvat & - & - & - & - & - & - & - & - & - & 0,23 \\
\hline Aminosäure und Vitamin Mixtur & - & - & - & - & - & - & - & - & - & $x$ \\
\hline Entwicklungsjahr & 1969 & 1976 & 1980 & 1986 & 1986 & 1989 & 1994 & 2000 & 2002 & 2005 \\
\hline Referenz (PMID) & 4187813 & 936278 & 6161427 & 2655211 & 3802886 & 2655211 & 8031565 & 11267013 & 12122511 & 15838888 \\
\hline
\end{tabular}

Abkürzungen: C-3: Collins, HOC: Hypertonic citrate, HTK: Histidin-Tryptophan-Ketoglutarat (Bretschneider Lösung), EC: EuroCollins, UW: University of Wisconsin, PBS: Phosphate buffered sucrose, 


\subsection{Zellimpermeable Substanzen}

Die zellimpermeablen Substanzen (Tab. 1) erhöhen die Osmolarität des extrazellulären Raumes und wirken während der kalten Ischämie dem intrazellulären osmotischen Druck und damit einer Zellschwellung entgegen (Belzer und Southard 1988, Maathuis et al. 2007).

\subsection{Kolloide}

Die Kolloide (Tab. 1) durchdringen nicht die Endothelbarriere und verbleiben im intravasalen Raum. Sie sollen die Entwicklung eines Gewebeödems verhindern (Belzer und Southard 1988, Maathuis et al. 2007). Ab einer Protektionierungszeit von größer als 24 Stunden scheint ein Kolloid nötig, um suffizient das Gewebeödem zu unterdrücken und die Organvitalität nach der Transplantation zu gewährleisten (Southard et al. 1990).

\subsection{Puffersubstanzen}

$\mathrm{Da}$ das Ausmaß der sich entwickelnden Azidose entscheidend für die pathophysiologische Wirkung auf das Gewebe ist (s.o.), ist die pH-Kontrolle im Gewebe durch Puffersubstanzen in den Protektionslösungen ein entscheidender Faktor für die Güte der Gewebeprotektionierung. Die UW-Lösung nutzt z.B. ein Phosphat-Puffersystem, während Celsior- (Menasche et al. 1994) und HTK-Lösung (Bretschneider 1980) sich der Aminosäure Histidin zum Puffern der anfallenden sauren Metabolite bedienen. Histidin gehört zu den basischen Aminosäuren. Zusätzlich zur obligatorischen a-Aminogruppe von Aminosäuren enthält Histidin eine weitere basische Gruppe im Imidazolring. Es ist ein exzellenter Puffer und wird daher in mehreren Organprotektionslösungen verwendet (z.B. HTK, Celsior, Polysol, siehe Tab. 1) (Rauen et al. 2007 b). HTK enthält größere Mengen dieser Aminosäure und hat von allen derzeit klinisch verfügbaren Protektionslösungen die höchste Pufferkapazität (Baicu und Taylor 2002). 


\subsection{Leicht verfügbare Substrate}

Als leicht verfügbare Substrate für den wieder anlaufenden oxidativen Stoffwechsel nach der Reperfusion werden z.B. a-Ketoglutarat (Bretschneider 1980) und LGlutaminsäure (Menasche et al. 1994) eingesetzt. Es sind Bestandteile bzw. unmittelbare Vorstufen von Substraten des Citratzyklus, die das Wiedereinsetzen des Zellmetabolismus unterstützen sollen. $\alpha$-Ketoglutarat kann bereits in der anaeroben Phase energiegewinnend metabolisiert werden.

\subsection{Antioxidanzien}

Als Gegenspieler der ROS werden direkte Antioxidanzien wie Glutathion (z.B. in UWLösung) (Wahlberg et al. 1986), Mannitol (z.B. in Marshalls-Lösung) (Ross et al. 1976), Tryptophan (z.B. in HTK-Lösung) (Bretschneider 1980) und die Vitamine C und E (z.B. in Polysol-Lösung) (Bessems et al. 2005 a, Bessems et al. 2005 b) eingesetzt. Andere Substanzen, wie z.B. der Xanthinoxidaseinhibitor Allopurinol (z.B. in UW-Lösung) (Wahlberg et al. 1986) sollen die Bildung von ROS supprimieren.

\subsubsection{Limitationen}

Die Limitationen der aktuell verfügbaren Protektionslösungen ergeben sich aus den potentiell zytotoxischen Effekten einzelner Komponenten der Lösungen. So gibt es z.B. Hinweise, dass Histidin und Phosphat als Puffersubstanzen in der hypothermen $\left(4^{\circ} \mathrm{C} / 21^{\circ} \mathrm{C}\right)$ und isothermen $\left(37^{\circ} \mathrm{C}\right)$ Zellkultur toxisch wirken können (Rauen und de Groot 2008). Die Toxizität von z.B. Histidin scheint über eisenabhängig gebildete ROS vermittelt zu werden (Rauen et al. 2007 b). Dies erklärt sich dadurch, dass Hypoxie, der Zusatz von Antioxidanzien oder Eisenchelatoren die schädigenden Wirkungen vermindern konnten. Als Mechanismus wird postuliert, dass Histidin in die Zellen gelangt und dort redox-aktive Eisenkomplexe bildet. Diese führen zur vermehrten ROS-Bildung und über eine Lipidperoxidation zum Zellschaden (Bahde et al. 2008). Es besteht weiterhin der Bedarf an grundsätzlich neuen Formulierungen (z.B. Puffersystem) von Protektionslösungen und der gezielten Auswahl neuer, protektiver Substanzen (z.B. Eisenchelatoren), um die Effektivität der Protektionslösungen zu optimieren. Mögliche Kandidaten neuer Schutzsubstanzen werden im folgenden Abschnitt vorgestellt. 


\subsubsection{Neue potentiell schützende Substanzen}

\subsubsection{Puffersubstanzen}

Na-Acetyl-L-Histidin (Abb. 1) ist ein natürlich vorkommendes Histidinderivat (Baslow 1997, Drescher MJ und Drescher DG 1991). Es zeigte in der Zellkultur eine deutlich geringere Toxizität als Histidin bei Erhalt seiner exzellenten Puffereigenschaften. Es könnte für die Organprotektion genutzt werden (Rauen et al. 2007 b). Die zelluläre Aufnahme und die Affinität von Na-Acetyl-L-Histidin zu Eisenionen ist geringer als bei Histidin und die Redox-Aktivität der Eisen-Komplexe ist reduziert (Bahde et al. 2008). In der bekannten HTK-Lösung ist jedoch ein vollständiger Austausch des enthaltenen Histidins durch Na-Acetyl-L-Histidin aufgrund der erforderlichen elektrochemischen Neutralität nicht möglich. Für die praktische Anwendung müssen beide Substanzen parallel eingesetzt werden. Um die potentiell toxischen Eigenschaften des noch enthaltenen Histidins über die Wirkung auf den chelatisierbaren redoxaktiven Eisenionenpool (s.o.) zu supprimieren, könnte der parallele Einsatz von Eisenchelatoren (s.u.) nötig sein.
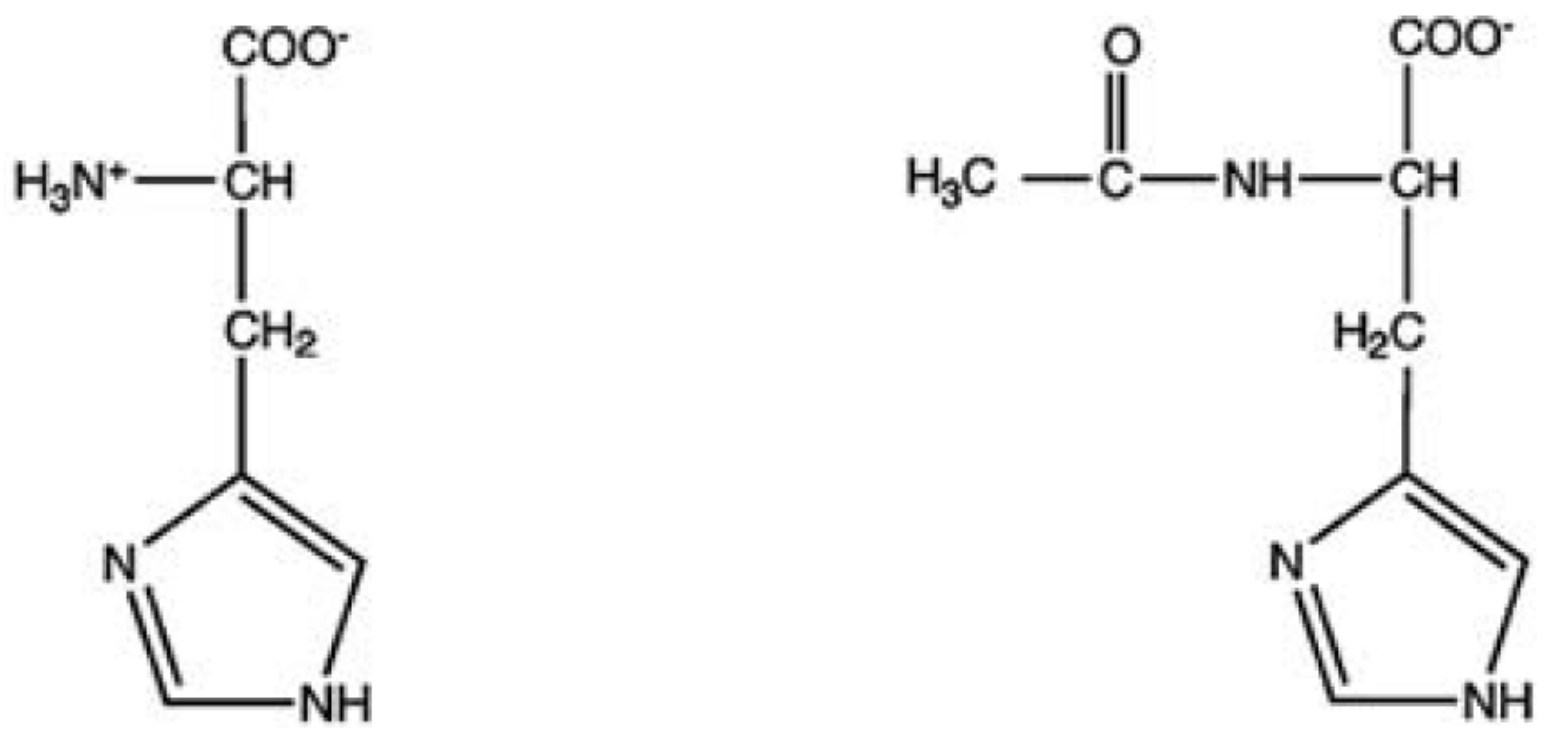

Abbildung 1: Darstellung der Aminosäure L-Histidin (links) und ihres Derivates NaAcetyl-L-Histidin (rechts) (Abbildung modifiziert nach Rauen et al. 2007 b, 194) 


\subsubsection{Eisenchelatoren}

\subsection{Hydroxamsäurederivat LK}

Das Hydroxamsäurederivat LK (Dimethoxy-N-methyl-benzhydroxamsäure) als lipophiler Eisenchelator auf Basis der Hydroxamsäure zeigte in der Anwendung mit Krebs-Henseleit-Histidin-Lösung eine protektive Wirkung und minderte den Zellschaden in der Zellkultur (Rauen et al. 2007 b). Die Kombination von Histidin, NaAcetyl-L-Histidin und LK könnte unter Erhalt der Puffereigenschaften von Histidin und seinem Derivat zur Protektionierung von Organen geeignet sein (Rauen et al. 2007 b).

\subsection{Deferoxamin}

Eine Präinkubation mit dem geringer lipophilen Eisenchelator Deferoxamin konnte in der Zellkultur Zellen vor der Schädigung durch kalte Ischämie schützen (Rauen et al. 2007 b, Rauen et al. 1997). Obwohl die Zellmembran für Deferoxamin als eher hydrophile Substanz wenig permeabel ist, wird trotzdem ein Schutzmechanismus über die Chelatisierung von intrazellulärem Eisen postuliert, der die zellschädigenden Effekte des Histidins reduziert.

\subsubsection{Aminosäuren}

\subsection{Glycin}

Glycin schützt isolierte Hepatozyten vor der Schädigung durch Anoxie, kalte Ischämie und Inhibition der Mitochondrienfunktion (Marsh et al. 1993). Glycin kann unspezifische Kationen-Kanäle hemmen und den Einstrom von schädlichen Natriumionen und/oder den Kationen der Elemente Kobalt und Nickel nach intrazellulär mindern. Es mildert so den konsekutiven Anstieg des intrazellulären Kalziums und die Aktivierung von zellschädigenden Katalasen (Frank et al. 2000). Ebenfalls kann Glycin das Zellödem nach hypoxischer Schädigung reduzieren, indem es unspezifisch die Membranintegrität stabilisiert (Zhong et al. 2003). Glycin scheint schon in geringer Konzentration auch in vivo bei der warmen Darmischämie und Reperfusion protektiv zu sein (mündliche Mitteilung über unpublizierte Ergebnisse im Tiermodell der Ratte von Petrat 2006). Es gibt zwei aktuelle, unabhängige Studien, die protektive Effekte von Glycin auf den Dünndarm in der 
Ischämie und Reperfusion (Lee et al. 2002) und der experimentellen Dünndarmtransplantation (Mangino et al. 1996) zeigen. Die exakten molekularen Mechanismen der Protektion durch Glycin sind bisher nicht geklärt.

\subsection{Alanin}

Alanin ist ähnlich dem Glycin protektiv gegen die hypotherme Schädigung von isolierten Hepatozyten (Marsh et al. 1993) sowie gegen die hypoxische Schädigung von renalen proximalen Tubuluszellen (Weinberg et al. 1990) wirksam. Allerdings sind nicht nur schützende Effekte durch Alanin beschrieben. In einem In-vivo-Modell der warmen Ischämie und Reperfusion am Rattendarm zeigten sich bei der intraluminalen Applikation von Alanin unerwünschte Effekte (Kozar et al. 2004). Die schützende Wirkvermittlung des Alanins ist noch unbekannt, jedoch scheint es sich nicht um einen metabolismusabhängigen Effekt, sondern eher um eine LigandAkzeptor-Interaktion zu handeln (Weinberg et al. 1990).

\subsection{Arginin}

Arginin kann die Proteinsynthese fördern und die Proteindegradation (Autophagie) inhibieren (Rhoads und Wu 2009). Es ist in verschiedene Signalwege involviert und stimuliert die Zellmigration und Restitution von Enterozyten (Rhoads et al. 2008). In der NO-cGMP-Signalkaskade reguliert es physiologische Ereignisse, die mit dem Erhalt der Zellhomöostase und der Zellvitalität assoziert sind (Rhoads et al. 2008, Rhoads und Wu 2009). Aus In-vitro- und In-vivo-Studien ist bekannt, dass Arginin zellschützende Effekte bei oxidativem Stress entfalten kann (Rhoads und Wu 2009). Es stimuliert die Reparation der Villusarchitektur der Mukosa nach Schädigung und kann vor nekrotisierender Enterokolitis, einer gefürchteten postpartalen Komplikation bei Frühgeborenen, schützen (Amin et al. 2002, Rhoads et al. 2008). Während eine adäquate, niedrige Konzentration von NO vor Apoptose schützt, kann eine lang andauernde Überproduktion von NO aus Arginin über die Aktivierung intrazellulärer Caspasen zur Apoptose führen (Choi et al. 2002, Rhoads et al. 2008). Eine aktuelle Studie zur Protektion vor Gewebeschäden durch intestinale Ischämie und Reperfusion zeigte im Großtierversuch am Schwein einen positiven Effekt einer intraluminalen Applikation von aminosäurehaltiger Pufferlösung (Salehi et al. 2008). Diese enthielt neben Arginin auch die Aminosäuren Glycin und Aspartat. In einer 
anderen Studie an renalen proximalen Tubuluszellen konnte keine protektive Wirkung von Arginin nach hypoxischer Schädigung nachgewiesen werden (Weinberg et al. 1990).

\subsection{Aspartat}

Aspartathaltige Kardioplegielösung konnte im Rattenmodell infarzierte Herzen (nach 20-stündiger Ischämie) vor funktionellen Schäden schützen. Die mit Aspartat behandelten Herzen zeigten eine signifikant bessere Herzfunktion nach der Reperfusion (Rosenfeldt et al. 1998). Zur Erklärung des Wirkmechanismus werden die Verminderung der ischämieinduzierten Depletion im Citratzyklus und eine Stimulation im Malat-Aspartat-Zyklus in der frühen Reoxygenierungsphase diskutiert. Ergänzend zu diesem Mechanismus könnte Aspartat in der kalten Ischämie während der anaeroben Phase als Substrat für die Glykolyse dienen und im Mitochondrium Malat für die Generation von ATP zur Verfügung stellen (Pisarenko et al. 1995). Zinkaspartat hat antioxidative und antiinflammatorische Effekte und kann den Lungenschaden infolge intestinaler Ischämie und Reperfusion mindern (Turut et al. 2009). Mechanistisch wird der protektive Effekt über die Wirkung von Zink auf die Bildung von reaktiven Sauerstoffspezies diskutiert. Auch im IschämieReperfusionsmodell des Rattenhinterlaufes zeigte Zinkaspartat protektive Effekte (Atahan et al. 2007). In einer anderen Studie an renalen proximalen Tubuluszellen konnte, wie auch für Arginin (s.o.), keine protektive Wirkung von Aspartat nach hypoxischer Schädigung nachgewiesen werden (Weinberg et al. 1990).

\subsubsection{Techniken zur Untersuchung der Organvitalität}

\subsubsection{Histologie}

Die Beurteilung des Gewebeschadens nach Ischämie- und Reperfusion mittels der herkömmlichen histomorphologischen Ex-vivo-Techniken entspricht dem aktuellen Standard. Es handelt sich hierbei immer um eine statische Momentaufnahme einer sehr dynamischen Pathophysiologie. Die histomorphologischen Parameter sind erst ab einer gewissen Schwere der Schädigung quantitativ erfassbar und die Einteilung in die Schädigungsgrade (Chiu-Score) ist relativ grob (Chiu et al. 1970). 


\subsubsection{Intravitalmikroskopie}

Um in vivo eine detailliertere Beurteilung der dynamischen Veränderungen in Geweben bei verschiedenen Pathophysiologien (z.B. einer gestörten Mikrozirkulation) zu ermöglichen, wurde die Technik der Intravitalmikroskopie in experimentellen Tiermodellen entwickelt (Bohlen und Gore 1976). Sie ist die einzige Methode, die es erlaubt, Aussagen über die Güte der Perfusion eines Transplantates auf der Ebene einer einzelnen Kapillare zu treffen (Vollmar und Menger 1998). Sie ermöglicht die Visualisierung des intestinalen Kapillarbettes, der Arteriolen und Venolen in situ und in vivo (Vollmar und Menger 1998). Quantitative Parameter der Mikrozirkulation wie der Perfusionsindex (Post et al. 1992) und die funktionelle Kapillardichte (Nolte et al. 1995) können gemessen werden. Gleichzeitig ist eine verlässliche Analyse der Leukozyten-Endothelzell-Interaktion in den submukösen Sammelvenen (Anthoni et al. 2002) oder den postkapillären Venolen möglich (Marzi et al. 1991, Menger et al. 1991). Diese mikroskopische Technik wurde daher schon erfolgreich zum Monitoring des Ischämie- und Reperfusionsschadens (Gonzalez et al. 1994, Massberg et al. 1998 a) als auch der akuten Abstoßungsreaktion (Stojanovic et al. 2002, Stojanovic et al. 2000) von Darmtransplantaten angewendet. In Arbeiten aus unserer Gruppe konnten wir zeigen, dass die intestinale, mukosale Mikrozirkulation ein sensitiver Parameter der Transplantatfunktion ist und den histologisch fassbaren morphologischen und immunhistochemischen Veränderungen im Sinne einer Transplantatschädigung vorausgeht (Stojanovic et al. 2002, Stojanovic et al. 2000). Die Intravitalmikroskopie ist daher nachweislich eine geeignete Technik, um die Veränderungen in der Mikrozirkulation und LeukozytenEndothelzell-Interaktion von Transplantaten nach kalter Ischämie und Reperfusion zu untersuchen (Massberg et al. 1998 b). Aufgrund dieser Eigenschaften kann man davon ausgehen, dass sie auch die schützenden Effekte eines modifizierten Protektionsregimes semiquantitativ erfassen kann.

\subsection{Zielsetzung der Arbeit}

Das primäre Ziel dieser Studie war, das multimodale Prinzip einer modifizierten HTKLösung und die Wirkung ihrer einzelnen potentiell protektiven Substanzen auf den Ischämie- und Reperfusionsschaden am Dünndarmtransplantat zu überprüfen, da das Dünndarmtransplantat sehr schwierig zu protektionieren ist und bedingt durch 
die große Endothelzelloberfläche dem Ischämie- und Reperfusionsschaden in besonderer Weise ausgesetzt ist. Um den größtmöglichen protektiven Effekt dieser Lösung (N36) zu ermitteln, sollte zunächst ein stabiles Schädigungsmodell etabliert werden. Ziel war es, nach einer definierten Ischämiezeit im syngenen Transplantationsmodell des Dünndarmes der Ratte eine subtotale Transplantatschädigung zu erzeugen. Die syngene Transplantation wurde gewählt, da aufgrund der Verwendung von Inzuchtstämmen Abstoßungsreaktionen infolge HLA- bzw. MHC-Inkompatibilität ausgeschlossen und keine weiteren immunsuppressiven Therapien notwendig sind. Nach der Transplantation sollten in diesem Schädigungsmodell sowohl die intestinale Mikrozirkulation als auch die histologischen und immunhistochemischen Schädigungsparameter von den unterschiedlich protektionierten Transplantaten analysierten werden. Die Beeinträchtigung der mukosalen Mikrozirkulation wurde mit Hilfe der Intravitalmikroskopie und die morphologische Schädigung anhand eines etablierten histologischen Scores (Chiu et al. 1970) nachgewiesen. Das Ausmaß des Zellunterganges (Apoptose) wurde mit standard-immunhistochemischen Techniken quantifiziert. Die speziellen Ziele der Arbeit waren:

1. Welche Dauer der kalten Ischämie führt im mit HTK-Lösung protektionierten Dünndarmtransplantat der Ratte in der Reperfusion zu einer subtotalen Schädigung, die als stabiles Schädigungsmodell zur Untersuchung neuer Protektionslösungen herangezogen werden könnte?

2. Wie beschaffen sind die Auswirkungen der einzelnen und die Kombination der potentiell protektiven Substanzen LK, Deferoxamin und Glycin in einer konventionellen und einer neuen modifizierten HTK-Lösung auf das funktionelle und morphologische Ausmaß des Transplantatschadens nach subtotaler Schädigung?

3. Welche Konzentrationen von lipophilen oder hydrophilen Eisenchelatoren sind geeignet, um mit Hilfe einer neuen, modifizierten HTK-Lösung den Ischämie- und Reperfusionsschaden von Dünndarmtransplantaten zu vermindern?

4. Kann eine Kombination der lipophilen und hydrophilen Eisenchelatoren den möglichen protektiven Effekt der neuen Lösung steigern? 


\section{Material und Methoden}

\subsection{Versuchstiere}

Für alle Versuche wurden männliche Ratten des Inzuchtstammes Lewis verwendet (Charles River $\mathrm{GmbH}$, Sulzfeld, Deutschland). Die Spendertiere hatten ein Körpergewicht von 220-320g und die Empfängertiere wogen 220-550g. Die Tiere wurden entsprechend den Richtlinien zur Haltung von Labortieren und unter einem konstanten Tag-Nacht-Rhythmus (12h/12h) mit Dämmerungsphasen gehalten. Sie hatten freien Zugang zu Wasser und Standardrattenfutter. Alle Untersuchungen wurden innerhalb der Zentralen Tierexperimentellen Abteilung der Universität Göttingen (Leiter: Dr. med. vet. K. Nebendahl) durchgeführt. Die operativen Eingriffe und tierexperimentellen Studien waren von der Bezirksregierung Braunschweig (Niedersächsisches Landesamt für Verbraucherschutz und Lebensmittelsicherheit, AZ: 33.42502/01-06.05) genehmigt und erfolgten entsprechend den Tierschutzbestimmungen. Alle Operationen wurden in Inhalationsnarkose mit Diethylether (Riedel-de Haën, Seelze, Deutschland) durchgeführt. Die Narkoseeinleitung erfolgte in einem mit Ether befüllten Narkosegefäß für Kleintiere. Zur Aufrechterhaltung der Narkose wurde ein Perfusorspritzenkolben vor die Schnauze des Tieres gelegt, der mit einem Ether getränkten Zellstofftupfer gefüllt war. Das Tier atmete spontan während der operativen Eingriffe dieses Luft-EtherGemisch ein. Diese Narkose war bei allen Tieren stabil und gut steuerbar. Sie wurde sowohl während der Explantationen und Transplantationen als auch der Intravitalmikroskopie angewendet.

\subsection{Versuchsprotokoll}

Die Arbeit teilte sich in zwei Abschnitte: Die Etablierung eines stabilen Schädigungsmodells während der Dünndarmtransplantation und die Analyse der statischen und dynamischen Schädigungsparameter in diesem Schädigungsmodell an unterschiedlich protektionierten Transplantaten.

\subsection{1 Überblick}

Als Modell wurde die Dünndarmtransplantation an der Ratte gewählt, da sowohl die Transplantation als auch die Intravitalmikroskopie an diesem Modell sowohl im Labor 
als auch in der Literatur etabliert und publiziert sind. Die Datenerhebung und Auswertung nahm mehrere Tage in Anspruch (Abb. 2). Alle Transplantationen erfolgten syngen in die heterotope Position auf die infrarenale Aorta abdominalis und Vena cava inferior nach 18- oder 24-stündiger kalter Ischämiezeit des Explantates. Zur Gewebeprotektion wurden während der kalten Ischämie die zu validierenden Protektionslösungen mit oder ohne zusätzliche Schutzsubstanzen verwendet. Nach 40-minütiger Reperfusionsphase im Kreislauf des Empfängertieres erfolgte eine Gewebeentnahme. Dazu wurde ein etwa 1-2 cm langes Stück Darm entnommen und in Formalinlösung 4\% über mindestens 24 Stunden fixiert. Im unmittelbaren Anschluss wurde die Intravitalmikroskopie des transplantierten Organs durchgeführt. Danach wurde ein weiteres Stück des transplantierten Darmgewebes entnommen (s.o.) und das Empfängertier durch Herzschnitt getötet.

\begin{tabular}{|c|c|c|c|}
\hline Tag 1 & Organentnahme & \multicolumn{2}{|c|}{ Protektionierung des Explantates 18 oder 24 Stunden } \\
\hline Tag 2 & $/ /$ Implantation & $\begin{array}{c}\text { Reperfusion / nach } 40 \\
\text { Minuten Gewebeentnahme }\end{array}$ & $\begin{array}{l}\text { Intravitalmikroskopie / } \\
\text { Gewebeentnahme }\end{array}$ \\
\hline Tag $3 / 4$ & \multicolumn{3}{|c|}{ Gewebeaufarbeitung (Fixierung, Einbettung, Schnitt, Färbung) } \\
\hline Tag 5 & \multicolumn{3}{|c|}{ Analyse und Auswertung der intravitalmikroskopischen Aufnahmen } \\
\hline
\end{tabular}

Abbildung 2: Überblick über die einzelnen Schritte im Versuchsprotokoll

Innerhalb der folgenden Tage wurden die Gewebeproben für die histologischen und immunhistochemischen Untersuchungen aufgearbeitet und die Daten der Intravitalmikroskopie ausgewertet.

\subsubsection{Protektionslösungen}

Es wurden zwei unterschiedliche Protektionslösungen verwendet.

\subsubsection{Basallösungen}

Als Basallösungen wurden eine herkömmliche HTK-Lösung und eine neu entwickelte Protektionslösung auf Basis der HTK-Lösung (N36-Lösung) verwendet. Die Zusammensetzungen der Lösungen sind in der Tabelle 2 aufgeführt. 
Tabelle 2: Zusammensetzung der Protektionslösungen (Basallösungen)

\begin{tabular}{|c|c|c|}
\hline Protektionslösung & HTK & N36 \\
\hline \multicolumn{3}{|l|}{ Ionen (mM) } \\
\hline $\mathrm{Na}+$ & 15 & 16 \\
\hline $\mathrm{K}_{+}$ & 10 & 10 \\
\hline $\mathrm{Ca}+$ & 0,015 & 0,02 \\
\hline Mg2+ & 4 & 8 \\
\hline Cl- & 50 & 0,04 \\
\hline \multicolumn{3}{|l|}{$\overline{\text { Puffer (mM) }}$} \\
\hline Histidin & 198 & 103 \\
\hline Na-Acetyl-L-Histidin & - & 94 \\
\hline Gesamtpuffer & 198 & 197 \\
\hline \multicolumn{3}{|c|}{ Impermeable Substanzen (mM) } \\
\hline Mannitol & 30 & - \\
\hline Saccharose & - & 22 \\
\hline Laktobionat & - & 9 \\
\hline \multicolumn{3}{|l|}{ ROS-Fänger (mM) } \\
\hline Tryptophan & 2 & 2 \\
\hline \multicolumn{3}{|l|}{ Aminosäuren (mM) } \\
\hline Glycin & - & 20 \\
\hline Alanin & - & 10 \\
\hline Arginin & - & 2 \\
\hline Aspartat & - & 7 \\
\hline Ketoglutarat & 1 & 2 \\
\hline $\mathrm{pH}$ & $7,02-7,2$ & 7,0 \\
\hline Osmolalität & 310 & 305,06 \\
\hline
\end{tabular}

\subsubsection{Getestete Zusätze}

In einem weiteren Schritt supplementierten wir die beiden Lösungen mit zusätzlichen Schutzsubstanzen.

\subsubsection{Eisenchelatoren}

Das Hydroxamsäurederivat LK wurde als lipophiler und zellgängiger Eisenchelator verwendet. Als Konzentrationen wählten wir 0,02 sowie 0,05 und $1 \mathrm{mM}$.

Deferoxamin verwendeten wir als hydrophilen, extrazellulären Eisenchelator in den Konzentrationen 0,2 sowie 0,5 und $1 \mathrm{mM}$. 


\subsection{Aminosäuren}

Glycin wurde als Zusatz zur Basallösung HTK in der Konzentration $10 \mathrm{mM}$ verwendet. In der Basallösung N36 war Glycin in einer Konzentration von 20 mM enthalten.

Alanin wurde in der Basallösung HTK nicht getestet. Alanin war in der Basallösung N36 in einer Konzentration von 10 mM enthalten.

Arginin wurde in der Basallösung HTK nicht getestet. Arginin war in der Basallösung N36 in einer Konzentration von 2 mM enthalten.

Aspartat wurde in der Basallösung HTK nicht getestet. Aspartat war in der Basallösung N36 in einer Konzentration von 7 mM enthalten.

\subsubsection{Versuchsgruppen}

Die Einteilung der Versuchgruppen erfolgte entsprechend der beiden Abschnitte der Untersuchung: Etablierung des Schädigungsmodells und Testung der Protektionslösungen und Schutzsubstanzen.

\subsubsection{Etablierung des Schädigungsmodells}

Die Versuchsgruppen zur Etablierung eines stabilen Schädigungsmodells bestanden aus einer Kontrollgruppe (keine Ischämie) und zwei Gruppen in denen die Transplantate für 18 oder 24 Stunden während der kalten Ischämie mit HTK-Lösung protektioniert wurden. Die Daten der Kontrollgruppe entstammen einer Studie unserer Arbeitsgruppe (Stojanovic et al. 2002). Eine Übersicht über die Gruppeneinteilung und die Fallzahlen gibt die Tabelle 3.

Tabelle 3: Gruppeneinteilung und Fallzahlen bei den Untersuchungen zur Etablierung eines stabilen Schädigungsmodells. Kontrolle: Untersuchungen ohne Ischämie; HTK 18h: kalte Ischämie mit 18-stündiger Inkubation in HTK-Lösung; HTK 24h: kalte Ischämie mit 24-stündiger Inkubation in HTK-Lösung.

\begin{tabular}{c|c|c|c} 
& Kontrolle & HTK 18h & HTK 24h \\
\hline $\mathrm{n}$ & 6 & 3 & 10
\end{tabular}




\subsubsection{Testung der Protektionslösungen und Schutzsubstanzen}

Die Versuchsgruppen zur Testung der Protektionslösungen und Schutzsubstanzen bestanden aus zwei Untergruppen (Teil A: HTK-Gruppe und Teil B: N36-Gruppe), in denen jeweils die zu testende Basallösung zur Protektion verwendet wurde: HTKLösung oder N36-Lösung. Als Ischämiedauer wurden aufgrund der Ergebnisse aus der Etablierung des Schädigungsmodells 24 Stunden gewählt. Die Gruppe HTK 24h, in der ein definierter, subtotaler Ischämie- und Reperfusionsschaden bestand, diente als Referenz für die Beurteilung der Schädigung.

Teil A: Untersuchungen mit einer Protektionslösung basierend auf der HTK-Lösung:

Tabelle 4: Gruppeneinteilung und Fallzahlen bei den Untersuchungen mit Protektionslösungen, die auf HTK-Lösung basieren. HTK: HTK-Lösung ohne Zusätze (entspricht der Gruppe HTK 24h, siehe Tab. 3); GLY: HTK-Lösung mit Zugabe von 10 mM Glycin; LK: HTK-Lösung mit Zugabe von 1 mM LK; DES: HTK-Lösung mit Zugabe von $1 \mathrm{mM}$ Deferoxamin.

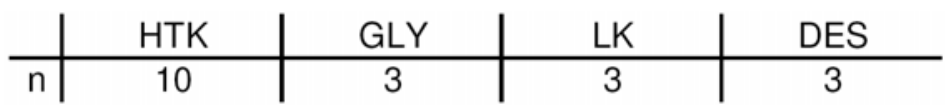

Teil B: Untersuchungen mit einer Protektionslösung basierend auf der N36-Lösung:

Tabelle 5: Gruppeneinteilung und Fallzahlen bei den Untersuchungen mit Protektionslösungen, die auf N36-Lösung basieren. N36: N36 Lösung ohne Zusätze; LK: N36-Lösung mit Zugabe von 0,05 mM LK (L0,05) oder 0,02 mM LK (L0,02); DES: N36-Lösung mit Zugabe von $1 \mathrm{mM}$ Deferoxamin (D1.0), 0,5 mM Deferoxamin $(D 0,5)$ oder 0,2 mM Deferoxamin (D0,2); LK+DES: N36-Lösung mit kombinierter Zugabe von LK und Deferoxamin in den Konzentrationen von 0,05 mM LK und $1 \mathrm{mM}$ Deferoxamin (L0,05D1,0) oder 0,02 mM LK und 0,2 mM Deferoxamin (L0,02D0,2).

\begin{tabular}{c|c|c|c|c|c|c|c|c}
\multirow{2}{*}{ N36 } & \multicolumn{2}{|c|}{$\mathrm{LK}$} & \multicolumn{3}{c|}{$\mathrm{DES}$} & \multicolumn{2}{c}{$\mathrm{LK}+\mathrm{DES}$} \\
\cline { 3 - 9 } & & $\mathrm{L} 0,05$ & $\mathrm{~L} 0,02$ & $\mathrm{D} 1,0$ & $\mathrm{D} 0,5$ & $\mathrm{D} 0,2$ & $\mathrm{~L} 0,05 \mathrm{D} 1,0$ & $\mathrm{~L} 0,02 \mathrm{D} 0,2$ \\
\hline $\mathrm{n}$ & 7 & 4 & 3 & 4 & 4 & 4 & 6 & 6
\end{tabular}

\subsubsection{Chirurgische Techniken}

Der Ablauf der Transplantation teilt sich in die Abschnitte Organentnahme mit Protektionierung des Transplantates (Kalte Ischämie) und Implantation auf. Alle 
Transplantationen führte cand. med. Ingmar Lautenschläger nach entsprechender Ausnahmegenehmigung durch das Niedersächsische Langesamt für Verbraucherschutz und Lebensmittelsicherheit (AZ: 509.42502/01-(§9)-05.03 vom 18.03.2003) durch. Grundlage für die Entwicklung der operativen Präparationstechnik war die Arbeit von Monchik und Russell (Monchik und Russell 1971).

\subsubsection{Organentnahme}

Nach medianer Laparotomie von der Symphyse bis zum Sternum und subkostalen Flügelschnitten wurde das Dünndarmkonvolut über die rechte Flanke des Tieres in feuchte Kompressen verlagert und das Duodenum mit Durchtrennung des Treitz'schen Bandes mobilisiert. Eine Kolektomie erfolgte nach Ligatur aller kollateralen Gefäße zum mesenterialen Gefäßstiel im Mesokolon. Das Kolon wurde $0,5 \mathrm{~cm}$ oral der Bauhin'schen Klappe vom lleum abgesetzt und verworfen. Danach erfolgte die Präparation der Aorta in Höhe des Abgangs der A. mesenterica superior. Alle umliegenden Gefäßabgänge wurden ligiert und die Aorta aus dem Retroperitoneum gelöst und zunächst in situ belassen. Nach Unterbindung der portalvenösen und mesenterialen Kollateralen zu Pankreas, Milz und Pylorus wurde die V. portae bis in das Leberbett dargestellt. Das Jejunum wurde auf Höhe des Treitz'schen Bandes vom Duodenum abgesetzt. Der gesamte Dünndarm vom distalen Ende des Duodenums bis zum terminalen lleum war nun einzig über die A. mesenterica superior und die V. portae mit dem Spendertier verbunden. Nach kranialem und kaudalem Ausklemmen der Aorta abdominalis wurde die V. portae in Höhe der Leberpforte durchtrennt. Das kaudale Ende des ausgeklemmten Aortenabschnittes wurde unterhalb des Abganges der A. mesenterica superior mit einer Kanüle (Sterican, Gr. 17, Braun, Melsungen, Deutschland) punktiert und das Gefäßbett des Explantates mit ca. $10 \mathrm{ml}$ der $4^{\circ} \mathrm{C}$ kalten Perfusionslösung gespült, bis das Effluat makroskopisch blutfrei erschien. Die intraluminal verbliebenen Stuhlreste wurden mit ca. $20 \mathrm{ml}$ der gleichen, kalten Perfusionslösung unter geringem, aber konstantem Druck ausgespült. Danach wurde die Aorta kaudal des Abganges der A. mesenterica superior, kranial der Punktionsstelle ligiert und aus dem Situs getrennt. Das Explantat wurde in $150 \mathrm{ml}$ der zu testenden Protektionslösung bei $4^{\circ} \mathrm{C}$ über $18 \mathrm{~h}$ oder $24 \mathrm{~h}$ gelagert und das Spendertier in tiefster Ethernarkose durch Herzschnitt getötet. 


\subsubsection{Implantation}

Die Prozedur der Implantation teilte sich in zwei Abschnitte: Die Etablierung von Kreislaufmonitoring und Gefäßzugängen für die Volumensubstitution und die eigentliche Organimplantation mit Beginn der Reperfusionsphase.

\subsection{Kreislaufmonitoring und zentraler Venenkatheter}

$\mathrm{Zu}$ Beginn der Empfängeroperation wurden Polyethylenkatheter mit einem Innendurchmesser von 0,58 mm (Dow Cornig Newark, New Jersey, USA) in die V. jugularis interna dextra und die $A$. carotis dextra eingelegt. Hierzu wurde im lateralen Halsdreieck zunächst die V. jugularis interna aufgesucht, dargestellt und nach kranial ligiert. Der Katheter wurde intravasal platziert und an der Gefäßwand mittels Ligaturfaden (Perma Handseide 7-0, Ethicon, Norderstedt, Deutschland) fixiert. Analog wurde mit der Kanülierung der A. carotis verfahren. Eine unter dem mobilisierten Gefäß aufgespreizte Uhrmacherpinzette okkludierte das Lumen und ermöglichte so die Kathetereinlage ohne Blutverlust (Abb. 3). Beide Katheter wurden mittels 3-Wege-Hähnen entweder an eine Spritzenpumpe (Perfusor secura, Braun, Melsungen, Deutschland) zur venösen Infusion, oder an die arterielle Druckmesseinheit konnektiert. Die arterielle Druckmesseinheit umfasste einen Druckaufnehmer (Combitrans Monitoring-Set, Braun, Melsungen, Deutschland) und einen Monitor (Sirecust 620, Siemens, Erlangen, Deutschland). Die erhaltenen Gefäßzugänge ermöglichten somit eine kontinuierliche Volumensubstitution über den zentralen Venenweg, eine gezielte arterielle Bolus-Applikation von Fluoreszenzfarbstoffen unter Umgehung der Lungenstrombahn, sowie eine kontinuierliche Überwachung und Dokumentation des Blutdruckes und der Pulswelle. 


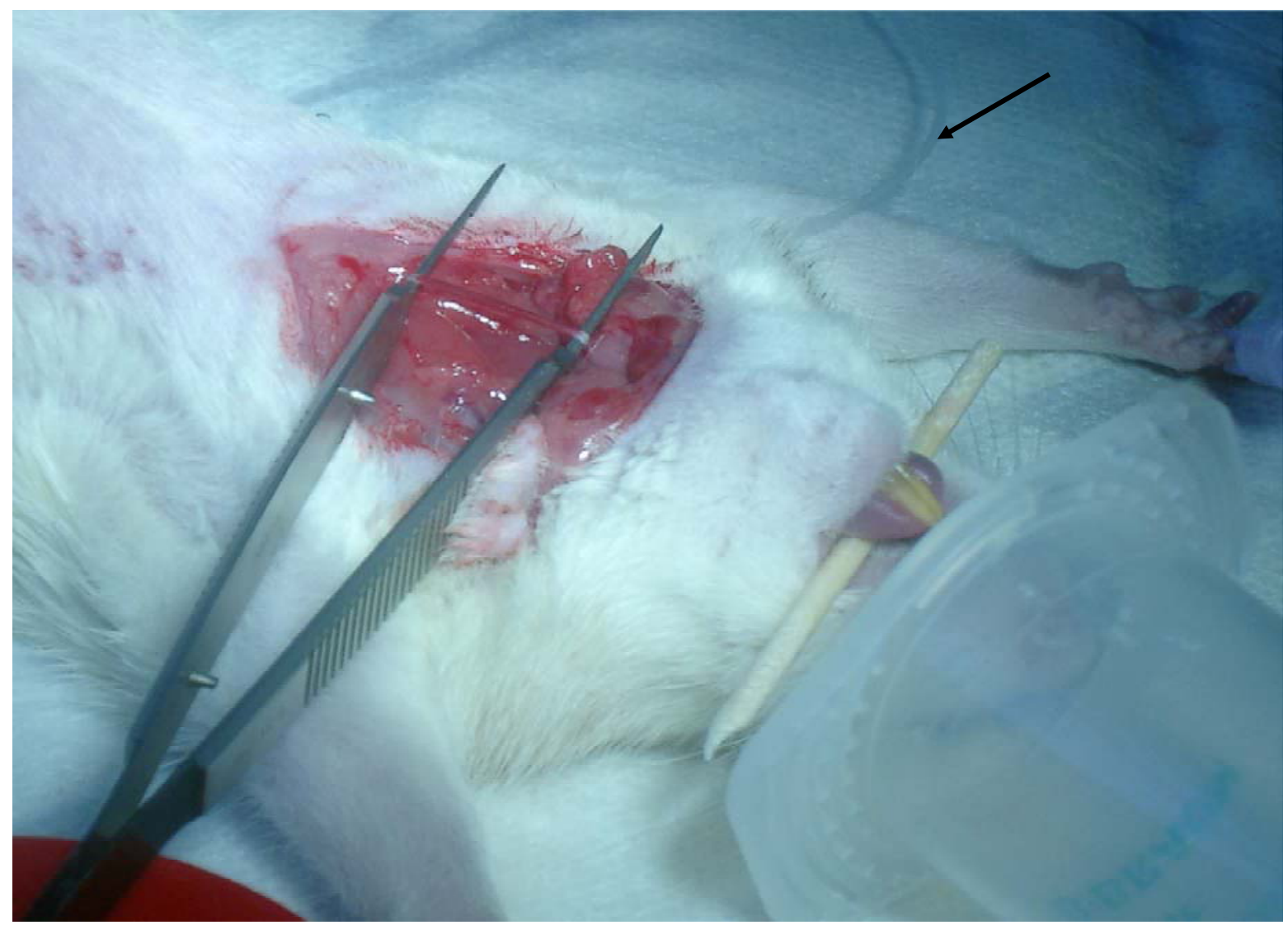

Abbildung 3: Arteria carotis dextra durch Pinzettenbranchen okkludiert, zentraler Venenkatheter bereits eingebracht (Pfeilmarkierung).

\subsubsection{Organimplantation}

Nach Rasur, Hautdesinfektion und Eröffnung des Abdomens wurde das intestinale Konvolut des Empfängertieres über die rechte Flanke luxiert, in Zellstoffkompressen eingeschlagen und stetig mit warmer, isotoner Kochsalzlösung feucht gehalten. Die Aorta abdominalis und $\mathrm{V}$. cava inferior wurden infrarenal vom parietalen Blatt des Peritoneums befreit und soweit aus dem Retroperitoneum mobilisiert, dass beide Gefäße auf einer Strecke von ca. $2 \mathrm{~cm}$ mittels Gefäßklemmen aus der Zirkulation isoliert werden konnten. Nach erfolgter Vasotomie durch Längsinzision wurde das Transplantat aus der Protektionslösung entnommen und links neben dem Tier in kalten, feuchten Kompressen bereitgelegt. Der Aortencuff des Transplantates wurde End-zu-Seit in fortlaufender Nahttechnik an die Aorta abdominalis anastomosiert (Abb. 4). Der venöse Anschluss der Spenderpfortader and die V. cava inferior des Empfängers erfolgte portokaval mit fortlaufendem Faden und zwei EinzelknopfEckstichen. Vor Vollendung der venösen Anastomose wurde die Aorta abdominalis punktiert. Mit ca. $10 \mathrm{ml}$ warmer, isotoner Kochsalzlösung wurde die verbliebene 
Protektionslösung aus dem mesenterialen Stromgebiet gespült, das Transplantat vorgewärmt und die arterielle Verbindung auf Dichtigkeit geprüft. Die Punktionsstelle wurde mit zwei Stichen einer Einzelknopftnaht verschlossen und die venöse Anastomose vervollständigt (Abb. 5). Als Nahtmaterial wurde eine atraumatische Nadel- und Faden- Kombination verwendet (8-0 Nylon, Ethicon, Norderstedt, Deutschland). Die Stichkanäle der Nähte waren somit glatt und im Durchmesser gering. Für die Anfertigung der Gefäßnähte wurde als optische Hilfe die 16-fache Vergrößerung eines Operationsmikroskops (M650, Wild, Heerbrugg, Schweiz) genutzt. Nach dem vaskulären Anschluss und der Freigabe der Perfusion wurde das Transplantat in die Bauchhöhle und der eigene Darm zurück in situ gelegt. Die Operationswunde wurde mit feuchten Zellstoffkompressen abgedeckt und regelmäßig mit isotoner Kochsalzlösung befeuchtet.

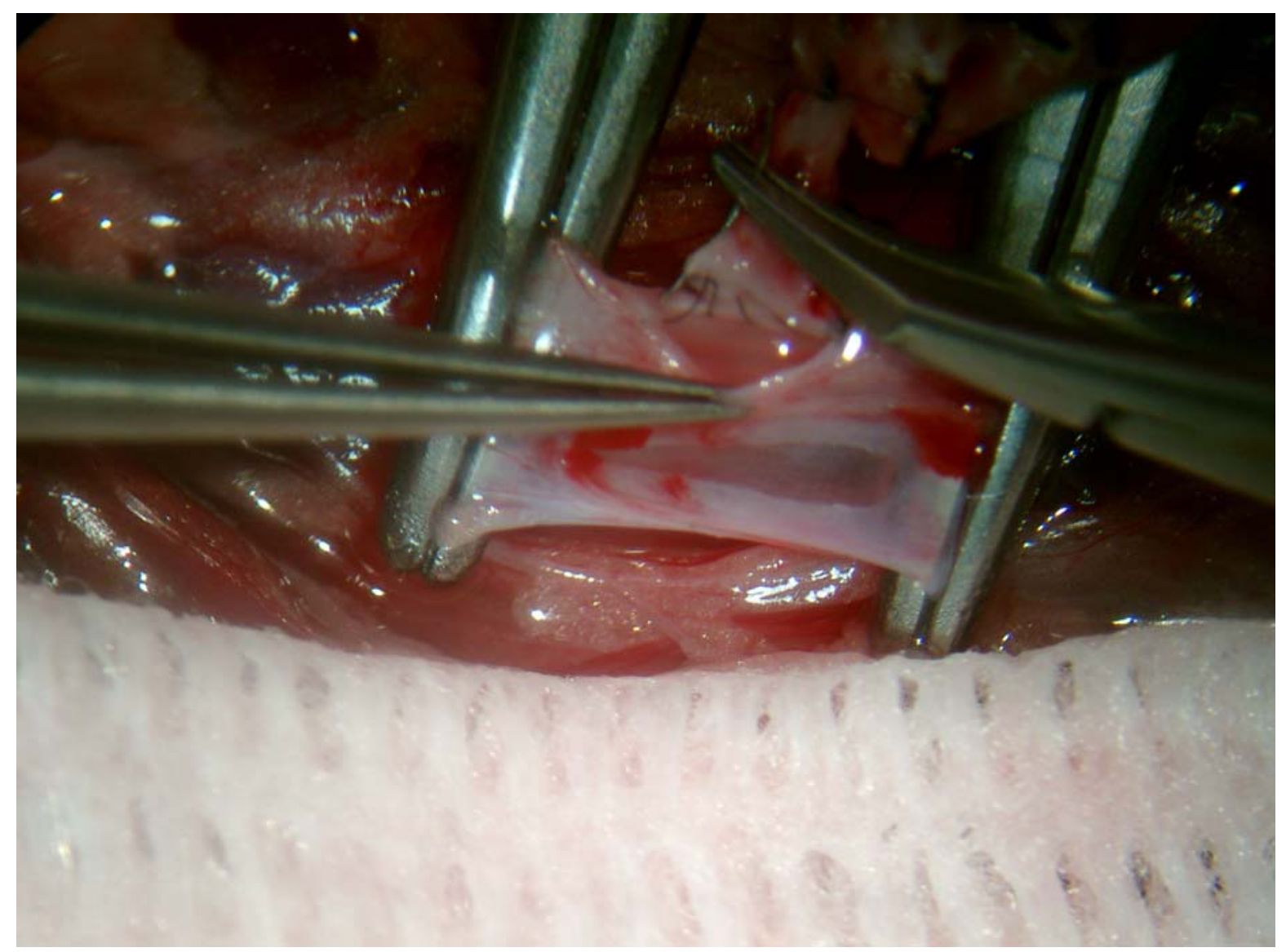

Abbildung 4: Anastomosierung der Arteria mesenterica (fortlaufende Nahttechnik) 


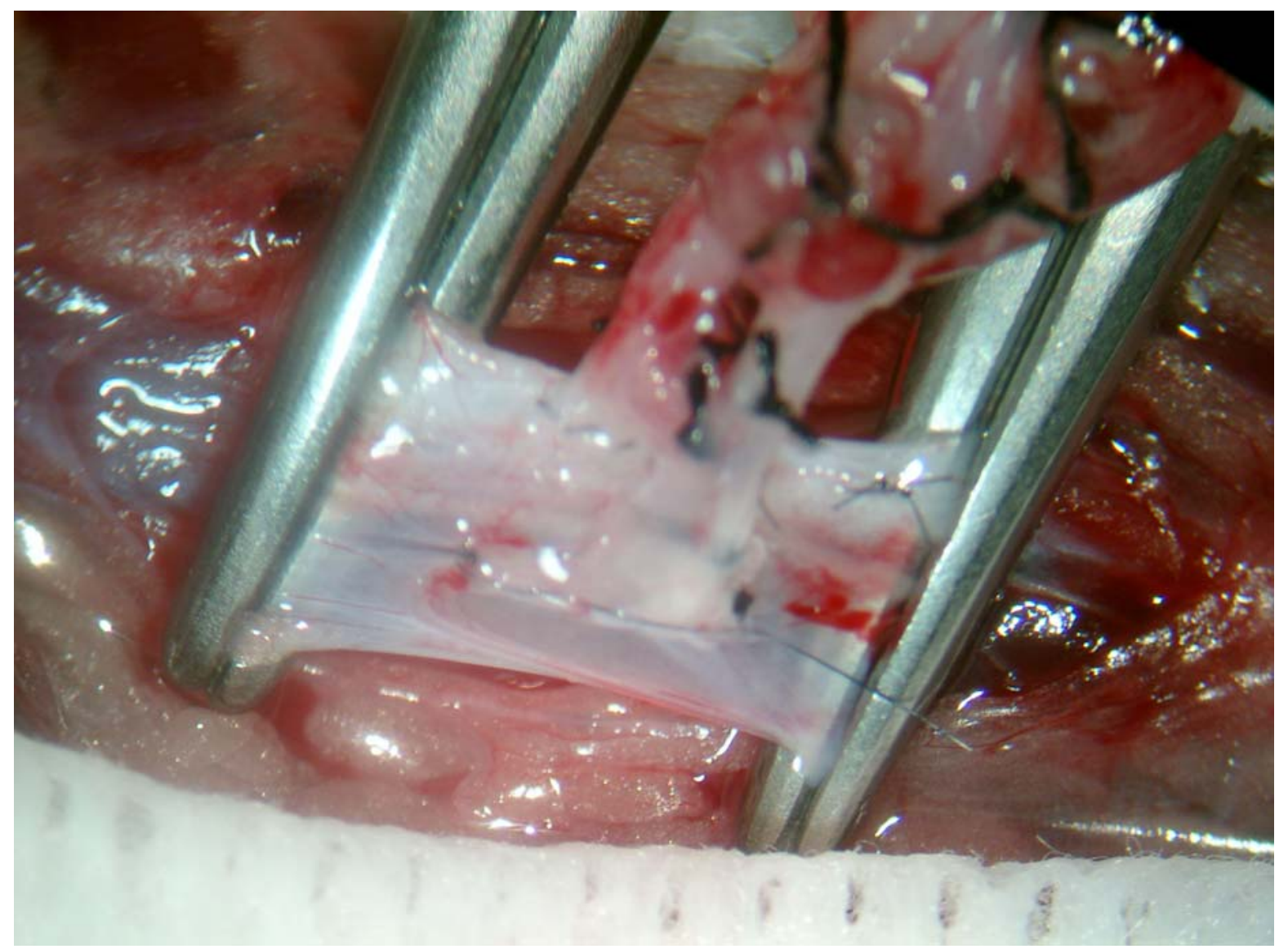

Abbildung 5: Fertige End-zu-Seit-Anastomosen des Spenderaortencuffs mit Arteria mesenterica und der Vena portae

\subsection{Reperfusionsphase}

Während einer 40-minütigen Reperfusionsphase erfolgten ausser der Volumensubstitution (Mittelwert 9,3 $\mathrm{ml} \cdot \mathrm{h}^{-1}$ ) mit einem Gemisch aus drei Teilen Sterofundin iso (Ecoflac plus, Braun, Melsungen, Germany) und einem Teil Gelafundin 4\% (Ecoflac plus, Braun, Melsungen, Germany) keine weiteren Interventionen. Der arterielle Blutdruck wurde kontinuierlich gemessen und in kurzen Zeitintervallen (ca. 5 Minuten) protokolliert. Am Ende der Reperfusionsphase wurde ein lleumsegment im proximalen Anteil des Transplantates mittels Ligaturen isoliert und für die histologische und immunhistochemische Aufarbeitung entnommen (s.u.).

\subsubsection{Untersuchungen der Schädigungsparameter}

Die Analyse des Ischämie- und Reperfusionsschadens des Dünndarmtransplantates erfolgte in vivo mittels Intravitalmikroskopie und zu zwei Zeitpunkten mittels 
herkömmlicher Lichtmikroskopie und histologischer sowie immunhistochemischer Techniken (Ablaufplan siehe Abb. 2).

\subsubsection{Intravitalmikroskopie}

Die Intravitalmikroskopie wurde nach einer Reperfusionszeit von 40 Minuten und Entnahme der ersten Gewebeprobe durchgeführt.

\subsection{Gefäßanatomie}

Am Darm unterscheidet man eine mesenteriale und eine antimesenteriale Seite. Die Gefäße verlaufen vom Mesenterium zunächst in der Tunica muscularis beidseitig um das Darmrohr nach antimesenterial (Abb. 6). Sie verzweigen sich auf diesem Wege in die Tela submucosa, in der sie einen Plexus bilden (Abb. 7). Von hier aus verlaufen Äste durch die Lamina muscularis mucosae in das Zottenstroma, die Lamina propria mucosae, und versorgen die gesamte Darmzotte bis nach subepithelial durch ein feines kapilläres Netzwerk. Das kapilläre Netzwerk eines Villus drainiert in ein oder zwei an der Zottenspitze beginnenden Venolen, die in den submukösen Plexus ableiten. Die Tunica muscularis teilt sich in die innere Lamina muscularis circularis und die äussere Lamina muscularis longitudinalis. Entsprechend der Ausrichtung dieser Muskelschichten verläuft ihr kapillares Netz entweder zirkulär oder longitudinal. 


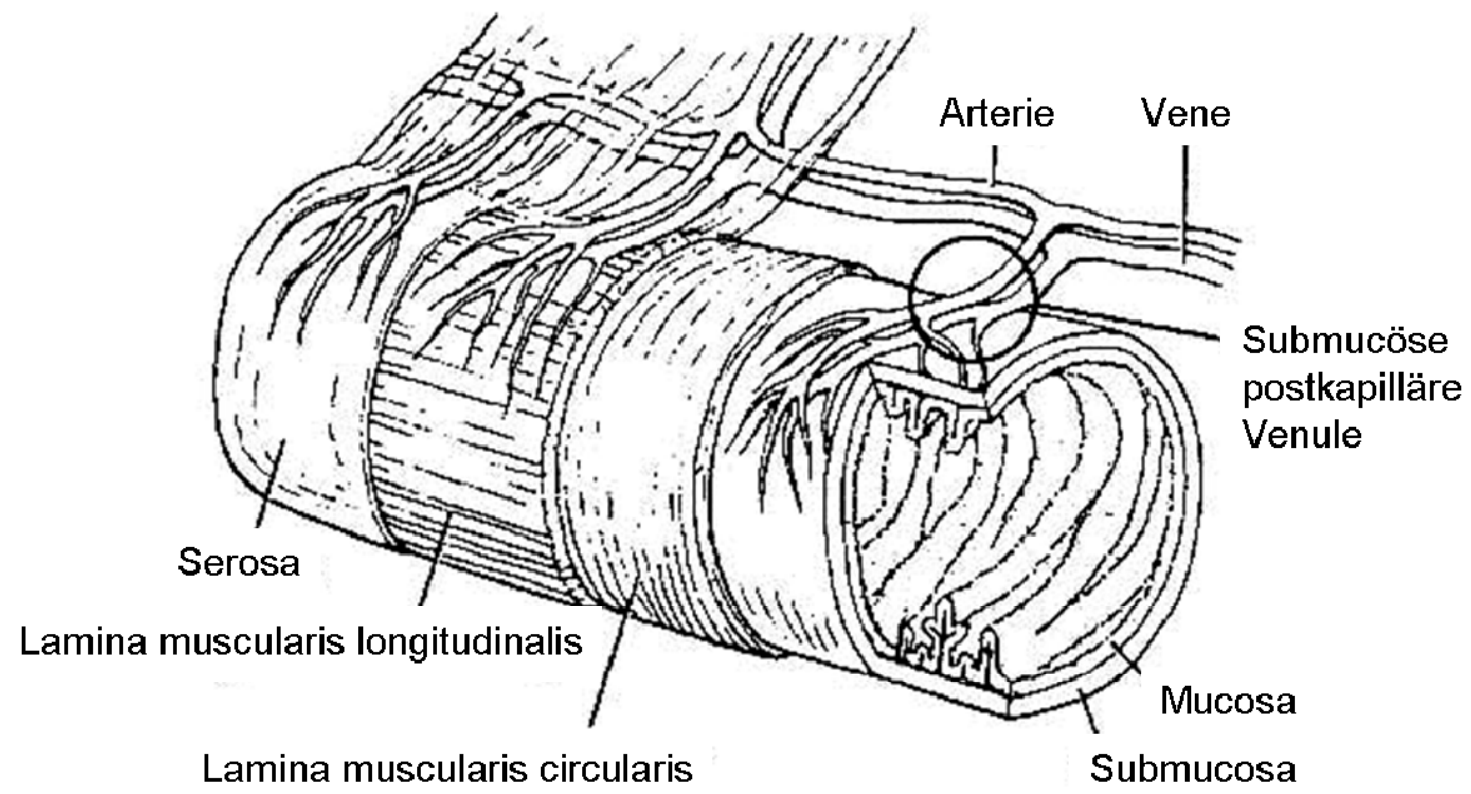

Abbildung 6: Aufbau der Dünndarmwand mit Gefäßversorgung (modifiziert nach Anthoni et al. 2002, 265)

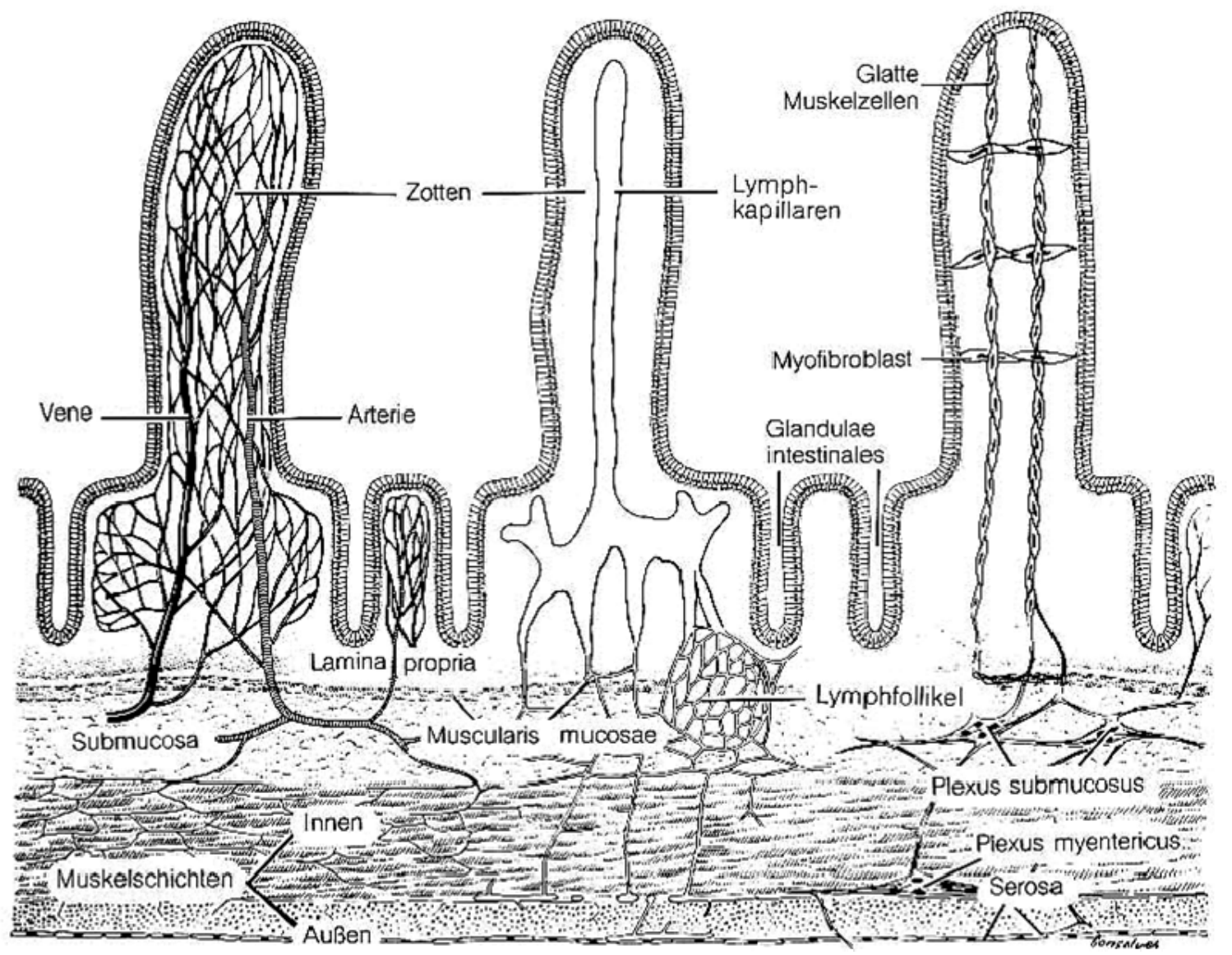

Abbildung 7: Mikroskopische Anatomie und Gefäßversorgung der Dünndarmwand (modifiziert nach Junqueira und Carneiro 1996, 506) 


\subsection{Versuchsaufbau- und Versuchsbedingungen}

Die intravitalmikrokopischen Untersuchungen erfolgten nach einer von Bohlen und Gore beschriebenen Technik (Bohlen und Gore 1976). Es wurde dabei eine für die Auflichtmikroskopie modifizierte Bühne verwendet (Abb. 8 und Abb. 9). Wichtige Grundvoraussetzungen für die Intravitalmikroskopie sind eine suffiziente, kontrollierbare Makrohämodynamik, eine physiologische Temperatur des ex corpore gelagerten Transplantatabschnittes sowie die konsequente Vermeidung von Zug an dessen mesenterialen Gefäßen. Alle diese Ziele wurden mit Blick auf standardisierte Untersuchungsbedingungen verfolgt. Der wichtigste Parameter für die Organperfusion ist der mittlere arterielle Druck (MAD). Er berechnet sich näherungsweise über die folgende Größengleichung: $M A D=P_{\text {dias }}+1 / 3 \times\left(P_{\text {sys }}\right.$ $\left.P_{\text {dias }}\right)$. Der Blutdruck wurde kontinuierlich mit Hilfe der oben beschriebenen invasiven Messmethode gemessen, dokumentiert und durch Volumensubstitution (Mittelwert 6,8 $\mathrm{ml} \cdot \mathrm{h}^{-1}$ ) weiterhin gestützt. Die Mikroskopierbühne war zur optimalen Wärmeleitung aus Kupfer angefertigt. Ein Wasserbad mit Umwälzpumpe (Exatherm U3 electronic, Julabo, Seelbach, Germany) durchströmte die Kammer mit $37^{\circ} \mathrm{C}$ temperiertem Wasser und verhinderte so ein Auskühlen des zu mikroskopierenden Gewebes. Das laparotomierte Tier wurde auf die linke Seite gelagert, sodass die Mesenterialwurzel des Transplantates mit der ca. $1 \mathrm{~cm}^{2}$ messenden Stempelfläche der Mikroskopierkammer im Niveau lag. Gleichzeitig konnte so der Abstand zwischen Tier und Mikroskopierbühne leicht angepasst und der Zug an den Gefäßen eliminiert werden. Zum Stützen dieser Lagerung wurde eine dem Rücken des Tieres angeformte Kupferschiene verwendet. Um eine Unterkühlung des Versuchtieres zu vermeiden, wurde ein beheizbarer Operationstisch verwendet und auf ca. $38^{\circ} \mathrm{C}$ gewärmt. 


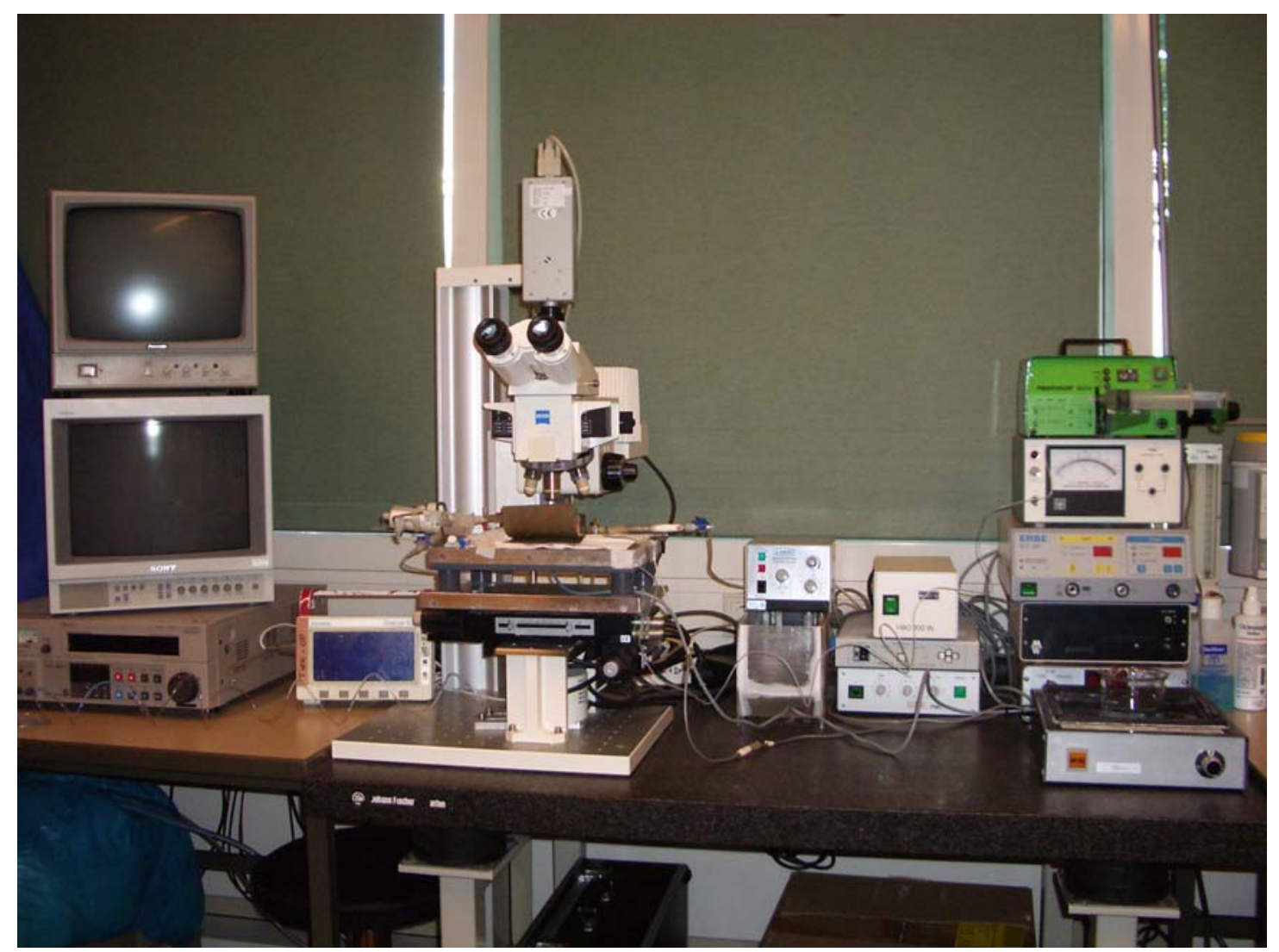

Abbildung 8: Versuchsaufbau für die Intravitalmikroskopie

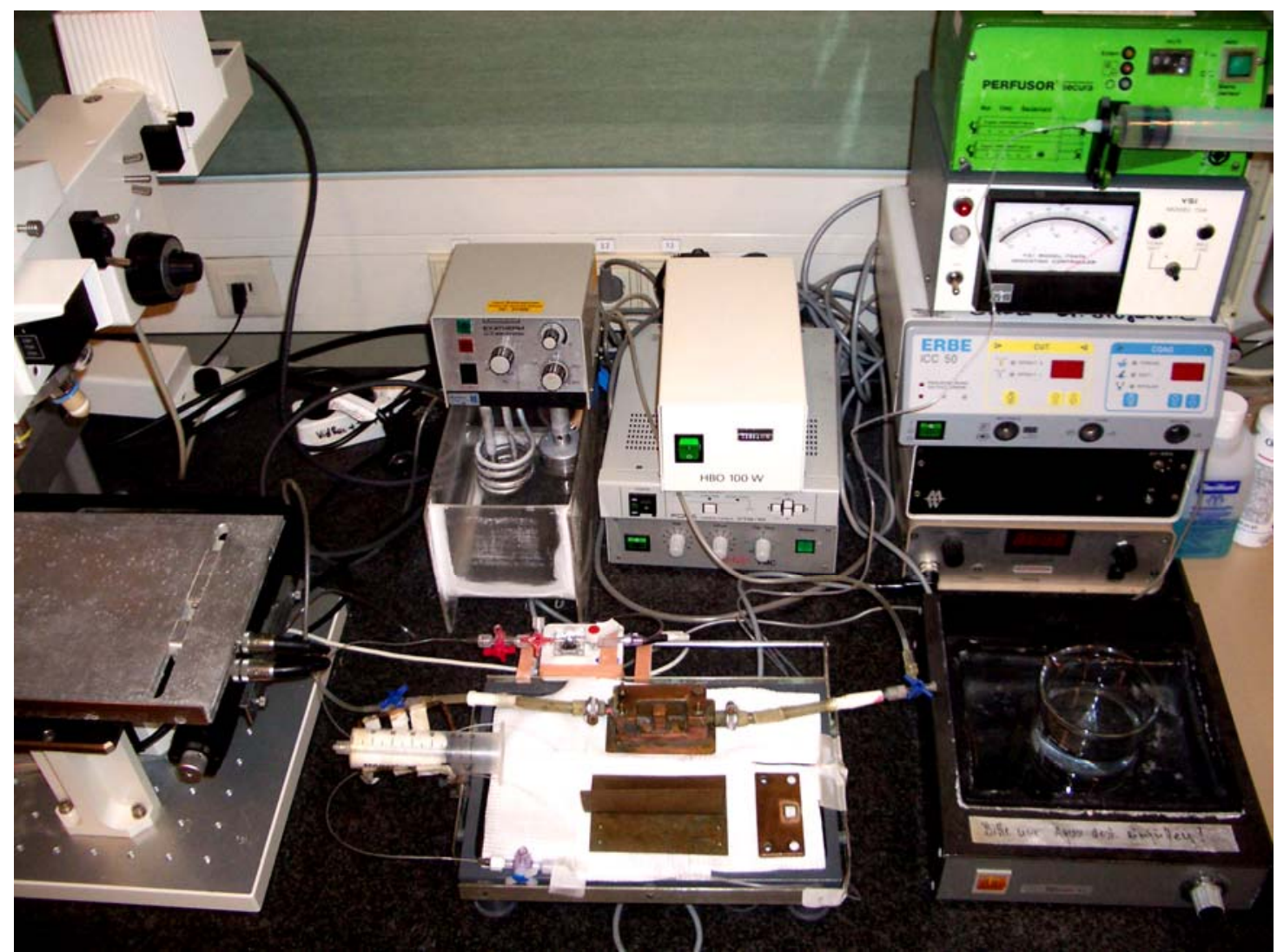

Abbildung 9: Temperierbare Mikroskopierbühne und Zubehör 


\subsection{Fluoreszenzfarbstoffe}

Zur Erfassung der Mikrozirkulation und Leukozyten-Endothelzell-Interaktion wurden zwei verschiedene Fluoreszenzfarbstoffe verwendet. Fluoreszein-Iso-Thio-CyanatDextran 500.000 (FITC-Dextran, Sigma-Aldrich Chemie GmbH, München, Germany) mit einem Molekulargewicht von $500 \mathrm{kDa}(0,5 \% \mathrm{ig})$ diente der positiven Kontrastierung des Blutplasmas gegen die korpuskulären Blutbestandteile und ermöglichte die Visualisierung der Mikrozirkulation. Rhodamin-6-G (0,2\%ig) (SigmaAldrich Chemie $\mathrm{GmbH}$, München, Germany) hingegen färbt hauptsächlich das Chromatin von Leukozyten und wurde zur Begutachtung ihrer Interaktionen mit dem Gefäßendothel verwendet. Es wurden kleine Boli (0,8 ml FITC-Dextran-Lösung und 0,2 ml Rhodamin-6-G-Lösung) der Farbstoffe unmittelbar vor der Aufnahme der mikroskopischen Bilder über den arteriellen Katheter in die A. carotis dextra injiziert.

\subsection{Technik und Aufbau der Videomikroskopiereinheit}

Die Intravitalmikroskopie wurde in Epiillumineszenz durchgeführt. Verwendet wurde ein optisches System bestehend aus einem Auflichtmikroskop (Axiotech vario 100 HD, Zeiss, Göttingen, Deutschland) und einer hochauflösenden schwarz-weiß CCDVideokamera (CF8/1, Kappa, Gleichen, Deutschland). Als Lichtquelle im Mikroskop diente eine Quecksilber-Hochdruck-Entladungslampe (HBO 100, Osram, München, Deutschland). Mit einem 10er Abstandsobjektiv und den 20er und 40er Wasserimmersionsobjektiven konnten Bilddarstellungen mit 236-, 468- und 946facher Vergrößerung im benutzten Bildanalysesystem (siehe Abschnitt 2.2.5.1.7 Bildanalysesystem) erreicht werden. In der Abbildung 10 ist der Strahlengang dieses optischen Systems dargestellt. 


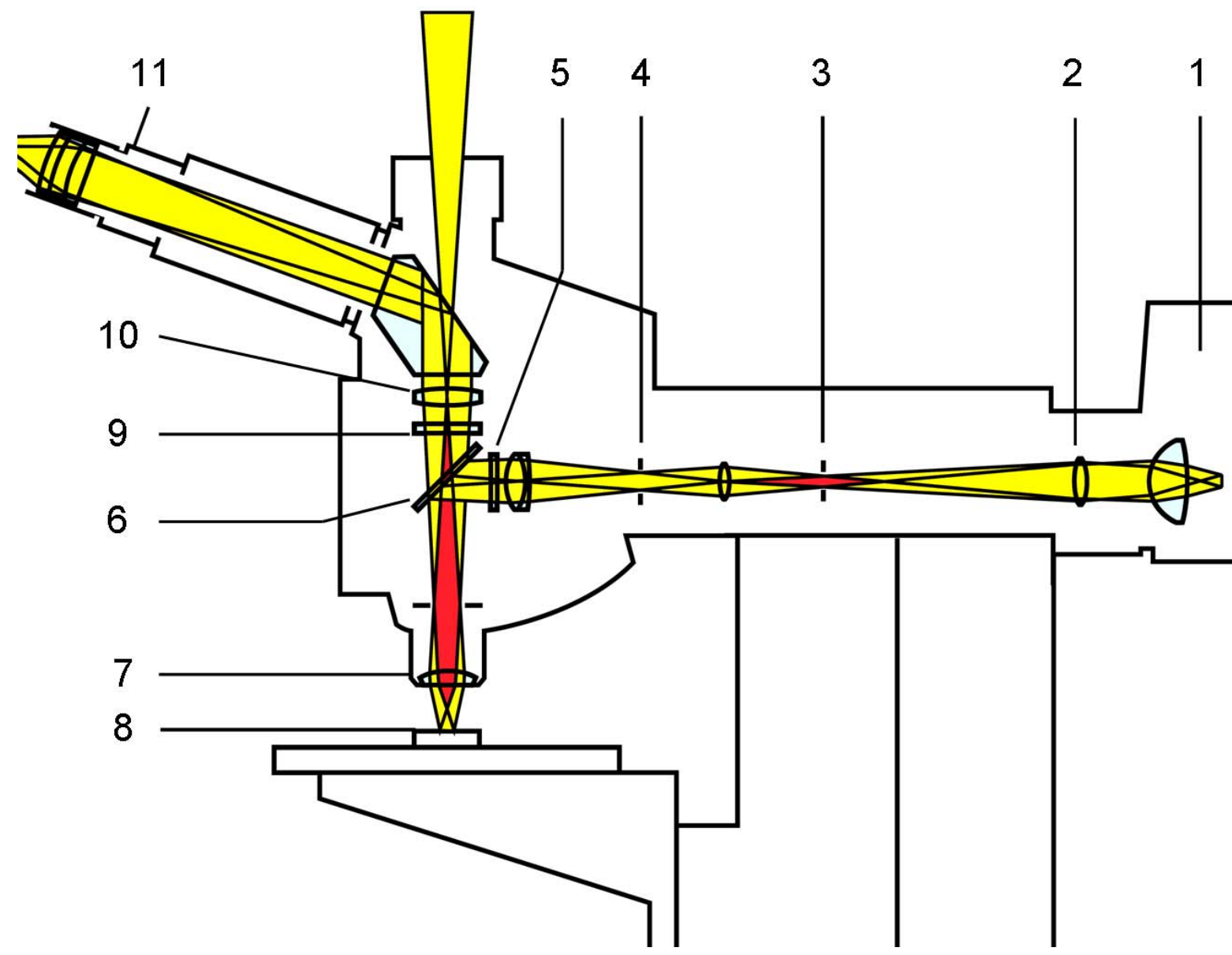

Abbildung 10: Die Abbildung zeigt den Strahlengang im Epiillumineszenzmikroskop Axiotech vario 100 (Zeiss, Göttingen, Deutschland). Das von der Quecksilberdampflampe (1) emittierte Licht gelangt über einen Wärmeschutzfilter (2), einen Rotdämpfungsfilter (3) und eine Leuchtfeldblende (4) zu einem im Reflektorschieber integrierten Anregungsfilter (5) mit Strahlenteiler (6). Hier wird das kurzwellige Anregungslicht durch den Strahlenteiler über das verwendete Objektiv (7) auf das Präparat (8) reflektiert. Das Objektiv sammelt die im Präparat entstehenden Lichtemissionen. Der Strahlenteiler lässt diese Photonen mit größerer Wellenlänge im Gegensatz zu denen des Anregungslichtes ungehindert passieren. Die bei der Bildformung potentiell störenden Reste des Anregungslichts werden durch den Emissionsfilter (9) aus dem weiterführenden Strahlengang eliminiert. Tubuslinse (10) und Okular (11) formen das Bild einzig aus Fluoreszenzlicht (Kapitza 1994, 30).

\subsection{Dokumentation der Videomikroskopie}

Die Videomikroskopie wurde mit einem S-VHS Videorecorder (AG 7355, Panasonic, USA) auf S-VHS Videobänder (E240 Pro, Fuji, Japan) umgesetzt. Für die exakte 
zeitliche Zuordnung der Bilder war ein Zeitnehmer zugeschaltet. Zur Aufnahmekontrolle war unmittelbar hinter die CCD-Kamera ein Monitor (Multiscan 17se, Sony, Japan) geschaltet. Ein weiterer Monitor (WV-BM, Panasonic, USA) diente als Hinterbandkontrolle für die Videoaufzeichnung.

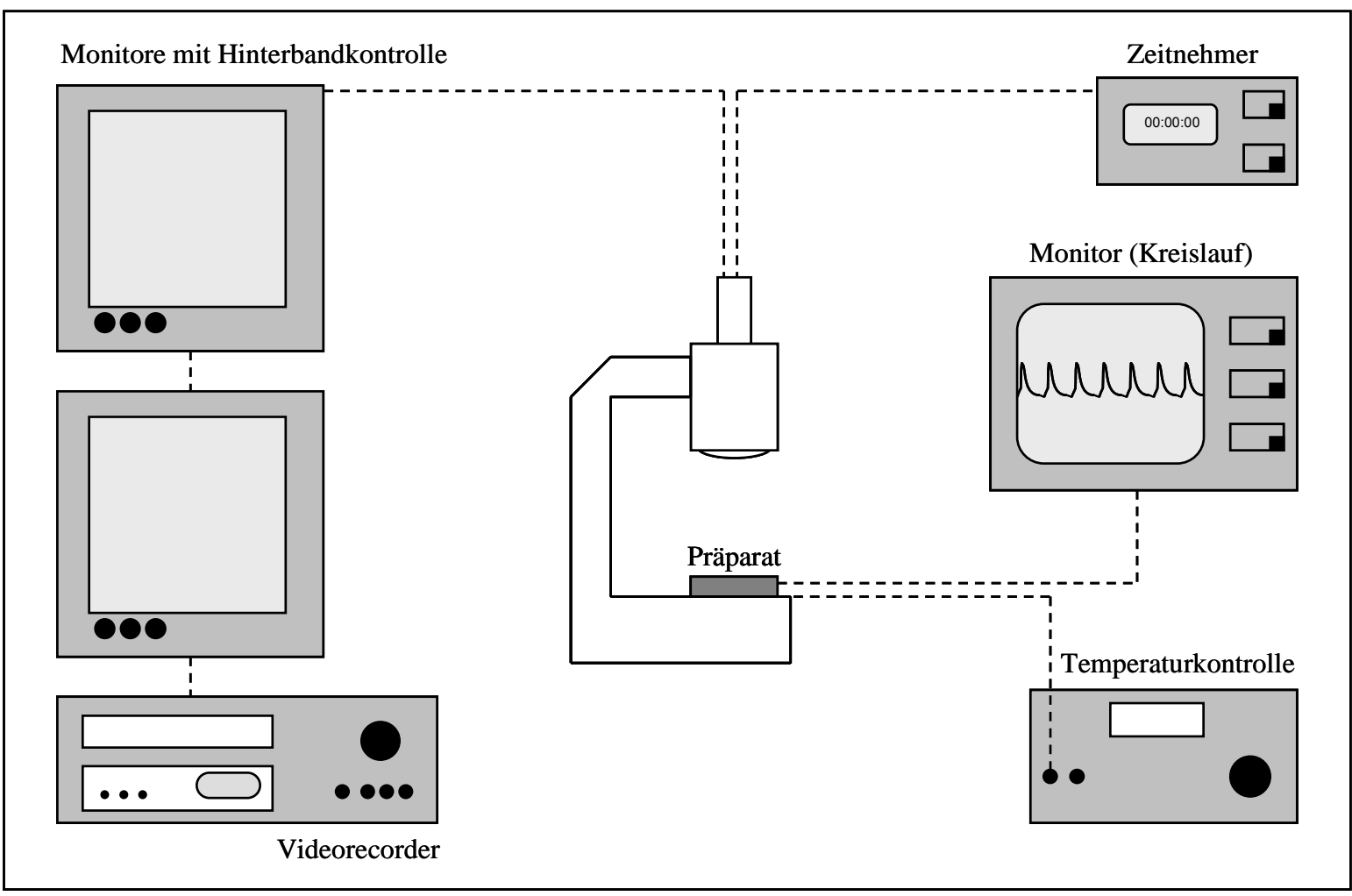

Abbildung 11: Videoaufnahmeeinheit

\subsection{Durchführung der intravitalmikroskopischen Untersuchungen}

Die intravitalmikroskopischen Untersuchungen der Transplantate erfolgten in mehreren Schritten.

\subsection{Gewebeauswahl und Auslagerung}

Für die Untersuchung der Mikrozirkulation wurde ein Darmsegment aus dem Jejunum des Transplantates ausgewählt. Wichtigstes Kriterium für die Auswahl war die Möglichkeit der optimalen zugfreien Auslagerung. Der gefäßfreie Abschnitt des Mesenteriums zwischen zwei Gefäßarkaden wurde von der Mesenterialwurzel bis zur Darmwand mit einer Mikroschere durchtrennt. Mit feuchten Watteträgern wurde das Darmsegment seitlich auf den Auslagerungsstempel platziert. Das in die Kupferabdeckung eingelassene Deckglas wurde mittels Abstandshaltern aus 
Knetmasse so über dem Gewebe eingestellt, dass der Kontakt von der Muskulariszur Glasoberfläche einzig durch Adhäsionskräfte getragen wurde. Es erfolgte von hier aus die Mikroskopie der Tunica muscularis und der Tela submucosa in Auflichttechnik. In einem zweiten Schritt wurde ein weiteres, distal gelegenes Segment ausgewählt und der Darm unter Schonung der übrigen Mukosa streng antimesenterial auf einer Strecke von ca. $2 \mathrm{~cm}$ Länge inzidiert. Die Darmmukosa war somit nach vorsichtiger Ausbreitung auf der Stempelfläche der Beobachtung zugänglich. Die Auslagerung des Segmentes und das Aufsetzen des Deckglases erfolgten analog nach den Kautelen der Muskularismikroskopie.

\subsection{Arbeitsschritte der intravitalmikroskopischen Untersuchungen}

Im proximalen Darmsegment wurde zunächst die Mikrozirkulation der Darmwand von aussen aufgenommen. Die zwei Ebenen der muskulären Wandung, die Tunica muscularis stratum longitudinale und die Tunica muscularis stratum circulare, wurden getrennt mikroskopiert. Es wurden je 10 Übersichtsaufnahmen in der Dauer von mindestens 30 Sekunden mit dem 20er Wasserimmersionsobjektiv aufgenommen. In der darunter liegenden Schicht der Tela submucosa wurde die Leukozyten-EndothelInteraktion untersucht. Es wurden dazu 10 postkapilläre Venolen aufgesucht und ebenfalls über mindestens 30 Sekunden mikroskopiert. Die Kriterien für die Auswahl waren ein möglichst gerader Gefäßverlauf über eine Strecke von ca. 100 $\mu \mathrm{m}$ und ein Durchmesser nicht größer als $30 \mu \mathrm{m}$. In einem weiteren Schritt wurde die Mikrozirkulation der Darmmukosa von innen aufgenommen. Nach antimesenterialer Inzision wurden 10 zufällig gewählte Gesichtsfelder der Mukosaoberfläche, über das 10er Objektiv mikroskopiert. Sie dienten der Bestimmung von Perfusions- und Staseindex. Über das 20er Wasserimmersionsobjektiv wurde die Mikrozirkulation von 10 zufällig gewählten Villi pro Transplantat zur Bestimmung der funktionellen Kapillardichte aufgenommen. Die Aufnahmen über das 40er Wasserimmersionsobjektiv ermöglichten die Messung der Blutkörperchenfließgeschwindigkeit in den untersuchten Villi. Es waren dabei nur noch Teilbereiche eines Villus pro Gesichtsfeld zu erkennen. 


\subsection{Bildanalysesystem}

Die Auswertung der Videoaufzeichnungen konnte mit Hilfe des Bildanalysesystems zeitlich unabhängig von der Mikroskopie durchgeführt werden (Abb. 12). Sie erfolgte mit einem S-VHS Videorecorder (AG 7355, Panasonic, USA), der auf einem analogen 21-Zoll-Monitor (TU 2100E, JVC, USA) und einem digitalen Bearbeitungsmonitor (EUM-1491 A, Mitsubishi, Japan) das Bild darstellte. Eine daran gekoppelte, computergestützte digitale Analyseeinheit ermöglichte die standardisierte, halbautomatische Auswertung mit der Software „Cap-Image 4.02“ (Cap-Image, Dr. Zeintl, Heidelberg, Deutschland). Zur Menuführung im Programm wurde ein weiterer handelsüblicher Monitor verwendet. Als Computer fand ein Personal Computer mit integrierter Bildfangschaltung Verwendung.

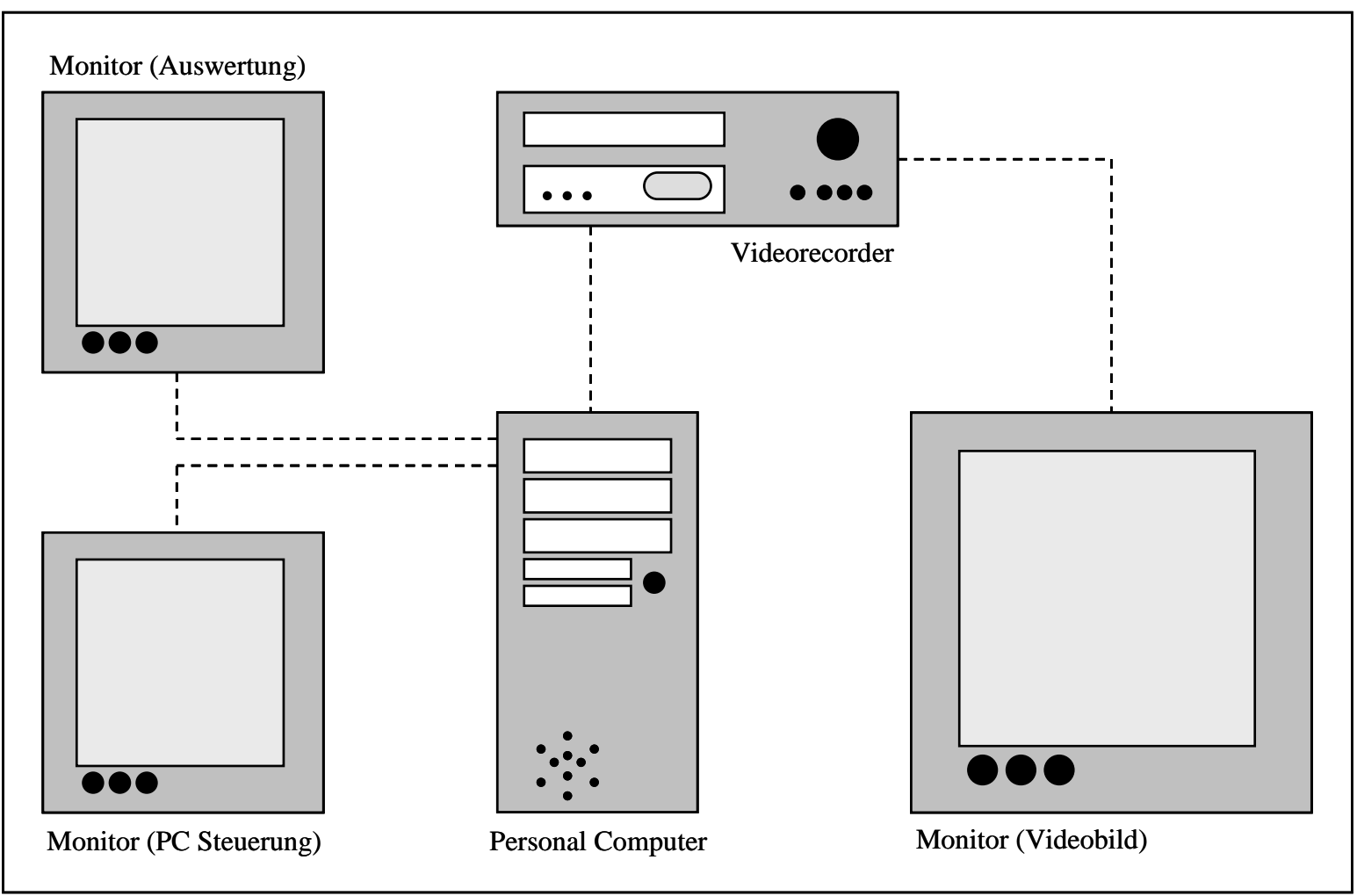

Abbildung 12: Bildanalysesystem

\subsection{Durchführung der Bildanalyse zur Quantifizierung der Mikrozirkulation}

Folgende Parameter sind in der Literatur etabliert (Gonzalez et al. 1994, Menger et al. 1992, Post et al. 1992) und wurden zur Beurteilung der intestinalen Mikrozirkulation herangezogen: 

a) Funktionelle Kapillardichte der Tunica Muscularis
b) Leukozytenindex
c) Perfusionsindex
d) Staseindex
e) Funktionelle Kapillardichte der Tunica Mucosa
f) Blutkörperchenfließgeschwindigkeit.

\subsection{Funktionelle Kapillardichte der Tunica muscularis (FKD muscularis)}

Die funktionelle Kapillardichte der Muskularis wurde mit dem Strahlengang über das 20er Wasserimmersionsobjektiv bestimmt (Gonzalez et al. 1994). Die Gesamtlänge der nutritiv perfundierten Kapillaren $\left(I_{k a p}\right)$ der inneren Ring- und der äusseren Längsmuskulatur wurde in Relation zur Fläche des jeweiligen Gesichtsfelds (A Gesichtsfeld $_{\text {) gesetzt: }}$

$F K D_{\text {muscularis }}=I_{\text {kap }} / A_{\text {Gesichtsfeld }}$

Die $F K D_{\text {muscularis }}$ hat die Einheit $\mathrm{cm}^{-1}$. Pro Transplantat wurden 10 Bildausschnitte ausgewertet. Je größer die funktionelle Kapillardichte, desto besser war die Mikrozirkulation in der Muskularis.

\subsection{Leukozytenindex}

Das Adhäsionsverhalten der Leukozyten in den postkapillären Venolen der Tela submucosa (Leukozyten-Endothelzell-Interaktion) wurde mit dem 20er Wasserimmersionsobjektiv beurteilt. Dabei wurden die adhärierenden Leukozyten untersucht. Sie wurden als "Sticker" definiert, sobald sie mindestens 30 Sekunden ortsfest am Endothel adhärierten (Gonzalez et al. 1994, Menger et al. 1992). Pro

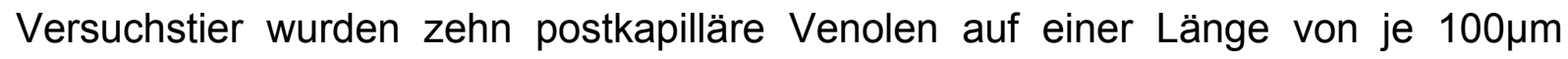
untersucht. Die Anzahl der "Sticker“ wurde als Index in Leukozyten pro $\mathrm{mm}^{2}$ Endotheloberfläche unter der Annahme einer zylindrischen Gefäßanatomie mit dem Durchmesser D und der Bezugslänge I angegeben:

Leukozytenindex $=\mathrm{n} / \mathrm{\pi} \cdot \mathrm{D} \cdot \mathrm{I}$ 
Je größer der Leukozytenindex, desto größer war auch die Leukozyten- und Endothelzellinteraktion.

\subsection{Perfusionsindex $\left(I_{p}\right)$}

Der Perfusionsindex wurde in der Vergrößerung, die über das 10er Abstandsobjektiv erreicht wurde, bestimmt. Es erfolgte eine visuell graduierte Einteilung der Villusperfusion in gut perfundierte Villi (alle Kapillaren im Villus durchströmt), irregulär perfundierte Villi (Villus mit Perfusionsausfällen im Kapillarnetz) und nicht perfundierte Villi (vollständige Stase). Aus diesen semiquantitativen Datensätzen wurde ein Perfusionsindex $\left(I_{p}\right)$ in Anlehnung an die Arbeit von Post (Post et al. 1992) nach folgender Gleichung berechnet:

$\mathrm{I}_{\mathrm{p}}=\left(\mathrm{n}_{\mathrm{g}}+0,5 \cdot \mathrm{n}_{\text {irr }}\right) / \mathrm{n}_{\mathrm{ges}}$

wobei $\mathrm{n}_{\mathrm{g}}$ die Anzahl der gut perfundierten, $\mathrm{n}_{\text {irr }}$ die Anzahl der irregulär perfundierten und $\mathrm{n}_{\text {ges }}$ die Gesamtanzahl der Villi im Gesichtsfeld widerspiegelt. Je größer der Perfusionsindex, desto besser war die villöse Perfusion. Pro Versuchstier wurden 10 Übersichtsfelder ausgewertet.

\subsection{Staseindex $\left(I_{S}\right)$}

Der Staseindex (Stojanovic et al. 2002) wurde ebenfalls in der Vergrößerung, die über das 10er Abstandsobjektiv erreicht wurde, bestimmt. $I_{s}$ diente der Quantifizierung des Anteils der nicht perfundierten Villi und wurde nach folgender Gleichung berechnet:

$\mathrm{I}_{\mathrm{s}}=\mathrm{n}_{0} / \mathrm{n}_{\mathrm{ges}}$

wobei $\mathrm{n}_{0}$ die Anzahl der nicht perfundierten Villi repräsentiert und $\mathrm{n}_{\text {ges }}$ die Gesamtanzahl der Villi im Gesichtsfeld. Je kleiner der Staseindex, desto besser war die villöse Perfusion. Pro Versuchstier wurden 10 Gesichtsfelder untersucht. 


\subsection{Funktionelle Kapillardichte der Tunica mucosa (FKD mucosa)}

Die funktionelle Kapillardichte der Mukosa wurde analog zur funktionellen Kapillardichte der Muskularis über das 20er Wasserimmersionsobjektiv bestimmt. Die Kapillarlänge $\left(I_{\text {kap }}\right)$ wurde dabei in das Verhältnis zur Villusfläche $\left(A_{\text {vil }}\right)$ gesetzt:

$F K D_{\text {mucosa }}=I_{\text {kap }} / A_{\text {vil }}$

FKD mucosa beschreibt die Gesamtlänge der nutritiv pefundierten Kapillaren $I_{\text {kap }}$ eines Villus in Relation zur Villusgrundfläche $A_{\text {vil }}$ und wird pro Villus und in $\mathrm{cm}^{-1}$ angegeben (Gonzalez et al. 1994). Zur Bestimmung der FKD mucosa wurde die durchströmte Kapillarstrecke nachgezeichnet und mit dem halbautomatischen Auswertungsprogramm ihre Länge bestimmt. Die Villusgrenzen wurden markiert und mit Hilfe des Computers die Villusfläche berechnet. Je größer die funktionelle Kapillardichte, desto besser war die villöse Perfusion.

\subsection{Blutkörperchenfließgeschwindigkeit (Red blood cell velocity (RBCV mucosa $)$}

Die Fließgeschwindigkeit des Blutes in den Kapillaren konnte durch Grauwertanalyse mit Hilfe der Software „Cap-Image 4.02“ (Cap-Image, Dr. Zeintl, Heidelberg, Deutschland (Zeintl et al. 1989)) bestimmt werden. Die Erythrozyten bildeten nach Plasmafärbung einen Negativkontrast. Durch die Perfusion kam es zu einer Kontraständerung innerhalb der Kapillaren, die mit der Line-to-Shift-Methode (Klyscz et al. 1997) eine Messung der Blutkörperchenfließgeschwindigkeit ermöglichte. Pro Versuchstier wurden 10 Villi mit einem 40er Wasserimmersionsobjektiv untersucht. In jedem Villus wurden 5 Kapillaren ausgewählt. Innerhalb jeder Kapillare wurden 6-8 Messpunkte gewählt und die Fließgeschwindigkeit des Blutes in den Kapillaren gemessen. Insgesamt ergab sich die kapilläre RBCV des Transplantates somit aus 50 Einzelwerten. Die Einheit der RBCV ist $\mathrm{mm} \cdot \mathrm{s}^{-1}$ und die Größe ist in der Literatur etabliert (Gonzalez et al. 1994). Je größer die Blutkörperchenfließgeschwindigkeit, desto besser war die mukosale Mikrozirkulation. 


\subsubsection{Lichtmikroskopische Untersuchungen}

Es wurde zu zwei Zeitpunkten (nach 40-minütiger Reperfusion und am Ende der intravitalmikroskopischen Untersuchung) Gewebematerial für die Histologie und Immunhistochemie gewonnen. Für beide Untersuchungsmethoden wurde das Gewebe zunächst in Formalinlösung 4\% über mindestens 24 Stunden bei $4{ }^{\circ} \mathrm{C}$ fixiert, in einer aufsteigenden Alkoholreihe dehydriert und in Paraffin eingebettet. Schnitte von $5 \mu \mathrm{m}$ (Histomorphologie) bzw. 1 m (Immunhistochemie) Schichtdicke wurden auf Objektträgern mit Xylen entwachst und in einer ansteigenden Alkoholreihe rehydriert. Die $5 \mu \mathrm{m}$ dicken Schnitte für die histomorphologische Untersuchung wurden abschließend mit Hämatoxylin und Eosin gefärbt.

Für die immunhistochemische Untersuchung der Apoptose wurden die $1 \mu \mathrm{m}$ dicken Präparate zum Wiederaufschließen der Antigene (Entfernung der Strukturveränderungen durch Aldehydgruppenbildung nach Formalinfixierung) mit Citratpuffer $10 \%$ bei $\mathrm{pH} 6$ bedampft, mit Trispuffer (TBS) $0,05 \mathrm{M}$ bei $\mathrm{pH} 7,6$ gewaschen und zur Blockade der endogenen Peroxidase für 15 Minuten mit $\mathrm{H}_{2} \mathrm{O}_{2}$ $3 \%$ in einer feuchten Kammer bei Raumtemperatur inkubiert und erneut mit TBS gewaschen. Dann wurde der Schnitt einmalig mit Antikörper-Diluent (DakoCytomation) vorbehandelt. Das Präparat wurde im Anschluss über Nacht mit dem primären Antikörper (1:50 verdünnt) gegen die aktivierte Caspase 3 (cleaved caspase-3, \#9661 Cell Signaling, Danvers, USA) inkubiert. Anschließend wurden durch erneutes Waschen mit TBS die überschüssigen Antikörperreste abgespült. Der Schnitt wurde mit dem sekundären Antikörper (1:100 verdünnt), einem polyklonalen Schweine- und Kaninchen-Antikörper der mit Meerrettichperoxidase gekoppelt ist IgG/HRP (P 0399 DakoCytomation, Glostrup, Denmark), für 30 Minuten in einer feuchten Kammer bei Raumtemperatur inkubiert. Danach erfolgten das erneute Waschen mit TBS und die Färbung mittels eines Diaminobenzidin Chromogen Systems (K3468 DakoCytomation, Glostrup, Denmark), sowie die Gegen-Färbung mit Hämatoxylin.

\subsection{Histomorphologische Untersuchung der Transplantatschädigung}

Zur quantitativen Bestimmung der Transplantatschädigung durch Ischämie und Reperfusion wurde das von Chiu und Kollegen vorgeschlagene Bewertungssystem angewendet (Chiu et al. 1970). Die entnommenen Gewebe wurden nach 40 und 
nach ca. 180 Minuten Reperfusion analysiert. Das Bewertungssystem unterscheidet fünf Schweregrade der Schädigung:

Grad 0: $\quad$ normale Mukosa

Grad 1: $\quad$ subepitheliale Spaltbildung an der Villusspitze, mit/ohne Kapillarstauung

Grad 2: $\quad$ steigende subepitheliale Spaltbildung mit beginnender Abhebung des Epithels von der Lamina propria mucosae

Grad 3: starke Abhebung des Epithels, auch an der Villusseite, einige Villusspitzen sind denudiert

Grad 4: denudierte Villi, Lamina propria mucosae liegt frei, Kapillaren sind gestaut

Grad 5: Andauung und Desintegration der Lamina propria mucosae, Hämorrhagien und Ulzerationen.

An den histologischen Schnitten wurde in einer geblindeten Untersuchung von einem erfahrenen Pathologen der jeweilige Grad der Schädigung festgestellt und dokumentiert.

\subsection{Immunhistochemische Untersuchung der Transplantatschädigung}

Zur Markierung von apoptotischen Zellen im Transplantatgewebe wurde eine immunhistochemische Färbung auf aktives Caspase-3-Protein durchgeführt (s.o.). Die Ausdehnung des Zellunterganges durch Apoptose wurde in einer geblindeten Untersuchung semiquantitativ erfasst und dokumentiert. Hierzu wurde je Transplantat ein Score (1: wenig positive Zellen; 2: mäßig viele positive Zellen; 3: viele positive Zellen) der aktivierte-Caspase-3-positiven epithelialen Zellen in mehreren Gesichtsfeldern bestimmt. Ausgewertet wurden die Gewebeschnitte durch einen erfahrenen Pathologen in fünf zufällig gewählten Gesichtsfeldern der Präparate. 


\subsubsection{Statistische Auswertung}

Alle statistischen Berechnungen und Auswertungen erfolgten mit der GraphPad Instat ${ }^{\circledR}$ und GraphPad Prism ${ }^{\circledR}$ 5.0 Software (Programm Version 5.01 GraphPad Software 2000). Alle Ergebnisse wurden als Mittelwert \pm SEM (Standardfehler des arithmetischen Mittels) angegeben. Der Gruppenvergleich erfolgte mit dem nichtparametrischen Mann-Whitney U-Test, oder dem ungepaarten t-Test mit Korrektur nach Welch. Eine Irrtumswahrscheinlichkeit von $p<0,05$ wurde als statistisch signifikant, eine Irrtumswahrscheinlichkeit von $p<0,001$ wurde als statistisch hochsignifikant angesehen.

\section{Ergebnisse}

In diesem Abschnitt werden die Ergebnisse der intravitalmikroskopischen, histomorphologischen und immunhistochemischen Untersuchungen dargestellt. Zunächst werden die Ergebnisse der Etablierung des stabilen Schädigungsmodells vorgestellt. Anschließend erfolgt die Ergebnisspräsentation der Untersuchung unterschiedlich protektionierter Transplantate. Alle Werte sind, sofern nicht anders vermerkt, als Mittelwert \pm SEM angegeben. Die Gruppenbezeichnungen werden in Klammern angegeben. Die Ergebnisse der Kontrolle der Makrohämodynamik finden sich am Ende des Abschnitts.

\subsection{Ergebnisse der Etablierung des Schädigungsmodells}

Zur statistischen Analyse der Unterschiede zwischen der Kontrolle und den jeweiligen Gruppen HTK 18h und HTK 24h erfolgte der Vergleich der Mittelwerte der intravitalmikroskopischen Parameter mit dem ungepaarten t-Test und einer Korrektur nach Welch.

Die funktionelle Kapillardichte der Tunica muscularis ( $\left.F K D_{\text {muscularis }}\right)$ war bereits nach 18-stündiger Ischämiedauer im Vergleich zur physiologischen Kontrollgruppe leicht reduziert, ohne das Signifikanzniveau zu erreichen ( $(\mathrm{HTK} 18 \mathrm{~h}) 272 \pm 35 \mathrm{~cm}^{-1}$ vs. (Kontrolle) $395 \pm 18 \mathrm{~cm}^{-1}$ ). Die $F K D_{\text {muscularis }}$ nahm bei Verlängerung der Ischämiedauer weiter $\mathrm{ab}$ und zeigte nach 24-stündiger Ischämiedauer eine hochsignifikante Verminderung der Mikrozirkulation an ((HTK 24h) $237 \pm 19 \mathrm{~cm}^{-1}$ vs. (Kontrolle) $395 \pm 18$ $\mathrm{cm}^{-1}, \mathrm{p}<0,001$ ) (Abb.13 A). Der Leukozytenindex nahm parallel zur Verminderung der 
Mikrozirkulation bei Verlängerung des Ischämieintervalls zu. Im Vergleich zum physiologischen Wert war der Leukozytenindex nach 18-stündiger Ischämiedauer bereits signifikant erhöht ((HTK 18h) $981 \pm 128 \mathrm{~mm}^{-2}$ vs. (Kontrolle) $209 \pm 37 \mathrm{~mm}^{-2}$, $p<0,05)$. Durch Verlängerung der Ischämiedauer auf 24 Stunden erhöhte sich der Leukozytenindex im Sinne einer subtotalen Transplantatschädigung mit ausgeprägter immunologischen Reaktion auf hochsignifikante Werte im Vergleich zur Kontrollgruppe ((HTK 24h) 1511 $\pm 191 \mathrm{~mm}^{-2}$ vs. (Kontrolle) $209 \pm 37 \mathrm{~mm}^{-2}, \mathrm{p}<0,001$ ) (Abb.13 B). In der Mukosa lag nach 18-stündiger kalten Ischämie eine deutliche Beeinträchtigung der Mikrozirkulation im Vergleich zu der physiologischen Durchblutung mit signifikanter Reduktion des $I_{p}$ vor ((HTK 18h) 0,270 $\pm 0,12$ vs. (Kontrolle) $0,987 \pm 0,10, p<0,05$ ). Die Verlängerung des Ischämieintervalls auf 24 Stunden verminderte den $I_{p}$ weiter auf hochsignifikant unterschiedliche Werte im

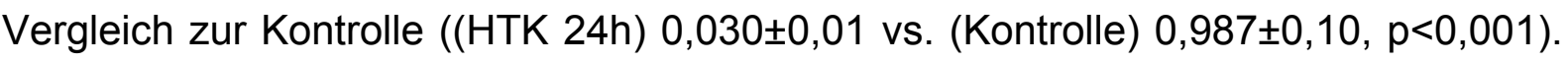
Da in der Kontrollgruppe der $I_{s}$ null betrug, war mit dem o.g. statistischen Verfahren keine Analyse des Parameters möglich. Die Erhöhung des $I_{\mathrm{s}}$ durch Verlängerung der Ischämiedauer war jedoch stark ausgeprägt und ist in der Graphik (Abb. 13 D) dargestellt. Auf Villus-Ebene zeigte sich in der Mukosa ( $F K D_{\text {mucosa}}$ ) ebenfalls eine signifikante Reduktion der Durchblutung nach 18-stündiger Ischämie ((HTK 18h) $142 \pm 51 \mathrm{~cm}^{-1}$ vs. (Kontrolle) $845 \pm 14 \mathrm{~cm}^{-1}, \mathrm{p}<0,05$ ) und nach 24-stündiger Ischämie eine subtotale Reduktion der Durchblutung, definiert als nahezu vollständiger Zusammenbruch der Mikrozirkulation in den Villi der Mukosa ((HTK 24h) $11 \pm 5 \mathrm{~cm}^{-1}$ vs. (Kontrolle) $845 \pm 14 \mathrm{~cm}^{-1}, \mathrm{p}<0,001$ ). Die RBCV mucosa war ebenfalls bereits nach 18 Stunden Ischämie im Vergleich zur Kontrolle signifikant ((HTK 18h) $0,270 \pm 0,05$ $\mathrm{mm} \cdot \mathrm{s}^{-1}$ vs. (Kontrolle) 0,530 $\left.\pm 0,01 \mathrm{~mm} \cdot \mathrm{s}^{-1}, \mathrm{p}<0,05\right)$ und nach 24 Stunden Ischämie hochsignifikant ((HTK 24h) 0,020 $\pm 0,02 \mathrm{~mm} \cdot \mathrm{s}^{-1}$ vs. (Kontrolle) 0,530 $00,01 \mathrm{~mm} \cdot \mathrm{s}^{-1}$, $\mathrm{p}<0,001)$ vermindert.

Aufgrund dieser Ergebnisse wählten wir für alle folgenden Untersuchungen als Ischämieintervall 24 Stunden. Die Gruppe HTK 24h diente als Kontrollgruppe für die nachfolgenden Untersuchungen und wird in den folgenden Abschnitte als Gruppe (HTK) ohne zusätzliche Angabe der Ischämiedauer bezeichnet. 
A
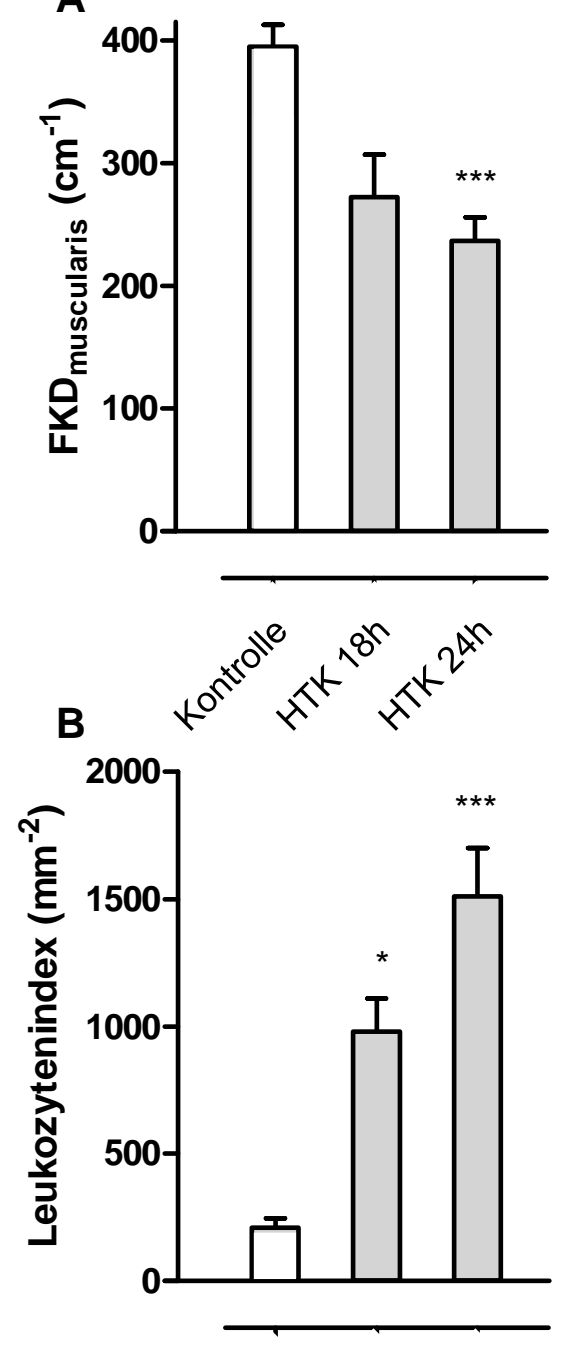

C

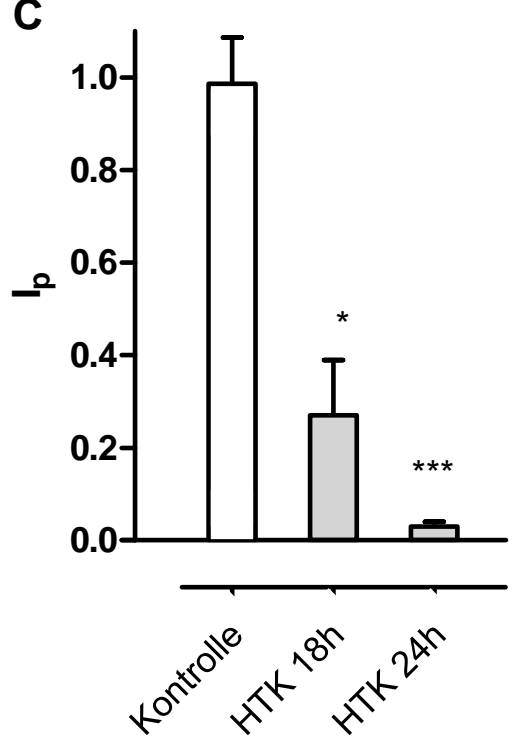

D
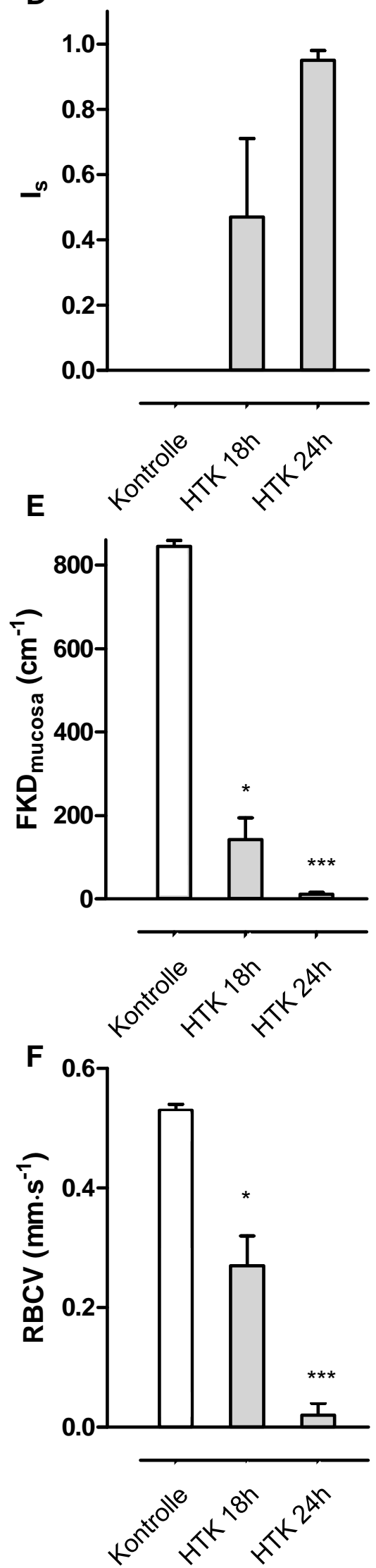

Abbildung 13: Mikrozirkulatorische Veränderungen im Transplantat nach Protektionierung mit HTK Lösung für 18 und 24 Stunden im Vergleich zur 
physiologischen Kontrolle ohne Ischämie (Stojanovic et al. 2002). Dargestellt sind die Mittelwerte und der Standardfehler (MW \pm SEM). *: $p<0,05$ signifikante Unterschiede vs. Kontrolle. ***: $p<0,001$ hochsignifikante Unterschiede vs. Kontrolle. Funktionelle Kapillardichte der Tunica muscularis ( $F K D_{\text {muscularis}}$ ), Leukozytenadhäsion in den submukösen Venolen (Leukozytenindex), Perfusionsindex $\left(I_{p}\right)$, Staseindex $\left(I_{s}\right)$, funktionelle Kapillardichte der Tunica mucosa (FKD mucosa), Blutkörperchenfließgeschwindigkeit (Red blood cell velocity $\left(\mathrm{RBCV}_{\text {mucosa }}\right)$ ) der Kapillaren in der Tunica mucosa. Kontrolle: Kontrollgruppe ohne Ischämie, HTK 18h: Gruppe mit 18 Stunden kalter Ischämiebehandlung in HTK, HTK 24h: Gruppe mit 24 Stunden kalter Ischämiebehandlung in HTK

\subsection{Ergebnisse der Testung der Protektionslösungen und Schutzsubstanzen}

In dem genutzten syngenen Transplantationsmodell Lewis auf Lewis mit 24-stündiger kalten Ischämie- und nachfolgender Reperfusionphase waren die Transplantate bezüglich ihrer Mikrozirkulation regelmäßig subtotal beeinträchtigt (Definition siehe oben). Analysiert wurden die Veränderungen der Mikrozirkulation, Histomorphologie und des Apoptose-Scores in den Transplantaten.

\subsubsection{Ergebnisse der Untersuchung der Mikrozirkulation}

Die Ergebnisse der intravitalmikroskopischen Untersuchungen zur Beurteilung der Mikrozirkulation und Leukozyten-Endothelzell-Interaktion sind entsprechend der Reihenfolge der Datenerhebung während der Intravitalmikroskopie dargestellt.

\subsubsection{Funktionelle Kapillardichte der Tunica muscularis}

In der Muskularisschicht, zeigte die quantitative Analyse der Mikrozirkulation nur geringe Veränderungen der funktionellen Kapillardichte (FKD muscularis) (Abb. 14). Trotzdem fand sich hier eine signifikante Verbesserung dieses Parameters, sofern die Protektionslösung N36 mit niedrigen Konzentrationen von LK und Deferoxamin $(0,02$ und $0,2 \mathrm{mM})$ supplementiert wurde $\left((\mathrm{HTK}) \quad 237 \pm 19 \mathrm{~cm}^{-1}\right.$ vs. $\left.(\mathrm{LK}+\mathrm{DES}(\mathrm{L0}, 02 \mathrm{D0}, 2)) 325 \pm 20 \mathrm{~cm}^{-1}, \mathrm{p}<0,05\right)(\mathrm{Abb} .14 \mathrm{~B})$. 

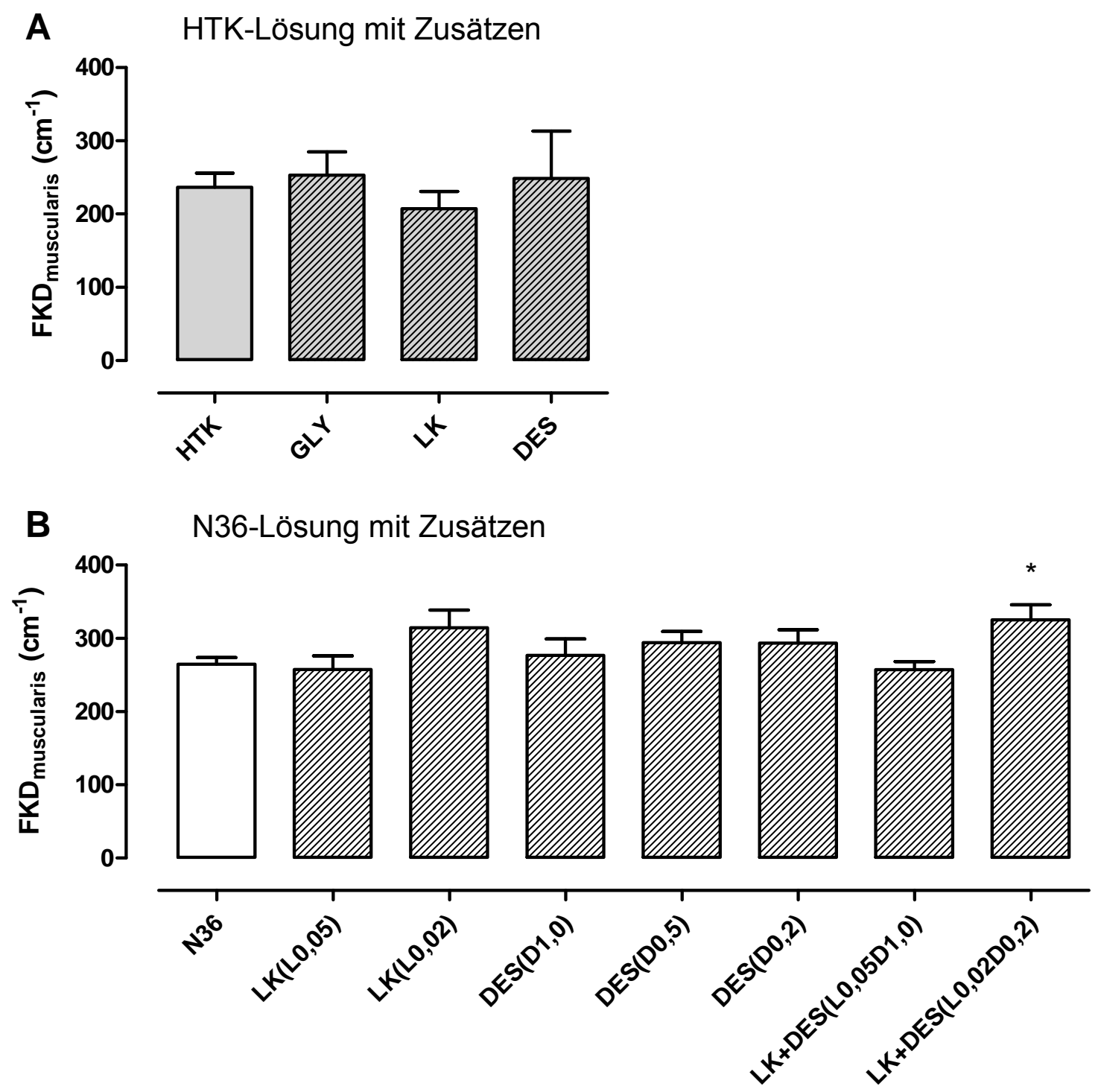

Abbildung 14: Funktionelle Kapillardichte der Tunica muscularis (FKD muscularis) der Transplantate nach 24 Stunden kalter Ischämie und 40 Minuten Reperfusionsphase. Dargestellt sind die Mittelwerte und die Standardfehler. *: $p<0,05$ signifikante Unterschiede vs. HTK. A: Graue Balken: HTK-Lösung, graue Balken mit Schraffur: HTK als Basislösung mit Zusatzstoff. HTK: herkömmliche HTK-Lösung; GLY: HTK+Glycin 10mM; LK: HTK+LK 1mM; DES: HTK+Deferoxamin 1mM; B: weiße Balken: N36-Lösung, weiße Balken mit Schraffur: N36-Lösung als Basislösung mit Zusatzstoff(en). N36: neu entwickelte Lösung; LK(0,05): N36+LK 0,05mM; LK(0,02): N36+Lk 0,02mM; $\quad$ DES(D1,0): N36+Deferoxamin $1 \mathrm{mM} ; \quad$ DES(D0,5): N36+Deferoxamin $\quad 0,5 \mathrm{mM} ; \quad$ DES(D0,2): N36+Deferoxamin $\quad 0,2 \mathrm{mM}$; LK+DES(L0,05D1,0): N36+LK 0,05mM+Deferoxamin 1mM; LK+DES(L0,02D0,2): N36+LK 0,02mM+Deferoxamin 0,2mM. 


\subsubsection{Leukozytenindex}

Zur funktionellen Untersuchung der Leukozyten-Endothelzell-Interaktion wurden die an der Gefäßinnenwand adhärierenden Leukozyten auf der Ebene der postkapillären Venolen in der Submukosa quantitativ gemessen (Leukozytenindex). Bezüglich der Inhibition der Leukozyten-Endothelzell-Interaktion in den Transplantaten zeigte sich im Vergleich zur Protektion mit der HTK-Lösung eine nicht signifikante Reduktion des Leukozytenindex, wenn diese mit der N36-Lösung behandelt wurden und eine signifikante Reduktion der Leukozyten-Endothelzell-Interaktion, wenn sie mit der herkömmlichen HTK-Lösung und zusätzlich niedrigen Konzentrationen von Glycin behandelt wurden $\left((\mathrm{HTK}) 1511 \pm 191 \mathrm{~mm}^{-2}\right.$ vs. (GLY) $\left.435 \pm 95 \mathrm{~mm}^{-2}, \mathrm{p}<0,05\right)(A b b .15)$. 


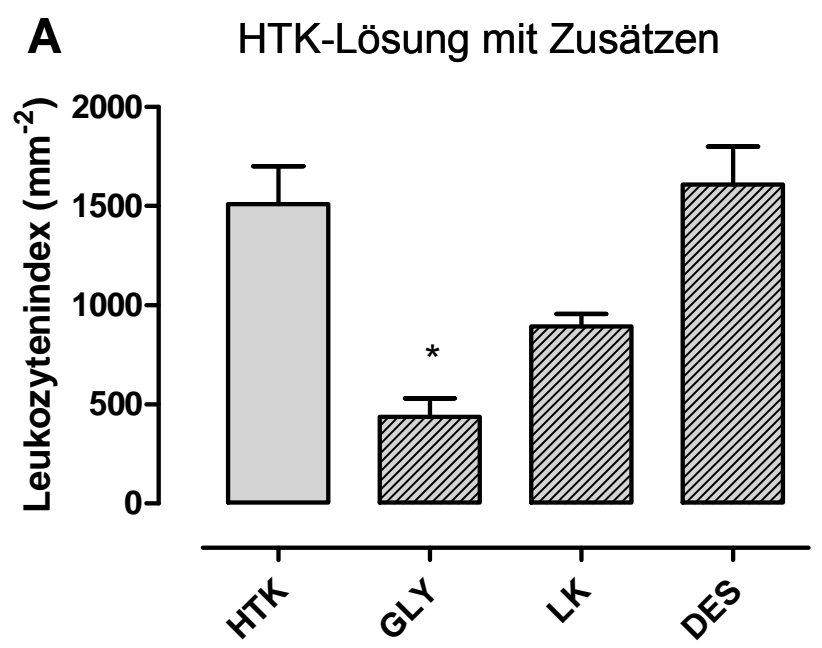

B N36-Lösung mit Zusätzen

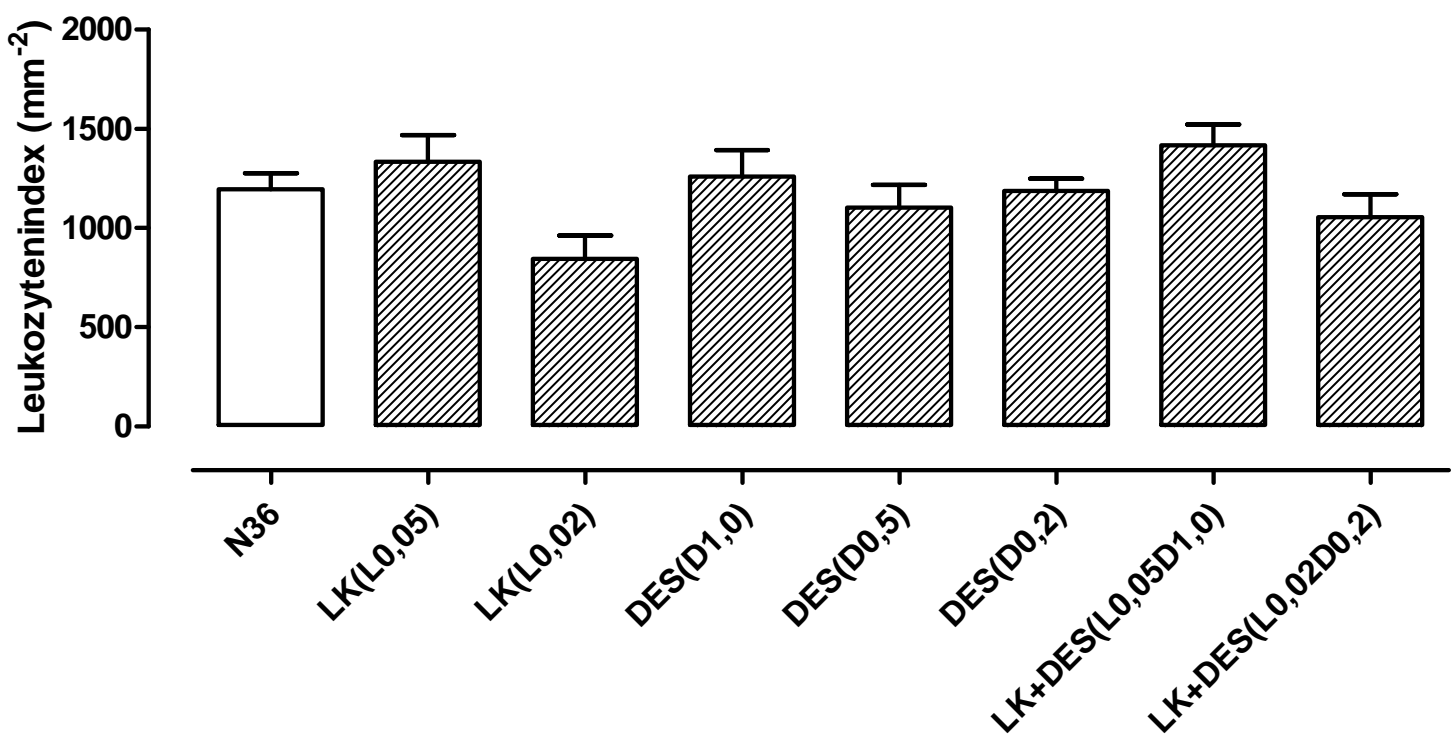

Abbildung 15: Leukozytenindex der Transplantate nach 24 Stunden kalter Ischämie und 40 Minuten Reperfusionsphase. Dargestellt sind die Mittelwerte und die Standardfehler. *: $p<0,05$ signifikante Unterschiede vs. HTK. A: Graue Balken: HTKLösung, graue Balken mit Schraffur: HTK als Basislösung mit Zusatzstoff. HTK: herkömmliche HTK-Lösung; GLY: HTK+Glycin 10mM; LK: HTK+LK 1mM; DES: HTK+Deferoxamin 1mM; B: weiße Balken: N36-Lösung, weiße Balken mit Schraffur: N36-Lösung als Basislösung mit Zusatzstoff(en). N36: neu entwickelte Lösung; LK(0,05): N36+LK $\quad 0,05 m M ; \quad L K(0,02): \quad N 36+L k \quad 0,02 m M ; \quad D E S(D 1,0)$ : N36+Deferoxamin 1mM; DES(D0,5): N36+Deferoxamin 0,5mM; DES(D0,2): N36+Deferoxamin 0,2mM; LK+DES(L0,05D1,0): N36+LK 0,05mM+Deferoxamin $1 \mathrm{mM}$; LK+DES(L0,02D0,2): N36+LK 0,02mM+Deferoxamin 0,2mM. 


\subsubsection{Perfusionsindex $\left(I_{p}\right)$}

Die quantitative Villusperfusion innerhalb der Mukosa wurde anhand des Perfusionsindex $\left(I_{p}\right)$ beurteilt (Abb.16). In den mit HTK-Lösung protektionierten Transplantaten war die überwiegende Anzahl der Darmzotten nach Reperfusion nicht durchblutet. Dies wurde über einen niedrigen $I_{p}((H T K)$ 0,030 0.01$)$ dokumentiert (Abbildung 16 A). Der Zusatz von Glycin zur HTK-Lösung erhöhte den $I_{p}$ leicht, ohne

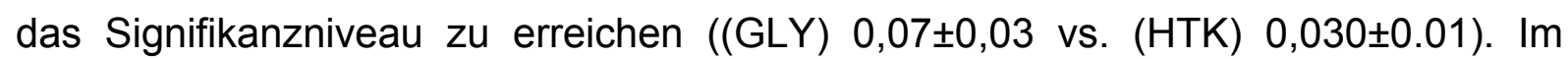
Gegensatz dazu erhöhte der lipophile, membrangängige Eisenchelator LK den $I_{p}$ signifikant im Vergleich zur Protektion mit HTK-Lösung ohne Zusatz ((LK) 0,13 $\pm 0,01$ vs. (HTK) 0,030 $\pm 0.01, p<0,05)$. Der Zusatz von Deferoxamin zur HTK-Lösung

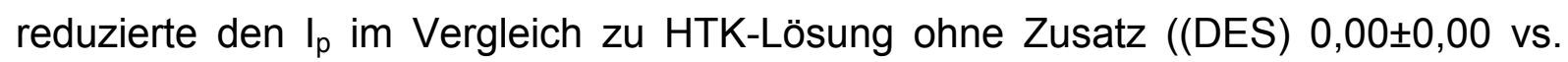

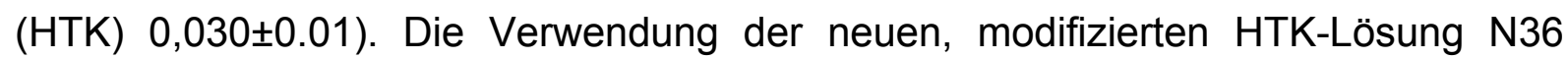
erhöhte den $I_{p}$ im Vergleich zur Protektion mit HTK-Lösung deutlich ((N36) 0,23 $\pm 0,04$ vs. (HTK) 0,030 $\pm 0.01, p<0,05)$. Der Zusatz von Deferoxamin zur N36 Lösung in beiden untersuchten hohen Konzentrationen (1 $\mathrm{mM}$ bzw. 0,5mM Deferoxamin) hatte keine oder nachteilige Effekte auf den $\mathrm{I}_{\mathrm{p}}$ im Vergleich zur Verwendung von N36-

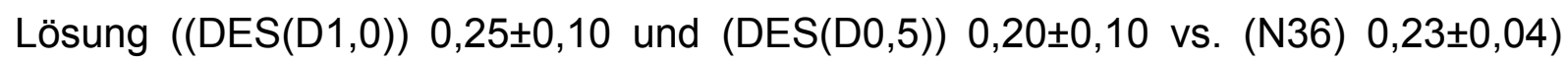
(Abbildung 16 B), brachte aber in niedriger Konzentration (0,2mM Deferoxamin) eine leichte Verbesserung, ohne Signifikanzniveau zu erreichen ((DES(D0,2)) 0,29 $\pm 0,03$ vs. (N36) 0,23 $\pm 0,04)$. Die Zugabe vom membrangängigen Eisenchelator LK (0,05mM und 0,02mM LK) verbesserte in allen genutzten Konzentrationen den $I_{p}$ im Vergleich zur Protektion mit N36-Lösung, ohne dabei Signifikanzniveau zu erreichen $(((\operatorname{LK}(\operatorname{LO}, 05)) \quad 0,38 \pm 0,04$ und $(\operatorname{LK}(\operatorname{LO}, 02)) \quad 0,30 \pm 0,01$ vs. (N36) 0,23 $\pm 0,04)$. Die Kombination von relativ hohen Konzentrationen LK und Deferoxamin (0,05mM LK mit $1 \mathrm{mM}$ Deferoxamin) als Zusatz zur N36-Lösung erhöhte ebenfalls den $I_{p}$ im Vergleich zur Behandlung mit N36, ohne dabei Signifikanzniveau zu erreichen

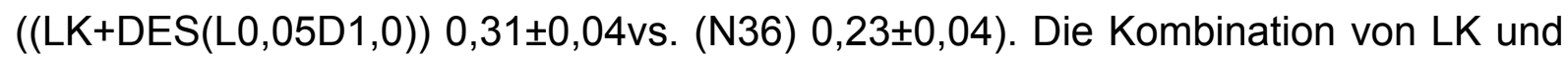
Deferoxamin in niedrigen Konzentrationen $(0,02 \mathrm{mM}$ LK mit 0,2mM Deferoxamin) erhöhte den $I_{p}$ im Vergleich zur Behandlung mit N36 signifikant

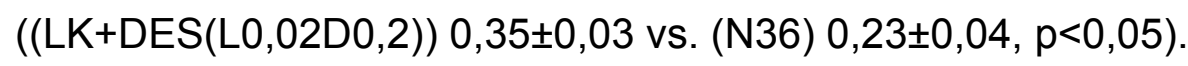



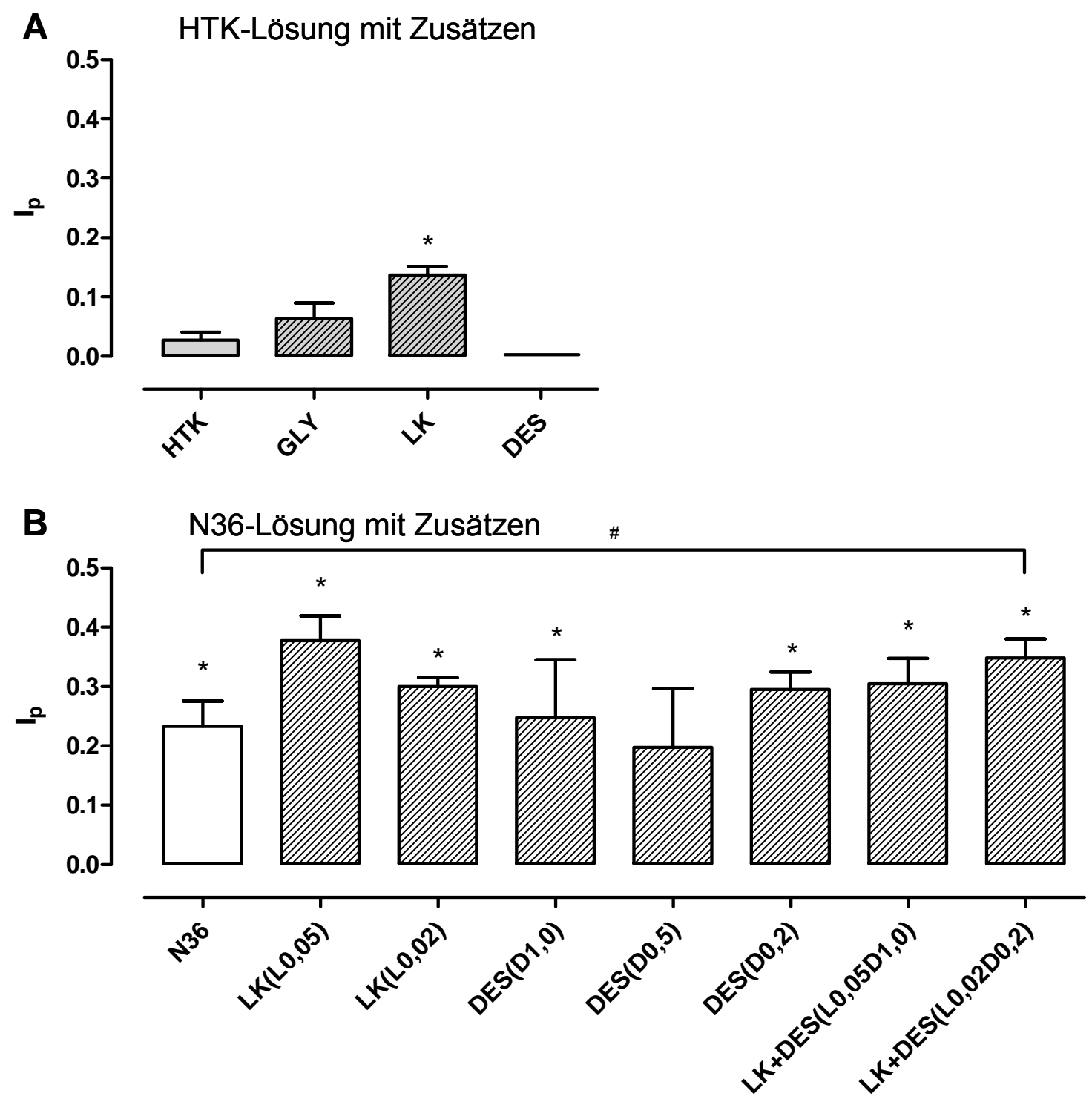

Abbildung 16: Perfusionsindex $\left(I_{p}\right)$ der Transplantate nach 24 Stunden kalter Ischämie und 40 Minuten Reperfusion. Dargestellt sind die Mittelwerte und die Standardfehler. *: $p<0,05$ signifikante Unterschiede vs. HTK; \#: $p<0,05$ signifikanter Unterschied vs. N36. A: Graue Balken: HTK-Lösung, graue Balken mit Schraffur: HTK als Basislösung mit Zusatzstoff. HTK: herkömmliche HTK-Lösung; GLY: HTK+Glycin 10mM; LK: HTK+LK 1mM; DES: HTK+Deferoxamin 1mM; B: weiße Balken: N36-Lösung, weiße Balken mit Schraffur: N36-Lösung als Basislösung mit Zusatzstoff(en). N36: neu entwickelte Lösung; LK(0,05): N36+LK 0,05mM; LK(0,02): N36+Lk 0,02mM; DES(D1,0): N36+Deferoxamin $1 \mathrm{mM} ; \quad$ DES(D0,5): N36+Deferoxamin $\quad 0,5 \mathrm{mM} ; \quad$ DES(D0,2): N36+Deferoxamin $\quad 0,2 \mathrm{mM}$; LK+DES(L0,05D1,0): N36+LK 0,05mM+Deferoxamin 1mM; LK+DES(L0,02D0,2): N36+LK 0,02mM+Deferoxamin 0,2mM. 


\subsubsection{Staseindex $\left(I_{s}\right)$}

Zur Beschreibung des Anteils an nicht perfundierten Darmvilli der Mukosa diente als Parameter der Staseindex $\left(I_{s}\right)$ (Abb. 17). Der Verbesserung des Perfusionsindex entsprechend war der Staseindex bei Protektion mit der herkömmlichen HTK-Lösung und Zugabe der Aminosäure Glycin im Vergleich zur Protektion mit HTK-Lösung

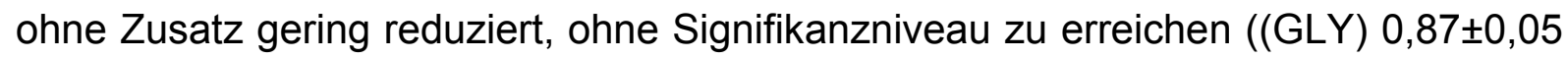

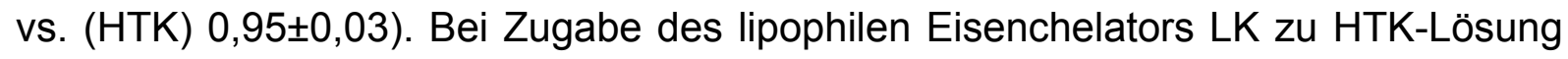
war der $\mathrm{I}_{\mathrm{s}}$ im Vergleich zur Behandlung mit HTK-Lösung signifikant reduziert ((LK) $0,73 \pm 0,03$ vs. (HTK) 0,95 $\pm 0,03, p<0,05$ ). Nach Zugabe von Deferoxamin zur HTK-

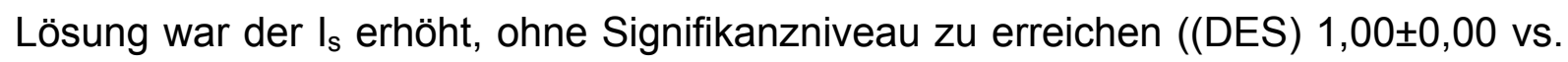
(HTK) 0,95 \pm ,03). Die Protektionsbehandlung mit der neu entwickelten N36-Lösung reduzierte den $\mathrm{I}_{\mathrm{s}}$ im Vergleich zur Behandlung mit HTK-Lösung deutlich ((N36) 0,53 $\pm 0,08$ vs. (HTK) 0,95 $\pm 0,03, p<0,05$ ). Der Zusatz von beiden getesteten Konzentrationen von LK (0,05 mM und 0,02 mM LK) und der Zusatz von zwei getesteten Konzentrationen von Deferoxamin (1,0 mM und 0,2 mM Deferoxamin) zur N36-Lösung reduzierten den $I_{s}$ im Vergleich zur Protektionierung mit der HTKLösung signifikant $((\operatorname{LK}(0,05)) \quad 0,24 \pm 0,09, \quad(\operatorname{LK}(0,02)) \quad 0,42 \pm 0,01, \quad(D E S(D 1,0))$

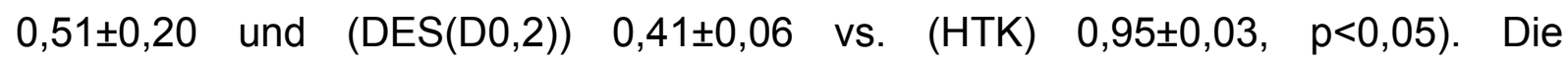
Kombination von LK und Deferoxamin in je unterschiedlichen Konzentrationen als Zusatz zu N36 verminderten ebenfalls den $I_{\mathrm{s}}$ im Vergleich zur Behandlung mit HTKLösung signifikant ((LK+DES(L0,05D1,0)) 0,39 $\pm 0,08$ und (LK+DES(L0,02D0,2)) $0,31 \pm 0,06$ vs. (HTK) 0,95 $\pm 0,03, p<0,05$ ). 

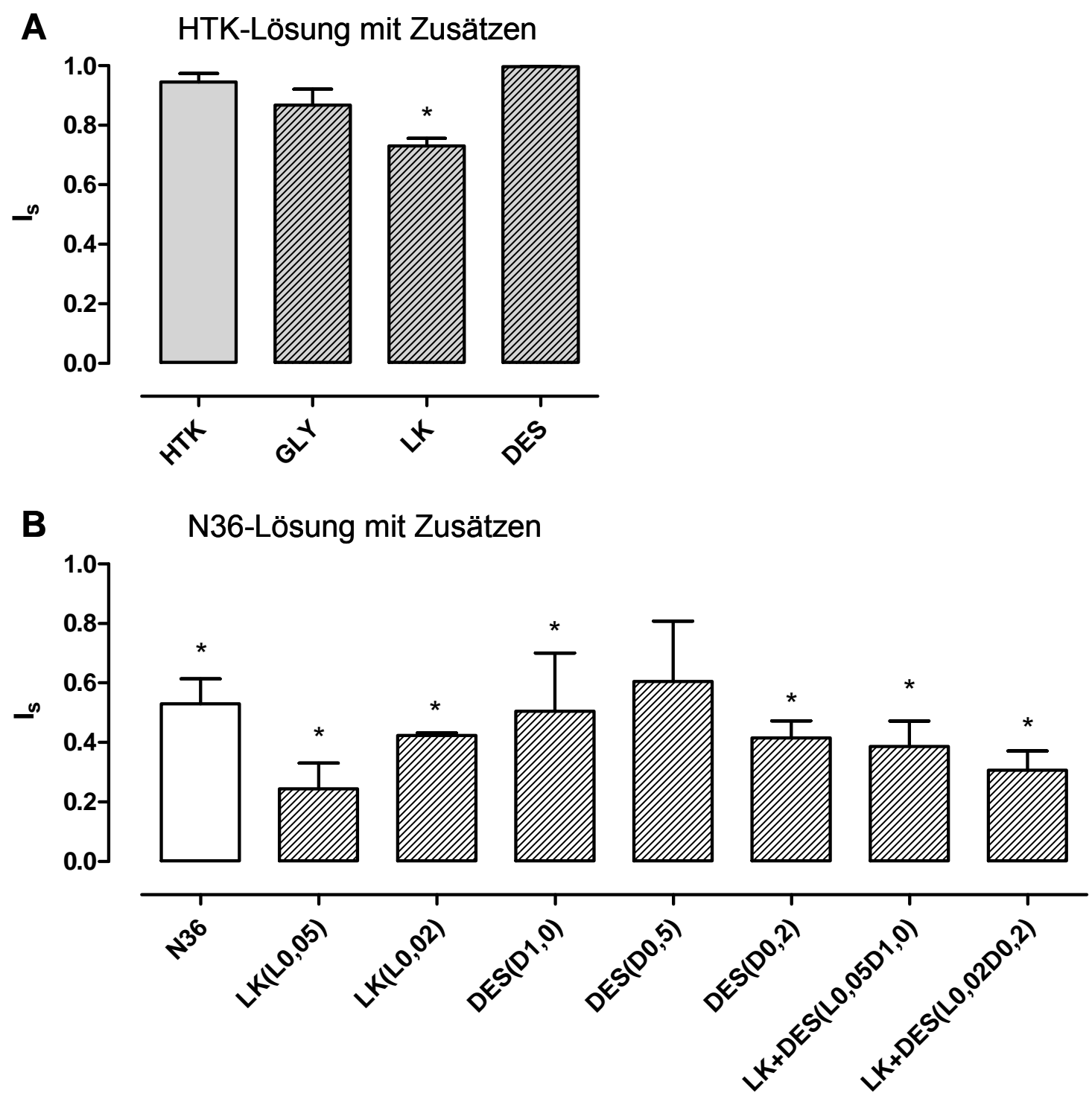

Abbildung 17: Staseindex $\left(\mathrm{I}_{\mathrm{s}}\right)$ der Transplantate nach 24 Stunden kalter Ischämie und 40 Minuten Reperfusionsphase. Dargestellt sind die Mittelwerte und die Standardfehler. *: $p<0,05$ signifikante Unterschiede vs. HTK. A: Graue Balken: HTKLösung, graue Balken mit Schraffur: HTK als Basislösung mit Zusatzstoff. HTK: herkömmliche HTK-Lösung; GLY: HTK+Glycin 10mM; LK: HTK+LK 1mM; DES: HTK+Deferoxamin 1mM; B: weiße Balken: N36-Lösung, weiße Balken mit Schraffur: N36-Lösung als Basislösung mit Zusatzstoff(en). N36: neu entwickelte Lösung; LK(0,05): N36+LK 0,05mM; LK(0,02): N36+Lk 0,02mM; DES(D1,0): N36+Deferoxamin 1mM; DES(D0,5): N36+Deferoxamin 0,5mM; DES(D0,2): N36+Deferoxamin 0,2mM; LK+DES(L0,05D1,0): N36+LK 0,05mM+Deferoxamin 1mM; LK+DES(L0,02D0,2): N36+LK 0,02mM+Deferoxamin 0,2mM. 


\subsubsection{Funktionelle Kapillardichte der Tunica mucosa (FKD mucosa)}

Die funktionelle Kapillardichte der Tunica mucosa (FKD mucosa) diente der quantitativen Beschreibung der nutritiv perfundierten Kapillarlänge im mikrovaskulären Netzwerk der Darmzotten (Abb. 18). Die Zugabe von Glycin zur herkömmlichen HTK-Lösung erzeugte keine Veränderung in der FKD mucosa ((GLY) $21,7 \pm 13,1 \mathrm{~cm}^{-1}$ vs. (HTK) $11 \pm 5 \mathrm{~cm}^{-1}$ ). Der Zusatzstoff LK verbesserte die funktionelle Kapillardichte signifikant, wenn er zur herkömmlichen HTK-Lösung hinzugefügt wurde ((LK) $78 \pm 8 \mathrm{~cm}^{-1}$ vs. (HTK) $\left.11 \pm 5 \mathrm{~cm}^{-1}, \mathrm{p}<0,05\right)$. Bei Einsatz von einer relativ hohen Konzentrationen des hydrophilen Eisenchelators Deferoxamin (1mM) als Zusatz zur HTK-Lösung zeigten sich gegensätzliche Effekte und die FKD mucosa war vermindert ((DES) $0,0 \pm 0,0 \mathrm{~cm}^{-1}$ vs. (HTK) $11 \pm 5 \mathrm{~cm}^{-1}$ ). Durch den Einsatz der neu entwickelten N36-Lösung konnte eine qualitative Verbesserung der Mukosaperfusion erzielt werden und die $\mathrm{FKD}_{\text {mucosa }}$ war im Vergleich zu HTK-Lösung signifikant erhöht ((N36) $147 \pm 32 \mathrm{~cm}^{-1}$ vs. (HTK) $\left.11 \pm 5 \mathrm{~cm}^{-1}, \mathrm{p}<0,05\right)$. Es fand sich ein Trend zur weiteren Verbesserung der FKD mucosa wenn die Basislösung N36 mit Eisenchelatoren supplementiert wurde. Den größten protektiven Effekt auf diesen Parameter zeigte die Zugabe einer niedrigen Konzentration von LK zur neuen Lösung N36 ((LK(L0,02)) $265,3 \pm 15,1 \mathrm{~cm}^{-1}$ vs. (N36) $147 \pm 32 \mathrm{~cm}^{-1}$ ), ohne jedoch Signifikanzniveau im Vergleich zu N36 zu erreichen. Die Kombination von niedrigen Konzentrationen von zwei verschiedenen Eisenchelatoren führte ebenfalls zur einer Verbesserung der FKD mucosa, ohne jedoch Signifikanzniveau zu erreichen ((LK+DES(L0,02D0,2)) $240 \pm 25 \mathrm{~cm}^{-1}$ vs. (N36) $147 \pm 32 \mathrm{~cm}^{-1}$ ). Auch in allen anderen Untergruppen der N36Lösung mit Verwendung von Zusatzstoffen bestanden keine signifikanten Unterschiede im Vergleich zur N36-Gruppe. 

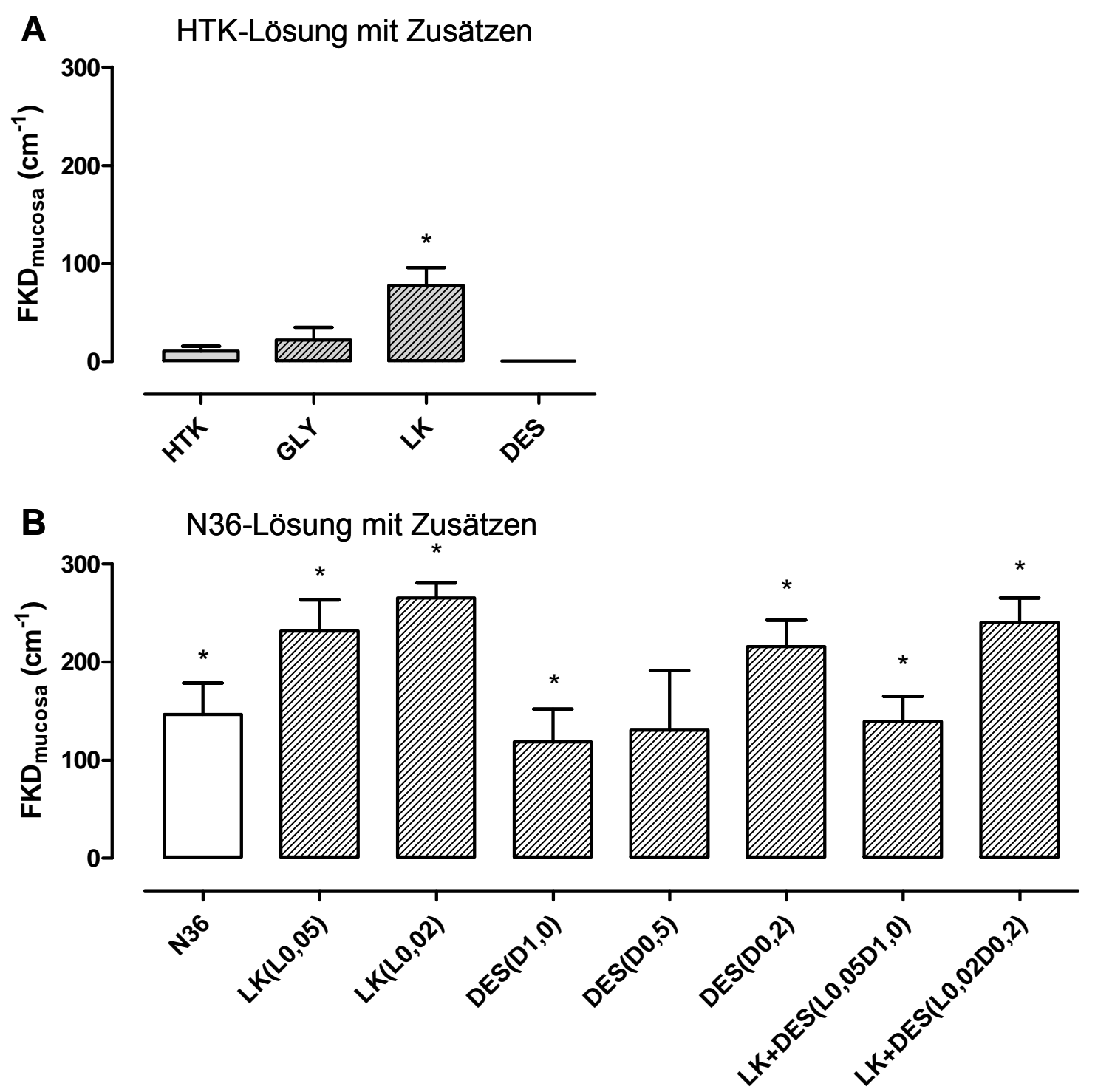

Abbildung 18: Funktionelle Kapillardichte in der Tunica mucosa ( $F K D_{\text {mucosa }}$ ) der Transplantate nach 24 Stunden kalter Ischämie und 40 Minuten Reperfusionsphase. Dargestellt sind die Mittelwerte und die Standardfehler. *: $p<0,05$ signifikante Unterschiede vs. HTK. A: Graue Balken: HTK-Lösung, graue Balken mit Schraffur: HTK als Basislösung mit Zusatzstoff. HTK: herkömmliche HTK-Lösung; GLY: HTK+Glycin 10mM; LK: HTK+LK 1mM; DES: HTK+Deferoxamin 1mM; B: weiße Balken: N36-Lösung, weiße Balken mit Schraffur: N36-Lösung als Basislösung mit Zusatzstoff(en). N36: neu entwickelte Lösung; LK(0,05): N36+LK 0,05mM; LK(0,02): N36+Lk 0,02mM; DES(D1,0): N36+Deferoxamin 1mM; DES(D0,5): N36+Deferoxamin $\quad 0,5 \mathrm{mM}$; DES(D0,2): N36+Deferoxamin $\quad 0,2 \mathrm{mM}$; LK+DES(L0,05D1,0): N36+LK 0,05mM+Deferoxamin 1mM; LK+DES(L0,02D0,2): N36+LK 0,02mM+Deferoxamin 0,2mM. 


\subsubsection{Blutkörperchenfließgeschwindigkeit (Red blood cell velocity (RBCV mucosa))}

Bei Transplantatbehandlung durch HTK mit dem Zusatz LK zeigte sich im Vergleich zur HTK-Lösung ohne Zusätze ein Trend zur Erhöhung der Blutkörperchenfließgeschwindigkeit innerhalb der Mukosa (Red blood cell velocity $\left.\left(\mathrm{RBCV}_{\text {mucosa }}\right)\right)$, jedoch war die Variation der Messwerte so groß, dass die Werte kein Signifikanzniveau erreichten ((LK) 0,24 $\pm 0,19 \mathrm{~mm} \cdot \mathrm{s}^{-1}$ vs. (HTK) 0,02 $\pm 0,02 \mathrm{~mm} \cdot \mathrm{s}^{-1}$ ) (Abb.19). Die RBCV $V_{\text {mucosa }}$ war in allen Transplantaten, die mit der neuen Lösung N36 ohne oder mit weiteren Zusatzstoffen behandelt wurden, im Vergleich zur Protektion mit HTK-Lösung deutlich verbessert $\left((\operatorname{LK}(0,05)) \quad 0,31 \pm 0,04 \mathrm{~mm} \cdot \mathrm{s}^{-1}, \quad(\operatorname{LK}(0,02))\right.$

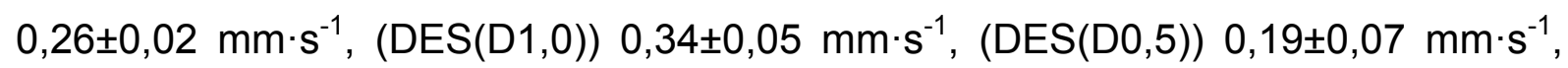
$(\operatorname{DES}(\mathrm{D0}, 2)) \quad 0,35 \pm 0,04 \quad \mathrm{~mm} \cdot \mathrm{s}^{-1}, \quad(L K+D E S(L 0,05 D 1,0)) \quad 0,22 \pm 0,04 \quad \mathrm{~mm} \cdot \mathrm{s}^{-1}$, $\left(\right.$ LK+DES(L0,02D0,2)) 0,25 $\pm 0,01 \mathrm{~mm} \cdot \mathrm{s}^{-1}$ vs. (HTK) 0,02 $\left.\pm 0,02 \mathrm{~mm} \cdot \mathrm{s}^{-1}, \mathrm{p}<0,05\right)$. 

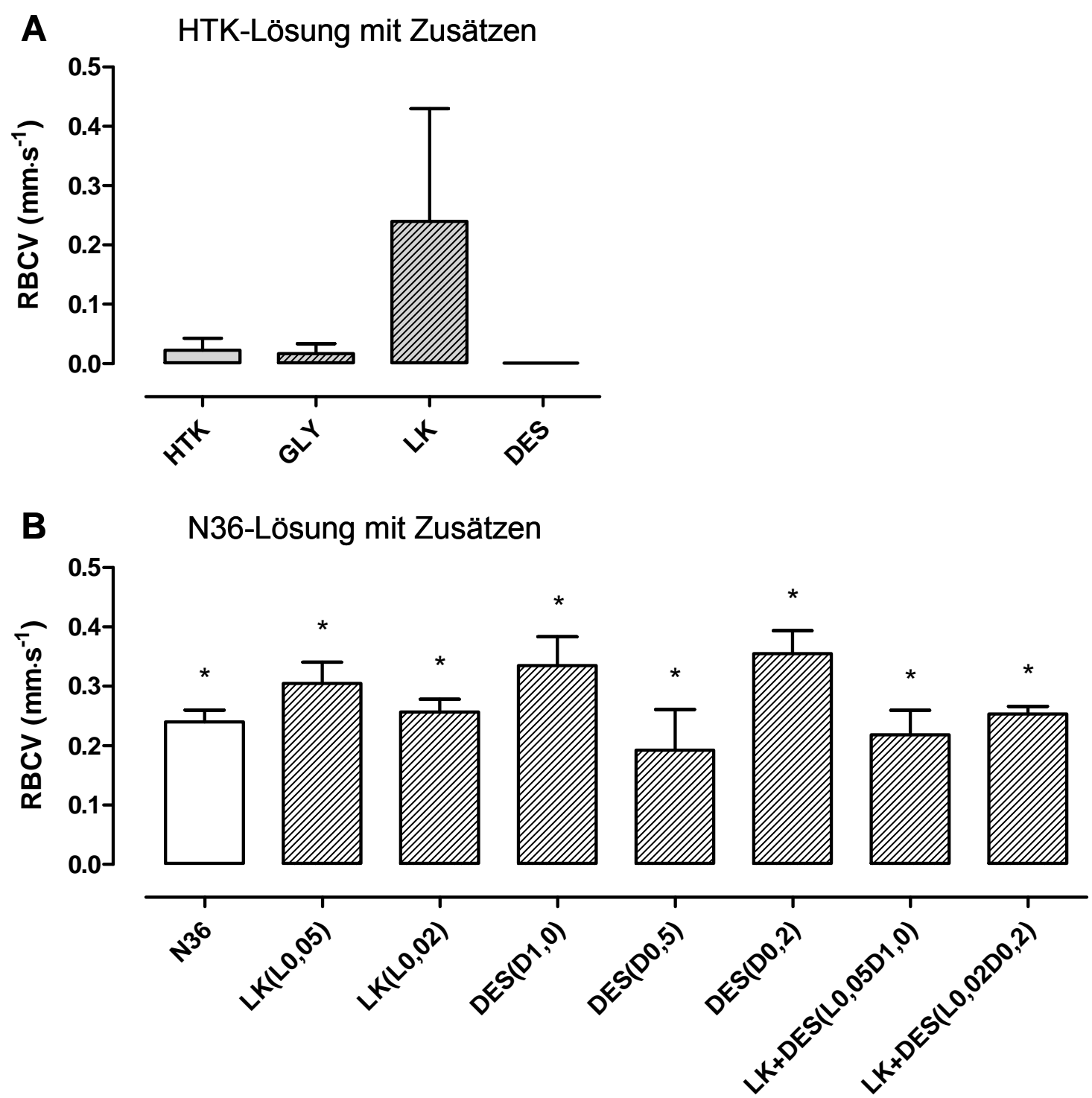

Abbildung 19: Blutkörperchenfließgeschwindigkeit in den Kapillaren der Tunica mucosa (Red blood cell velocity $\left(\mathrm{RBCV}_{\text {mucosa }}\right)$ ) der Transplantate nach 24 Stunden kalter Ischämie und 40 Minuten Reperfusionsphase. Dargestellt sind die Mittelwerte und die Standardfehler. *: p<0,05 signifikante Unterschiede vs. HTK. A: Graue Balken: HTK-Lösung, graue Balken mit Schraffur: HTK als Basislösung mit Zusatzstoff. HTK: herkömmliche HTK-Lösung; GLY: HTK+Glycin 10mM; LK: HTK+LK 1mM; DES: HTK+Deferoxamin 1mM; B: weiße Balken: N36-Lösung, weiße Balken mit Schraffur: N36-Lösung als Basislösung mit Zusatzstoff(en). N36: neu entwickelte Lösung; LK(0,05): N36+LK 0,05mM; LK(0,02): N36+Lk 0,02mM; DES(D1,0): N36+Deferoxamin 1mM; DES(D0,5): N36+Deferoxamin 0,5mM; DES(D0,2): N36+Deferoxamin 0,2mM; LK+DES(L0,05D1,0): N36+LK 0,05mM+Deferoxamin 1mM; LK+DES(L0,02D0,2): N36+LK 0,02mM+Deferoxamin 0,2mM. 


\subsubsection{Ergebnisse der Untersuchung der Histomorphologie}

Die Beurteilung des Ischämie- und Reperfusionsschadens erfolgte mittels Histologie unter Anwendung des Chiu-Score zu zwei Zeitpunkten: nach 40 Minuten (Abb. 20) und nach 180 Minuten (Abb. 21) Reperfusion. Zu beiden Zeitpunkten fanden sich im Vergleich zur Protektion mit HTK-Lösung keine signifikanten Unterschiede im ChiuScore der Gruppen, die mit der Basislösung HTK und Zusatzstoffen behandelt wurden (Abb. 20 A und Abb. 21 A). Nach 40 Minuten Reperfusion war der histologisch nachweisbare Schaden in den mit N36-Lösung, den mit N36-Lösung und Deferoxamin (1mM) und in den mit N36-Lösung und LK (0,05mM) sowie Deferoxamin $(1 \mathrm{mM})$ behandelten Transplantaten im Vergleich zur Protektion mit

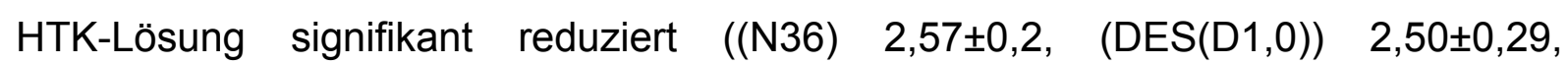

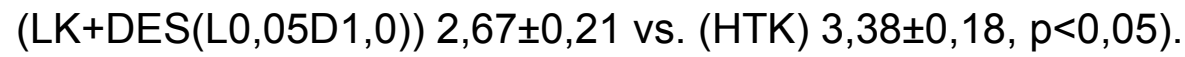




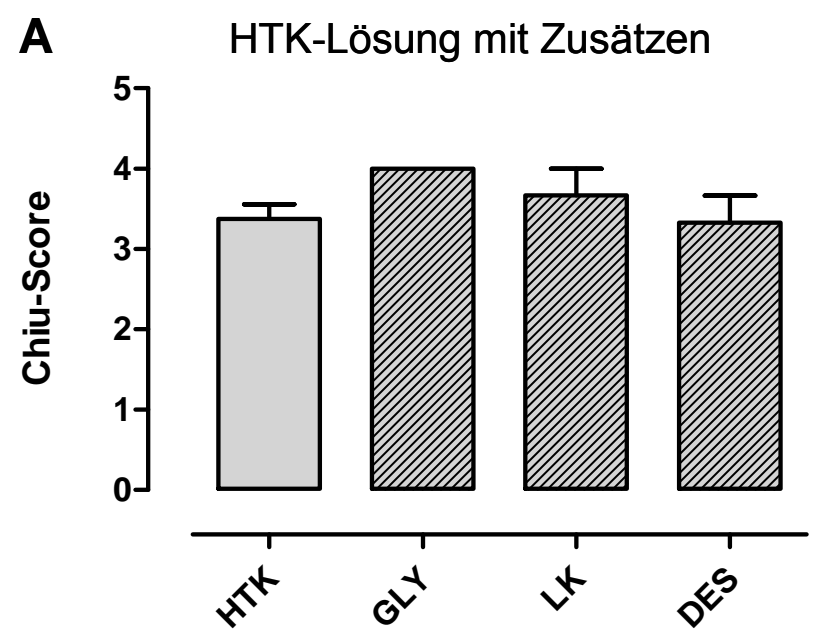

B N36-Lösung mit Zusätzen

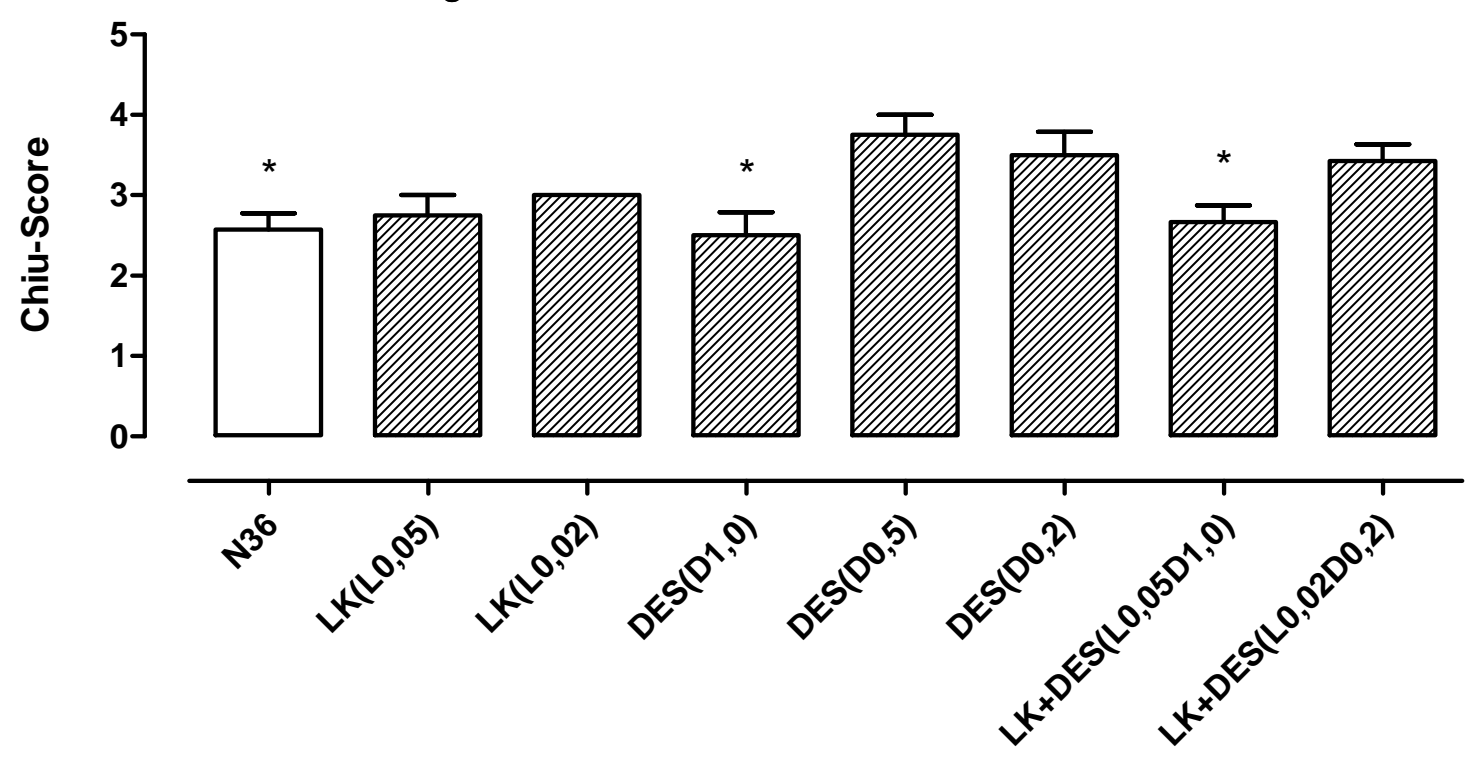

Abbildung 20: Histologische Beurteilung der Transplantate mittels Chiu-Score nach 24 Stunden kalter Ischämie und 40 Minuten Reperfusionsphase. Dargestellt sind die Mittelwerte und die Standardfehler. *: $p<0,05$ signifikante Unterschiede vs. HTK. A: Graue Balken: HTK-Lösung, graue Balken mit Schraffur: HTK als Basislösung mit Zusatzstoff. HTK: herkömmliche HTK-Lösung; GLY: HTK+Glycin 10mM; LK: HTK+LK 1mM; DES: HTK+Deferoxamin 1mM; B: weiße Balken: N36-Lösung, weiße Balken mit Schraffur: N36-Lösung als Basislösung mit Zusatzstoff(en). N36: neu entwickelte Lösung; LK(0,05): N36+LK 0,05mM; LK(0,02): N36+Lk 0,02mM; DES(D1,0): N36+Deferoxamin 1mM; DES(D0,5): N36+Deferoxamin 0,5mM; DES(D0,2): N36+Deferoxamin 0,2mM; LK+DES(L0,05D1,0): N36+LK 0,05mM+Deferoxamin 1mM; LK+DES(L0,02D0,2): N36+LK 0,02mM+Deferoxamin 0,2mM. 
Nach 180 Minuten Reperfusion war der Chiu-Score bei der Behandlung mit N36Lösung und dem Zusatzstoff Deferoxamin (1mM) sowie N36-Lösung mit LK $(0,05 \mathrm{mM})$ und Deferoxamin $(1 \mathrm{mM})$ im Vergleich zur Behandlung mit HTK-Lösung

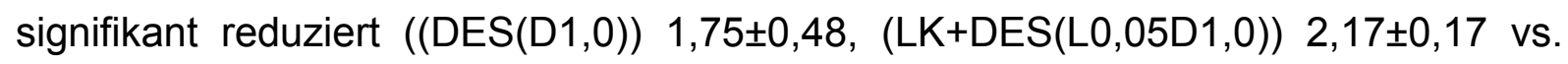
(HTK) 3,25 $\pm 0,16, p<0,05)$. Auch der Einsatz der neuen modifizierten Lösung N36 mit oder ohne Zusatz von LK $(0,5 \mathrm{mM})$ reduzierte den Chiu-Score nach 180 Minuten Reperfusion deutlich im Vergleich zur Protektion mit HTK-Lösung ((N36) 2,00 0 0,00

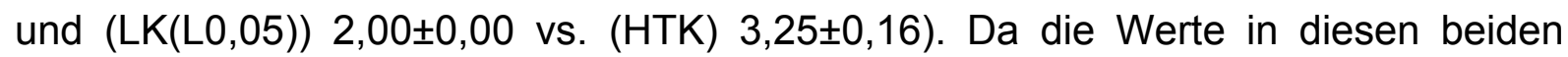
Gruppen bei allen Versuchen identisch waren, konnte keine statistische Analyse mit dem nicht-parametrischen Mann-Whitney-U-Test erfolgen.

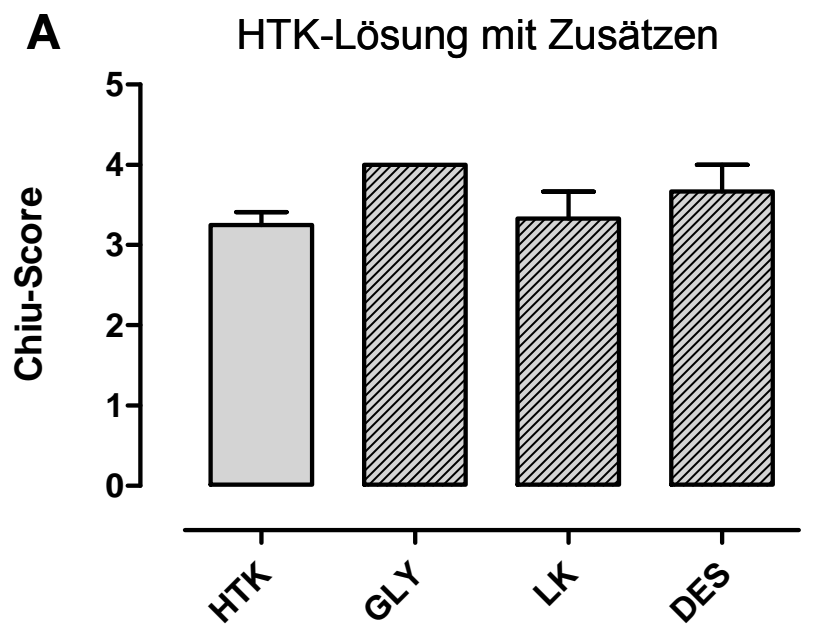

B N36-Lösung mit Zusätzen

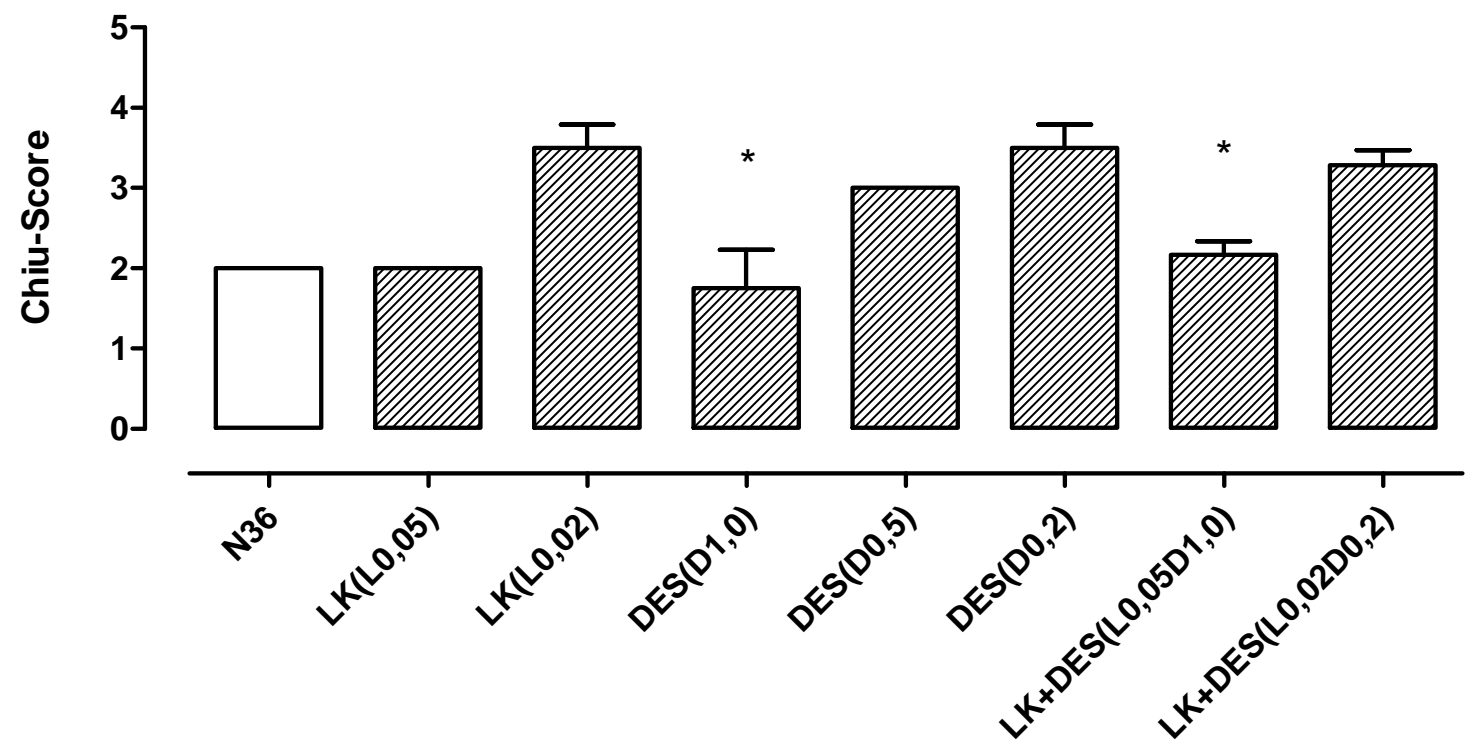

Abbildung 21: Histologische Beurteilung der Transplantate mittels Chiu-Score nach 24 Stunden kalter Ischämie und 180 Minuten Reperfusionsphase. Dargestellt sind 
die Mittelwerte und die Standardfehler. *: $p<0,05$ signifikante Unterschiede vs. HTK. A: Graue Balken: HTK-Lösung, graue Balken mit Schraffur: HTK als Basislösung mit Zusatzstoff. HTK: herkömmliche HTK-Lösung; GLY: HTK+Glycin 10mM; LK: HTK+LK 1mM; DES: HTK+Deferoxamin 1mM; B: weiße Balken: N36-Lösung, weiße Balken mit Schraffur: N36-Lösung als Basislösung mit Zusatzstoff(en). N36: neu entwickelte Lösung; LK(0,05): N36+LK 0,05mM; LK(0,02): N36+Lk 0,02mM; DES(D1,0): N36+Deferoxamin 1mM; DES(D0,5): N36+Deferoxamin 0,5mM; DES(D0,2): N36+Deferoxamin 0,2mM; LK+DES(L0,05D1,0): N36+LK 0,05mM+Deferoxamin 1mM; LK+DES(L0,02D0,2): N36+LK 0,02mM+Deferoxamin 0,2mM.

\subsubsection{Ergebnisse der immunhistochemischen Untersuchung der Apoptose}

Nach 40 Minuten Reperfusion wurde der Apoptose-Score, über die immunhistochemische Messung der Caspaseaktivität, nur in den Transplantaten untersucht, die mit der herkömmlichen HTK-Lösung oder der neuen Lösung N36 mit/ohne Zusätze von Eisenchelatoren protektioniert wurden. In den mit HTK protektionierten Transplantaten fand sich eine deutliche zytoplasmatische Aktivität der Caspase-3 ((HTK) 2,2 $\pm 0,09$ ) (Abb. 22). Im Vergleich dazu fand sich in den durch N36 ohne/mit LK ((N36) $1,7 \pm 0,08$ vs. (HTK) 2,2 $\pm 0,09, p<0,0001$ und (LK(L0,02)) $1,7 \pm 0,11$ vs. (HTK) 2,2 $\pm 0,09, p<0,05$ ) oder mit beiden Eisenchelatoren in niedrigen Konzentrationen ((LK+DES(L0,02D0,2)) 1,5 $\pm 0,10$ vs. (HTK) 2,2 $\pm 0,09, p<0,0001$ ) protektionierten Transplantaten eine signifikante Reduktion der Apoptose (Abb. 22). Im Gegensatz dazu war der Apoptose-Score bei Behandlung mit der neuen Lösung und dem Zusatz Deferoxamin $(0,02 \mathrm{mM})$ ähnlich hoch wie bei der Protektionierung mit HTK-Lösung ((N36D0.2) 2,18 $\pm 0,12$ vs. (HTK) 2,2 $\pm 0,09)$ (Abb. 22). 


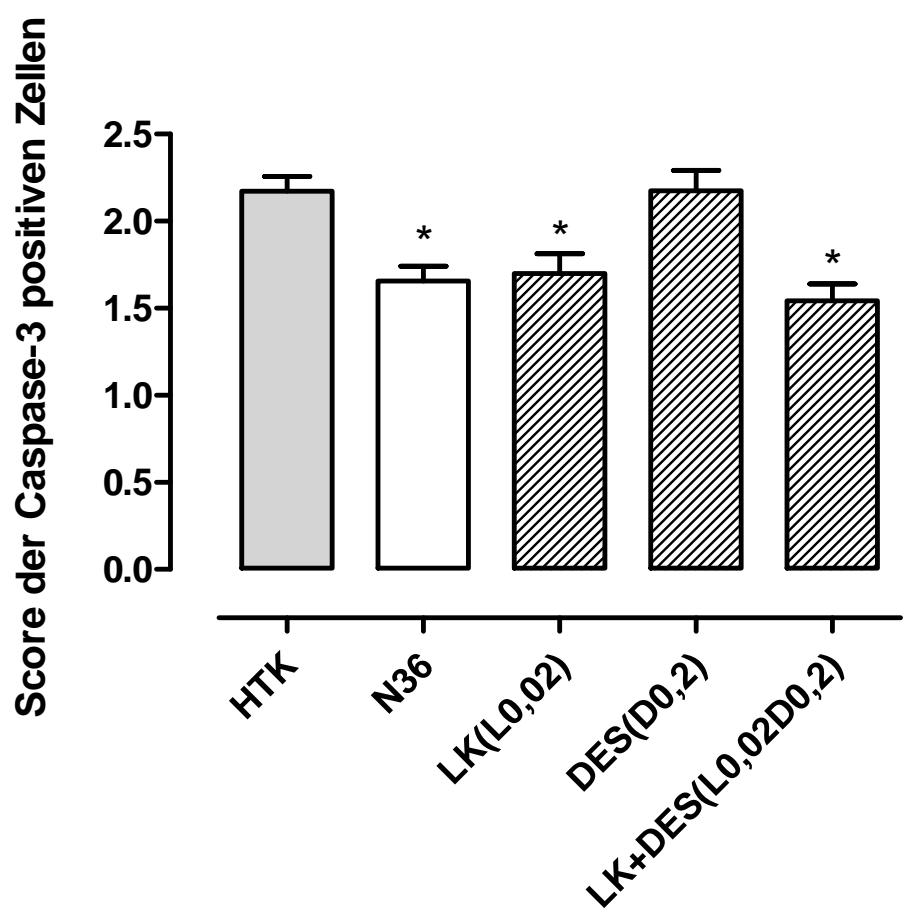

Abbildung 22: Ergebnisse der immunhistochemischen Untersuchung der Transplantate nach 24 Stunden kalter Ischämie und 40 Minuten Reperfusionsphase. Dargestellt sind die Mittelwerte des Scores für die Caspase-3 positiven Zellen im Gesichtsfeld und die Standardfehler. *: p<0,05 signifikante Unterschiede vs. HTK. Grauer Balken: HTK: herkömmliche HTK-Lösung; weiße Balken: N36-Lösung, weiße Balken mit Schraffur: N36-Lösung als Basislösung mit Zusatzstoff(en). N36: neu entwickelte Lösung; LK(0,02): N36+Lk 0,02mM; DES(D0,2): N36+Deferoxamin 0,2mM; LK+DES(L0,02D0,2): N36+LK 0,02mM+Deferoxamin 0,2mM.

\subsection{Kontrolle der Makrozirkulation}

In diesem Abschnitt sind die Ergebnisse der Kontrolle der Makrohämodynamik zusammengestellt.

Der Vergleich des Mittelwertes der mittleren arteriellen Drücke (MAD) zeigte in nur einer Gruppe (DES(D0,5)), in der die Transplantate mit der N36-Lösung und dem Zusatz des Eisenchelators Deferoxamin behandelt waren, eine signifikante Erhöhung des MAD im Vergleich zur Protektionierung mit der HTK-Lösung ((DES(D0,5)) 67,5 $\pm 4,5 \mathrm{mmHg}$ vs. (HTK) 55,0 $\pm 1,7 \mathrm{mmHg}, \mathrm{p}<0,05$ ) (Abb. 23). In den übrigen Gruppen gab es keine signifikanten Unterschiede im MAD, wobei die intravenöse Volumensubstitution mit Blick auf einen konstanten MAD erfolgte. Die Volumensubstitution lag in der initialen Reperfusionsphase (0-40 Minuten) im Mittel 
bei 9,3 $\pm 0,4 \mathrm{ml} \cdot \mathrm{h}^{-1}$ und reduzierte sich in der zweiten Phase während der Intravitalmikroskopie auf $6,8 \pm 0,2 \mathrm{ml} \cdot \mathrm{h}^{-1}$.
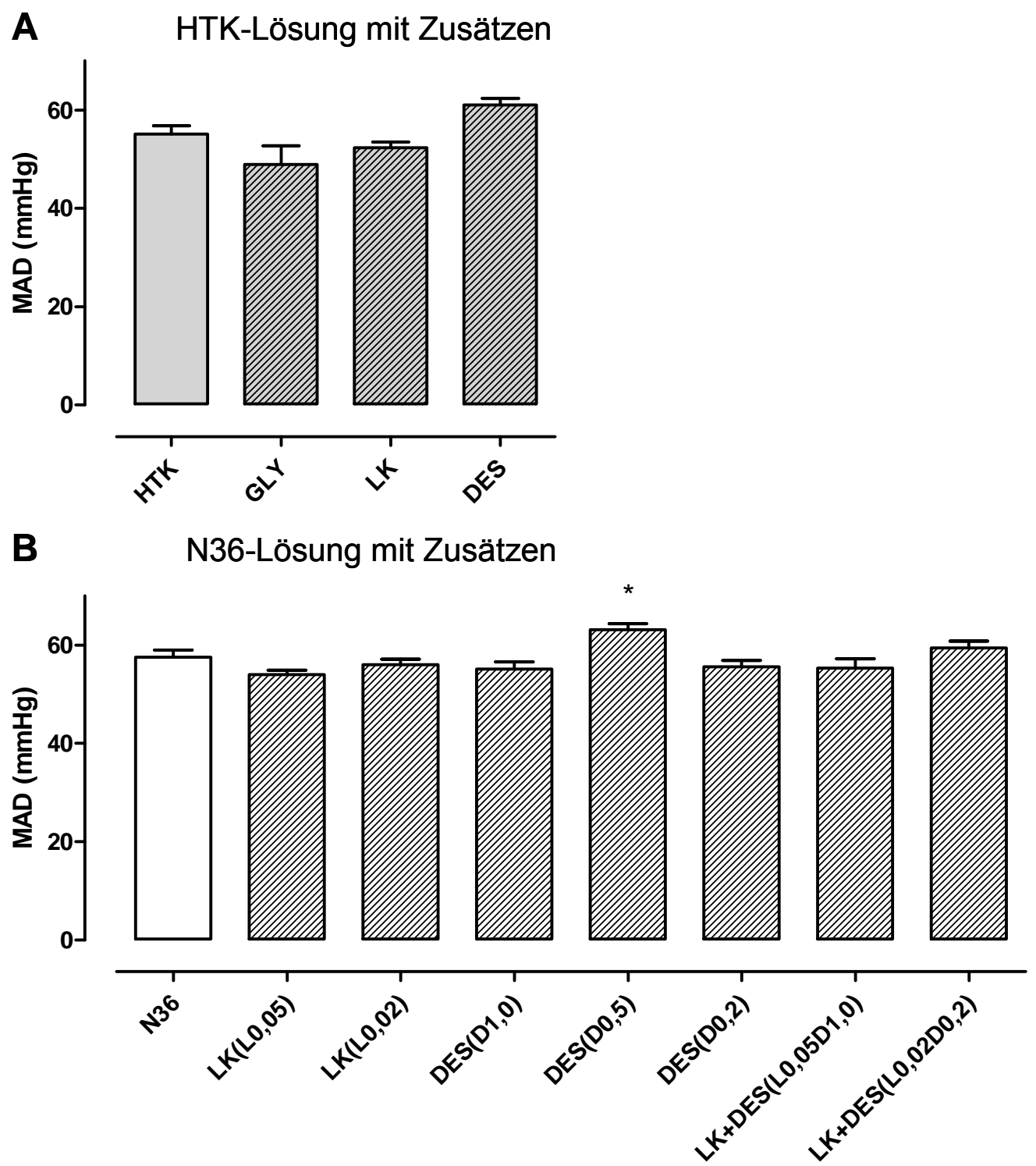

Abbildung 23: Mittlerer arterieller Druck (MAD) während der Intravitalmikroskopie. Dargestellt sind die Mittelwerte und die Standardfehler. *: $p<0,05$ signifikante Unterschiede vs. HTK. A: Graue Balken: HTK-Lösung, graue Balken mit Schraffur: HTK als Basislösung mit Zusatzstoff. HTK: herkömmliche HTK-Lösung; GLY: HTK+Glycin 10mM; LK: HTK+LK 1mM; DES: HTK+Deferoxamin 1mM; B: weiße Balken: N36-Lösung, weiße Balken mit Schraffur: N36-Lösung als Basislösung mit Zusatzstoff(en). N36: neu entwickelte Lösung; LK(0,05): N36+LK 0,05mM; LK(0,02): N36+Lk 0,02mM; DES(D1,0): N36+Deferoxamin $1 \mathrm{mM}$; DES(D0,5): N36+Deferoxamin $\quad 0,5 \mathrm{mM}$; DES(D0,2): N36+Deferoxamin $\quad 0,2 \mathrm{mM}$; 
LK+DES(L0,05D1,0): N36+LK 0,05mM+Deferoxamin 1mM; LK+DES(L0,02D0,2): N36+LK 0,02mM+Deferoxamin 0,2mM.

\section{Diskussion}

Die Transplantation des Dünndarmes ist mittlerweile eine reelle therapeutische Option im Endstadium des Kurzdarmsyndroms (Mangus et al. 2009). Das Transplantat- und Empfängerüberleben ist jedoch nicht zufriedenstellend, insbesondere, wenn man die Ergebnisse mit denen anderer Organersatzbehandlungen vergleicht, wie zum Beispiel der Nieren- oder Lebertransplantation (Vianna et al. 2008). Dies liegt vor allem daran, dass die Transplantation von intestinalem Gewebe sowohl durch eine starke Immunreaktion des Empfängers (Nakao et al. 1997), als auch durch die mukosale Hyperpermeabilität infolge der Ischämie- und Reperfusionsschädigung, kompliziert wird (Wattanasirichaigoon et al. 1999). Eine Optimierung der Organpreservation durch Einsatz neuer Protektionslösungen könnte den primären Organschaden reduzieren, die Ergebnisse nach Transplantation verbessern, den Pool an geeigneten Spendern (marginale Organe) und Empfängern vergrößern und somit möglicherweise der Problematik des Organmangels entgegenwirken.

\subsection{Protektionslösungen}

Die einfache Kaltlagerung von intestinalen Organtransplantaten in Protektionslösungen ist die herkömmliche klinische Praxis zur Reduktion des Ischämie- und Reperfusionsschadens (Tesi et al. 1996). Seit den Anfängen der Transplantationschirurgie sind dafür eine Vielzahl von Protektionslösungen mit unterschiedlichen Elektrolytzusammensetzungen entwickelt worden (Tab. 1).

Ein zentrales Arbeitsfeld bei der Entwicklung dieser Lösungen war die Verminderung eines Zell- und Gewebeödems. Initial ging man davon aus, dass ein hohes, dem intrazellulären Milieu angepasstes Kalium-Natrium-Verhältnis den Einstrom von Natrium- und Chloridionen nach intrazellulär hemmt und damit ein Zellödem verhindern kann (Baatard et al. 1993). Neuere Studien zeigen allerdings ebenso erfolgreiche oder sogar bessere Resultate mit Lösungen wie Celsior oder HistidinTryptophan-Ketoglutarat (HTK), die ein niedriges Kalium-Natrium-Verhältnis 
aufweisen (Ben Abdennebi et al. 1998, Hauet et al. 2003, Shiiya et al. 1993, Sumimoto et al. 1991, Urushihara et al. 1992, Wicomb et al. 1991). Ein niedrigerer Gesamtkaliumgehalt innerhalb einer Protektionslösung kann den beim Spülen auftretenden Vasospasmus verhindern und erleichtert möglicherweise so die Organspülung.

\subsubsection{HTK-Lösung}

Die HTK-Lösung ist eine günstige, und aufgrund niedriger Viskosität gut zu verarbeitende Protektionslösung. Sie wurde ursprünglich für die Kardioprotektion am Physiologischen Institut der Universität Göttingen entwickelt (Bretschneider 1980). Sie wird heutzutage auch als Protektionslösung für andere Organe benutzt. In einer neueren multizentrischen, randomisierten und prospektiven Studie wurden keine Unterschiede zwischen den beiden etablierten Protektionslösungen HTK- und University-of-Wisconsin-Lösung (UW) bezüglich des späten Transplantatversagen von Nieren gefunden (de Boer et al. 1999).

Zur Protektionierung von Organen mittels einfacher Kaltlagerung für länger als 24 Stunden ist die Datenlage für HTK im Vergleich zu UW kontrovers (Agarwal et al. 2006 vs. Roels et al. 1998), wobei aktuelle Daten zur Nierentransplantation (Agarwal et al. 2006) und die technischen Vorteile bei der Lebertransplantation (Testa et al. 2003) für die Verwendung von HTK sprechen. So muss die HTK-Lösung vor der Reperfusion in der Regel nicht aus dem transplantierten Organ ausgespült werden, was die Abläufe ökonomisiert.

HTK-Lösung wird daher in vielen Zentren als Standardlösung für alle abdominellen Organtransplantate verwendet (Agarwal et al. 2006). Mit Blick auf die antioxidativen Eigenschaften der Lösung hat HTK allerdings im Vergleich zu UW, in der Radikalfänger (z.B. Glutathion) enthalten sind, eine Schwäche (Rauen et al. 1997). Wegen der weiten Verbreitung und Akzeptanz von HTK, sowie der guten Verarbeitbarkeit, scheint es sinnvoll die noch vorhandenen Defizite in der Lösung (hypothermie- und hypoxieinduzierter Schaden, sowie Toxizität von Bestandteilen der Lösungen) auszugleichen (s.u.).

Verschiedene Studien konnten zeigen, dass mit der beschriebenen Methode der kaltischämischen Protektionierung Darmgewebe für 24 Stunden effektiv geschützt werden kann (Kakinoki et al. 2004, Kuroda et al. 1996). Die danach auftretende 
Fehlfunktion der mukosalen Barriere korreliert mit dem abnehmenden Adenosin 5'Triphosphat (ATP) Gehalt in der Mukosa (Wattanasirichaigoon et al. 1999).

\subsubsection{Alternative Methoden zur Organprotektion}

Daher fokussieren alternative Methoden der Organprotektion auf die Bereitstellung eines höheren Sauerstoffgehaltes in den Protektionslösungen und im Transplantatgewebe. Die „cavitary two-layer“ Methode (Kakinoki et al. 2004, Yoshikawa et al. 2005), bei der das Explantat in einer zweiphasigen, oxygenierbaren Lösung aufbewahrt wird, bedient sich dabei der physikochemischen Eigenschaften von Perfluorocarbonen. Diese Substanzen besitzen einen hohen Löslichkeitskoeffizienten für Sauerstoff und ermöglichen bei der Begasung mit Carbogen, einer Mischung aus Sauerstoff und Kohlenstoffdioxid, die Bereitstellung einer höheren Sauerstoffspannung im Gewebe bei physiologischem pH-Wert. Im tierexperimentellen Versuchsaufbau konnte damit die tolerable kalte Ischämiezeit von Dünndarmtransplantaten von $24 \mathrm{~h}$ auf $48 \mathrm{~h}$ verdoppelt werden (Kuroda et al. 1996). Bisher hat ein solches Verfahren keine klinische Anwendung gefunden.

Um zum einen dem Transplantat mehr Sauerstoff und zum anderen frische Pufferlösung zuzuführen und darüber den Gewebeschaden gering zu halten, wurden schon vor Jahrzehnten von Belzer und Kollegen Perfusionspumpensysteme propagiert (Belzer und Southard 1980, Rice et al. 1985) und für die Nierenprotektionierung entwickelt und genutzt (Hoffmann et al. 1989). Die nötige Zeit für das Zurücklegen der großen Strecken vom Organentnahme- zum Transplantationszentrum konnten so besser überbrückt werden. Die Techniken der hypo- oder normothermen Maschinenperfusion mit kontinuierlichem oder pulsatilem Fluss werden gerade unter einem neuen Gesichtspunkt „wiederentdeckt“, nämlich um den höheren Anforderungen (Minimierung des Ischämie- und Reperfusionsschadens) von marginalen, älteren, unter Umständen bereits vorgeschädigten Organen gerecht zu werden. Die Technik ist dabei mit einem deutlich erhöhten apparativen, logistischen und finanziellen Aufwand verbunden und wird daher momentan wenig genutzt (nur ca. 20\% der Nierenprotektion in den USA wird mit Maschinenperfusion durchgeführt) (Wight et al. 2003). Bei der Anwendung der kontinuierlichen Maschinenperfusion muss auch das potentiell höhere Risiko der Gewebeschädigung insbesondere am Endothel durch Scherkräfte während der Perfusion beachtet werden (Pegg 1986). 


\subsection{Hypotherme Lagerung}

Das gut etablierte, einfach durchzuführende klinische Standardverfahren zur Organprotektion ist die kaltischämische Lagerung. Die Kühlung von Zellsystemen verzögert in der Regel alle nicht-enzymatischen und enzymatischen Prozesse um den Faktor 1,5 bis 3 pro $10{ }^{\circ} \mathrm{C}$ Temperaturreduktion (Belzer und Southard 1988, Zachariassen 1991). Die Hypothermie reduziert den Zellmetabolismus und den ATPVerbrauch und vermindert die Schädigungsprozesse die durch den Energiemangel angestoßen werden.

Die prolongierte hypotherme Lagerung selbst kann jedoch eine Gewebeschädigung triggern. Dafür müssen die Zellen nicht einmal eingefroren werden. Bereits eine Reduktion der Temperatur auf 0 bis $10{ }^{\circ} \mathrm{C}$ führt zur starken Schädigung der Zellfunktionen. Es konnte gezeigt werden, dass die kalte Lagerung von verschieden Zelltypen, wie Hepatozyten, Endothelzellen oder renalen Tubulusepithelzellen bei 4 ${ }^{\circ} \mathrm{C}$ zu einem starken Verlust der Vitalität und/oder Funktion der kultivierten Zellen führt (Bartels-Stringer et al. 2003, Kerkweg et al. 2003, Peters et al. 1998, Rauen und de Groot 1998). Diese negativen Effekte treten sogar bei Ausschluss eines Sauerstoffmangels und bei Behandlung mit Protektionslösung auf (Rauen und de Groot 2004, Rauen et al. 1999, Salahudeen et al. 2000).

In der frühen Entwicklung der Transplantationsmedizin war eine geläufige Hypothese, dass die Inhibition der $\mathrm{Na}^{+} / \mathrm{K}^{+}$-ATPase mit der konsekutiven Akkumulation von intrazellulärem Natrium, Einstrom von Chlorid aus dem Extrazellularraum und Ausbildung eines Zellödems, die hypotherme Zellschädigung vermittelt (Belzer und Southard 1988, Hochachka 1986). Daher wurden die Protektionslösungen darauf ausgelegt, diesem Pathomechanismus entgegenzuwirken (Belzer und Southard 1988, Gubernatis et al. 1990, Isemer et al. 1988). Bestimmte Elektrolytzusammensetzungen, Puffersysteme, impermeable Substanzen, Kolloide und Substrate des oxidativen Stoffwechsels finden dabei ihre Anwendung (Tab. 1).

In neueren Studien hingegen zeigen verschiedene Typen von kultivierten Zellen während einer kalten Inkubation keine ansteigenden intrazellulären Natriumkonzentrationen (Fuckert et al. 2000, Gizewski et al. 1997), erfahren aber trotzdem eine hypotherme Schädigung, welche über eine eisenabhängige Bildung von reaktiven Sauerstoffspezies (ROS) vermittelt wird (Peters et al. 1998). Die Bildung dieser, hochaktiven Sauerstoffspezies wird von dem durch Kälte 
induzierbaren redoxaktivem freien, chelatisierbaren Eisenionenpool der Zellen getriggert (Rauen und de Groot 2004, Rauen et al. 2000, Rauen et al. 1999, Salahudeen et al. 2000). Dieser Schaden kann durch Eisenchelatoren inhibiert werden, aber die aktuell im klinischen Einsatz befindlichen Protektionslösungen nehmen sich diesem Mechanismus nicht an (Rauen et al. 2007 a). Insbesondere die für die intestinalen Transplantate verfügbaren Organprotektionslösungen wurden nicht vor dem Hintergrund entwickelt, kältegetriggerte, schädigende Effekte zu minimieren. Der kälteinduzierte, eisenabhängige, Schädigungsmechanismus, welcher initial in der Zellkultur entdeckte wurde (s.o.), konnte kürzlich auch für die Endothelzellen in kaltgelagerten Gefäßen (Wille et al. 2008) und Herzen (Wu K et al. 2010) gezeigt werden.

\subsection{Schutzwirkungen am Darm}

Der Darm ist in seiner Gewebezusammensetzung sehr komplex (Muskelzellen, Endothelzellen, Bindgewebszellen, Immunzellen, Enterozyten) und so ist es wahrscheinlich, dass im Darmtransplantat eine kälteinduzierte Schädigung über den redoxaktiven Eisenionenpool und ROS-Bildung eine komplexe pathophysiologische Relevanz hat.

\subsubsection{LK}

Im Einklang mit den Ergebnisse aus Versuchen an Gefäßen und Herzen (Wille et al. 2008, Wu K et al. 2010) verbesserte in den vorliegenden Experimenten der gut membrangängige, lipophile Eisenchelator LK als Zusatz zu beiden Protektionslösungen (herkömmliche HTK und neue modifizierte HTK Lösung N36) die Mikrozirkulation von kalt gelagerten Dünndarmtransplantaten, wie der Anstieg aller relevanten Perfusionsparameter (Perfusionsindex, funktionelle Kapillardichte, Blutkörperchenfließgeschwindigkeit) und die Reduktion des Apoptose-Scores belegt. LK ist ein neuartiges Hydroxamsäurederivat (Wu S et al. 2009). Der aromatische Ring gewährleistet die Lipophilie des Moleküls und vermittelt die Membranpermeabilität während die Methylierung der Hydroxamsäuregruppe seine Toxizität verhindert und die zwei Methoxygruppen am aromatischen Ring die Eigenschaft als Eisenchelator verbessern (mündliche Mitteilung unpublizierter Ergebnisse von Rauen 2006). 


\subsubsection{Deferoxamin}

Der hydrophile Eisenchelator Deferoxamin beinhaltet drei Hydroxamsäuregruppen und ist damit zwar ein sehr starker sechszähniger Ligand, jedoch auch schlechter membrangängig. Daher wurde Deferoxamin in sehr hohen Konzentrationen eingesetzt. Diese hohen Konzentrationen (0,5 und $1 \mathrm{mM})$ zeigten jedoch Hinweise auf Toxizität in einigen Parametern (Perfusionsindex, Staseindex und funktionelle Kapillardichte der Mukosa). In niedrigeren Konzentrationen (0,2mM) zeigte Deferoxamin bei einigen Parametern (Perfusionsindex, Staseindex, funktionelle Kapillardichte der Mukosa und Blutkörperchenfließgeschwindigkeit innerhalb der Mukosa) Schutzeffekte war jedoch im Vergleich dem protektiven Effekt von LK unterlegen.

\subsubsection{Kombination von LK und Deferoxamin}

Die Kombination von beiden Eisenchelatoren, welche in der Studie zur Protektion von Gefäßen von Vorteil war (Wille et al. 2008), verfehlte in der vorliegenden Studie die Überlegenheit gegenüber der alleinigen Verwendung von LK zu zeigen und hatte teils sogar gegensätzliche Effekte. Es ist gut bekannt, dass sehr starke Eisenchelatoren bzw. die Kombination von Eisenchelatoren toxische Effekte im Sinne einer Eisenverarmung erzeugen können (Chaston und Richardson 2003). Die Konzentration des starken Eisenchelators Deferoxamin in der hier verwendeten modifizierten HTK-Lösung N36 (LK+DES(L0,02D0,2)) ist noch nicht optimiert, da die positiven Effekte von LK bezüglich der histopathologischen Untersuchung durch Zugabe der niedrigeren Konzentrationen von Deferoxamin reduziert wurden. In der vorliegenden Arbeit lag der Hauptfokus allerdings darauf, den prinzipiell protektiven Effekt der modifizierten und mit Eisenchelatoren supplementierten Lösung zu zeigen.

\subsubsection{Glycin}

Für die einfache Aminosäure Glycin ist gezeigt worden, dass sie die hypoxische Schädigung von Hepatozyten, Tubuluszellen der Nieren, Endothelzellen und neuronalen Zellen vermindern kann. In den Hepatozyten scheint dieser Schutzeffekt über eine Verminderung des hypoxieinduzierten Natriumeinstroms (Carini et al. 1997, Frank et al. 2000), höchstwahrscheinlich über die Blockade der Ausbildung von hypoxieinduzierten Membranporen vermittelt zu sein (Frank et al. 2000). Die 
Blockade der Ausbildung von Membranporen durch Glycin unter Hypoxie oder anderen Bedingungen, die einen zellulären Energiemangel erzeugen, ist bereits in renalen Zellen (Dong et al. 1998) und Endothelzellen (Nishimura und Lemasters 2001) gezeigt worden. Die strukturell sehr ähnliche Aminosäure Alanin scheint über den gleichen Mechanismus ihre protektiven Effekte zu vermitteln (Frank et al. 2000). In der hier vorgestellten Studie erbrachte der Zusatz von Glycin zur herkömmlichen HTK-Lösung einen Schutzeffekt mit deutlicher Reduktion des Leukozytenindex. In den meisten der untersuchten Parameter (Perfusions- und Staseindex, funktionelle Kapillardichte der Mukosa und Blutkörperchenfließgeschwindigkeit innerhalb der Mukosa) bestand kein Unterschied zu den Werten, die bei Protektion mit der herkömmlichen HTK-Lösung erreicht wurden. Die neue modifizierte HTK-Lösung N36 verfügte jedoch über einen deutlichen Schutzeffekt und dieser ist sehr wahrscheinlich zumindest teilweise durch Glycin und Alanin bedingt, da die Zugabe von diesen beiden Zusatzstoffen eine der maßgeblichen Änderungen gegenüber der herkömmlichen HTK-Lösung ist.

\subsubsection{Puffersubstanzen}

Ein weiterer entscheidender Unterschied zwischen der herkömmlichen HTK-Lösung und N36 besteht in der Zusammensetzung der Puffersubstanzen. In der neuen modifizierten Lösung N36 ist ein Teil der Puffersubstanz Histidin durch sein Derivat Na-Acetyl-L-Histidin ersetzt. Na-Acetyl-L-Histidin hat eine ähnliche Pufferkapazität wie Histidin, dabei aber eine deutlich geringere Toxizität insbesondere in hohen Dosierungen (Rauen et al. 2007 b). Es ist also wahrscheinlich, dass die Substitution eines Teils des Histidins durch Na-Acetyl-L-Histidin, zum Teil für die Überlegenheit der neuen Lösung N36 gegenüber der herkömmlichen HTK verantwortlich ist.

Es kann nicht ausgeschlossen werden, dass einige der weiteren Änderungen in der neuen Lösung N36 gegenüber HTK ebenfalls einen Teil des zusätzlichen Schutzeffektes ausüben, jedoch scheinen die Komponenten Glycin, Alanin und NaAcetyl-L-Histidin den vermutlich größten Anteil am verbesserten Schutz zu haben und die Effekte aller Einzelkomponenten können in einer solchen, sehr aufwendigen Studie nicht untersucht werden. 


\subsection{Fazit und Ausblick}

Die Kombination von beiden Ansatzpunkten, der neuen Lösung N36 (mit Glycin, Alanin und Na-Acetyl-L-Histidin) mit zusätzlichen Eisenchelatoren, war bei dieser Studie in der Lage, eine beeindruckende Erhöhung des Perfusionsindex auf mehr als das 10-Fache zu erzielen. Die Formulierung der Lösung N36 und der Zusatz von Eisenchelatoren scheint im Sinne eines multimodalen Ansatzes geeignet zu sein, um Dünndarmtransplantate vor dem Ischämie- und Reperfusionsschaden effektiv zu schützen. Ähnliche Verbesserungen der Organkonservierung wurden unter Verwendung einer ähnlichen Basislösung mit leicht abgeänderten Konzentrationen der gleichen Eisenchelatoren für die kalte Lagerung von Leber (Wu S et al. 2009) und Herz (Wu K et al. 2010) gezeigt. Es scheint, dass N36-Lösung mit dem Zusatz von Eisenchelatoren als Protektionslösung für Dünndarmtransplantate geeignet ist, da sie zur verbesserten Aufrechterhaltung der Mikrozirkulation führte.

Bei der Protektionierung von Organen scheinen multimodale Konzepte zielführend zu sein. Die optimale Abstimmung von verträglichen lonenkonzentrationen mit nicht toxischen Puffersystemen, zellimpermeablen Substanzen, Substraten für den Stoffwechsel und möglicherweise Antioxidanzien als Gegenspielern freier Radikale ist eine Voraussetzung für den ausreichenden Schutz von Transplantaten in der extrakorporalen Phase. Die Parameter der Transplantatdurchblutung in der akuten Phase nach Reperfusion und die histomorphologischen sowie immunhistochemischen Untersuchungen zeigten in dieser Studie einen verbesserten Schutz der transplantierten Dünndärme vor der Schädigung durch die kaltischämische Lagerung unter Verwendung der neuartigen Protektionslösung N36 in Anlehnung an die herkömmliche HTK-Lösung von Bretschneider. Ob die Anwendung der neuentwickelten Lösung und der Zusatz der lipophilen und/oder hydrophilen Eisenchelatoren im transplantierten Tier auch einen Überlebensvorteil bewirken können, müssen Folgeversuche im syngenen und allogenen Transplantationsmodell zeigen. Die vorgelegte Studie eröffnet neue Einblicke in die Pathophysiologie der Transplantatschädigung von Dünndärmen im experimentellen Rattentiermodell während der Zeit zwischen der Explantation und der Implantation und könnte zu einer Optimierung der Organkonservierung sowie in der Folge der Transplantatfunktion führen. In letzter Konsequenz könnte somit das Transplantatund Empfängerüberleben nach Dünndarmtransplantation verbessert werden. 


\section{Zusammenfassung}

Aktuell sind die Protektionslösungen University-of-Wisconsin-Lösung (UW, Viaspan ${ }^{\circledR}$ ) und Histidin-Tryptophan-Ketoglutarat (HTK, Custodiol ${ }^{\circledR}$ ) für die Organkonservierung in der Transplantationsmedizin etabliert. Diese Lösungen sind in den letzten Jahrzehnten auf der Grundlage eines mechanistischen Verständnisses der Ischämieund Reperfusionsschädigung entwickelt worden. In der letzten Zeit sind jedoch die Mechanismen weiterer Schädigungsprozesse entschlüsselt worden, wie z.B. die Bildung von hypoxiebedingten Membranporen, welche durch die Aminosäuren Glycin und Alanin inhibiert werden können, der kälteinduzierte Schaden mit Bildung von reaktiven Sauerstoffspezies (ROS), der durch den redoxaktiven Eisenionenpool vermittelt wird, und nicht zuletzt die inhärente Toxizität der Protektionslösungen selbst, welche überwiegend durch die eingesetzten Puffersubstanzen hervorgerufen werden. Die traditionellen Protektionslösungen schützen gegen die genannten Prozesse nicht.

In dieser Studie wurden die protektiven Effekte einer neu entwickelten, modifizierten HTK-Lösung N36 ohne und in Kombination mit zwei verschiedenen Eisenchelatoren in unterschiedlichen Konzentrationen im syngenen Dünndarmtransplantationsmodell der Ratte untersucht. In der verwendeten Lösung sind Teile des in höherer Konzentration toxisch wirkenden Puffers Histidin durch Na-Acetyl-L-Histidin ersetzt worden. Zusätzlich sind die einfachen Aminosäuren Glycin und Alanin enthalten, um die hypoxieinduzierte Membranporenbildung zu reduzieren. Zwei in ihren Lösungseigenschaften unterschiedliche Eisenchelatoren (LK und Deferoxamin) wurden einzeln und in Kombination hinzugefügt, um den kälteinduzierten Schaden durch den intrazellulären, redoxaktiven Eisenionenpool zu unterdrücken.

Das Ausmaß und die Konsequenzen des aufgetretenen Ischämie- und Reperfusionsschadens wurden mit Hilfe der Intravitalmikroskopie, Histologie und Immunhistochemie bestimmt. Hierzu wurden auf der Ebene der Darmzotten der Perfusionsindex, der Staseindex, die funktionelle Kapillardichte und die Blutkörperchenfließgeschwindigkeit, sowie innerhalb der Muskularis bzw. Submukosa die funktionelle Kapillardichte bzw. die Leukozyten-EndothelzellInteraktion gemessen. Für die Quantifizierung des morphologischen Schadens wurde das Beurteilungssystem von Chiu und Kollegen (Chiu et al. 1970) auf die histologischen Schnitte angewendet. Für die Quantifizierung des Zelluntergangs 
verwendeten wir einen semiquantitativen Score für die Anzahl der apoptotischen epithelialen Zellen (Caspase-3 positiven Zellen) in den Transplantaten.

Die Konservierung der Transplantate in der neuen Protektionslösung N36 führte zu einer deutlichen Verminderung des Transplantatschadens. Dies wurde dokumentiert durch eine Verbesserung aller mikrozirkulatorischen sowie der histomorphologischen und immunhistochemischen Parameter. Im Einzelnen waren die Parameter im Vergleich zur Protektion mit HTK-Lösung um den folgenden Faktor (in Klammern) verbessert: funktionelle Kapillardichte der Tunica muscularis $(1,1 \mathrm{x})$, Leukozytenindex $(1,3 x)$, Perfusionsindex $(7,6 x)$, Staseindex $(1,8 x)$, funktionelle Kapillardichte der Mukosa (13,5x), Blutkörperchenfließgeschwindigkeit innerhalb der Mukosa (12x), Chiu-Score nach 40 Minuten (1,3x), Chiu-Score nach 180 Minuten $(1,6 x)$ und Apoptose-Score (1,3x). Der Zusatz des lipophilen, membrangängigen Eisenchelators LK führte bezüglich der meisten Parameter zu einer weiteren Verminderung des Ischämie- und Reperfusionsschadens, jedoch zeigte der Zusatz des potenteren, hydrophilen Eisenchelators Deferoxamin zum Teil nachteilige Effekte auf die Parameter der Mikrozirkulation und Histologie, insbesondere dann, wenn höhere Konzentrationen eingesetzt wurden.

Mit der Kombination von verschiedenen Ansatzpunkten zur Verbesserung des Konservierungsergebnisses in der neuen Lösung N36 unter Verwendung von Glycin, Alanin und Na-Acetyl-L-Histidin sowie geringen Konzentrationen zusätzlicher Eisenchelatoren konnte eine deutliche Erhöhung der Transplantatperfusion und Verminderung der histologischen Schädigungsparameter erzielt werden. Die neue Lösung N36 und der Zusatz von Eisenchelatoren scheinen geeignet zu sein, um Dünndarmtransplantate vor dem Ischämie- und Reperfusionsschaden besser als die bisher verfügbaren Lösungen $\mathrm{zu}$ schützen. $\mathrm{Ob}$ sich daraus auch ein Überlebensvorteil mit erhöhtem Transplantat- und Empfängerüberleben ergibt, könnten Folgeversuche im syngenen und allogenen Transplantationsmodell zeigen. 


\section{Literaturverzeichnis}

Agarwal A, Murdock P, Fridell JA (2006):

Comparison of histidine-tryptophan ketoglutarate solution and University of Wisconsin solution in prolonged cold preservation of kidney allografts

Transplantation $\underline{81}, 480-482$

Ames A, Wright RL, Kowada M, Thurston JM, Majno G (1968):

Cerebral ischemia. II. The no-reflow phenomenon

Am J Pathol $\underline{52}, 437-453$

Amin HJ, Zamora SA, McMillan DD, Fick GH, Butzner JD, Parsons HG, Scott RB (2002):

Arginine supplementation prevents necrotizing enterocolitis in the premature infant

J Pediatr 140, 425-431

Angelico M, Della Guardia P (2000):

Review article: hepatobiliary complications associated with total parenteral nutrition Aliment Pharmacol Ther 14 Suppl 2, 54-57

Anthoni C, Rijcken EJ, Laukoetter MG, Spiegel HU, Senninger N, Schurmann G, Krieglstein CF (2002):

Submucosal collecting venules: a reliable site for intestinal intravital microscopy in rats

J Invest Surg $\underline{15}, 259-267$

Asfar S, Zhong R, Grant D (1994):

Small bowel transplantation

Surg Clin North Am $\underline{74}, 1197-1210$

Atahan E, Ergun Y, Belge Kurutas E, Cetinus E, Guney Ergun U (2007):

Ischemia-reperfusion injury in rat skeletal muscle is attenuated by zinc aspartate J Surg Res $\underline{137}$, 109-116 
Baatard R, Pradier F, Dantal J, Karam G, Cantarovich D, Hourmant M, Bourbigot B, Soulillou JP (1993):

Prospective randomized comparison of University of Wisconsin and UW-modified, lacking hydroxyethyl-starch, cold-storage solutions in kidney transplantation Transplantation $\underline{55}, 31-35$

Bahde R, Palmes D, Gemsa O, Minin E, Stratmann U, de Groot H, Rauen U, Spiegel HU (2008):

Attenuated cold storage injury of rat livers using a modified HTK solution

J Surg Res $\underline{146}, 49-56$

Baicu SC, Taylor MJ (2002):

Acid-base buffering in organ preservation solutions as a function of temperature: new parameters for comparing buffer capacity and efficiency

Cryobiology $\underline{45}, 33-48$

Bartels-Stringer M, Kramers C, Wetzels JF, Russel FG, de Groot H, Rauen U (2003):

Hypothermia causes a marked injury to rat proximal tubular cells that is aggravated by all currently used preservation solutions

Cryobiology $\underline{47}, 82-91$

Baslow MH (1997):

A review of phylogenetic and metabolic relationships between the acylamino acids, $\mathrm{N}$-acetyl-L-aspartic acid and $\mathrm{N}$-acetyl-L-histidine, in the vertebrate nervous system J Neurochem $\underline{68}, 1335-1344$

Beath SV (2006):

Closure and summary of Ninth International Small Bowel Transplantation Symposium Transplant Proc $\underline{38}, 1657-1658$

Belzer FO, Southard JH (1980):

The future of kidney preservation

Transplantation $\underline{30}, 161-165$

Belzer FO, Southard JH (1988):

Principles of solid-organ preservation by cold storage

Transplantation 4도 $673-676$ 
Ben Abdennebi H, Steghens JP, Margonari J, Ramella-Virieux S, Barbieux A, Boillot O (1998):

High-Na+ low-K+ UW cold storage solution reduces reperfusion injuries of the rat liver graft

Transpl Int $\underline{11}$, 223-230

Bessems M, Doorschodt BM, Hooijschuur O, van Vliet AK, van Gulik TM (2005 a):

Optimization of a new preservation solution for machine perfusion of the liver: which is the preferred colloid?

Transplant Proc $\underline{37}, 329-331$

Bessems M, Doorschodt BM, van Vliet AK, van Gulik TM (2005 b):

Improved rat liver preservation by hypothermic continuous machine perfusion using polysol, a new, enriched preservation solution

Liver Transpl 11, 539-546

de Boer J, de Meester J, Smits JMA, Groenewoud AF, Bok A, van der Velde O, Doxiadis IIN, Persijn GG (1999):

Eurotransplant randomized multicenter kidney graft preservation study comparing HTK with UW and Euro-Collins

Transpl Int $\underline{12}, 447-453$

Bohlen HG, Gore RW (1976):

Preparation of rat intestinal muscle and mucosa for quantitative microcirculatory studies

Microvasc Res $11,103-110$

Bond GJ, Mazariegos GV, Sindhi R, Abu-Elmagd KM, Reyes J (2005):

Evolutionary experience with immunosuppression in pediatric intestinal transplantation

J Pediatr Surg 쓰, 274-280

Bonventre JV, Cheung JY (1985):

Effects of metabolic acidosis on viability of cells exposed to anoxia Am J Physiol 249, 149-159 


\section{Braun F, Broering D, Faendrich F (2007):}

Small intestine transplantation today

Langenbecks Arch Surg 392, 227-238

\section{Bretschneider HJ (1980):}

Myocardial protection

Thorac Cardiovasc Surg 28, 295-302

Carini R, Bellomo G, Grazia De Cesaris M, Albano E (1997):

Glycine protects against hepatocyte killing by $\mathrm{KCN}$ or hypoxia by preventing intracellular $\mathrm{Na}+$ overload in the rat

Hepatology $\underline{26}, 107-112$

\section{Chaston TB, Richardson DR (2003):}

Iron chelators for the treatment of iron overload disease: relationship between structure, redox activity, and toxicity

Am J Hematol $\underline{73}$, 200-210

Chiu CJ, McArdle AH, Brown R, Scott HJ, Gurd FN (1970):

Intestinal mucosal lesion in low-flow states. I. A morphological, hemodynamic, and metabolic reappraisal

Arch Surg 101, 478-483

Choi BM, Pae HO, Jang SI, Kim YM, Chung HT (2002):

Nitric oxide as a pro-apoptotic as well as anti-apoptotic modulator

J Biochem Mol Biol $\underline{35}, 116-126$

\section{Dong Z, Patel Y, Saikumar P, Weinberg JM, Venkatachalam MA (1998):}

Development of porous defects in plasma membranes of adenosine triphosphatedepleted Madin-Darby canine kidney cells and its inhibition by glycine

Lab Invest $\underline{78}, 657-668$

\section{Drescher MJ, Drescher DG (1991):}

$\mathrm{N}$-acetylhistidine, glutamate, and beta-alanine are concentrated in a receptor cell layer of the trout inner ear J Neurochem $\underline{56}, 658-664$ 


\section{Eppihimer MJ, Granger DN (1997):}

Ischemia/reperfusion-induced leukocyte-endothelial interactions in postcapillary venules

Shock 으, 16-25

Fishbein TM, Schiano T, Leleiko N, Facciuto M, Ben-Haim M, Emre S, Sheiner PA, Schwartz ME, Miller CM (2002):

An integrated approach to intestinal failure: results of a new program with total parenteral nutrition, bowel rehabilitation, and transplantation

J Gastrointest Surg $\underline{6}, 554-562$

Frank A, Rauen U, de Groot H (2000):

Protection by glycine against hypoxic injury of rat hepatocytes: inhibition of ion fluxes through nonspecific leaks

J Hepatol $\underline{32}$, 58-66

Fuckert O, Rauen U, de Groot H (2000):

A role for sodium in hypoxic but not in hypothermic injury to hepatocytes and LLCPK1 cells

Transplantation $\underline{70}, 723-730$

Furukawa H, Smith C, Lee R, Knisely AS, Irish W, Reyes J, Abu-Elmagd K, Starzl TE, Todo S (1997):

Influence of donor criteria on early outcome after intestinal transplantation

Transplant Proc $\underline{29}, 690$

Ghanekar A, Grant D (2001):

Small bowel transplantation

Curr Opin Crit Care $\underline{7}, 133-137$

Gizewski ER, Rauen U, Kirsch M, Reuters I, Diederichs H, de Groot H (1997):

Rapid decrease in cellular sodium and chloride content during cold incubation of cultured liver endothelial cells and hepatocytes

Biochem J 322, 693-699

Gonzalez AP, Sepulveda S, Massberg S, Baumeister R, Menger MD (1994):

In vivo fluorescence microscopy for the assessment of microvascular reperfusion injury in small bowel transplants in rats

Transplantation $\underline{58}, 403-408$ 
Grant D, Abu-Elmagd K, Reyes J, Tzakis A, Langnas A, Fishbein T, Goulet O, Farmer D (2005):

2003 report of the intestine transplant registry: a new era has dawned

Ann Surg 241, 607-613

de Groot H, Rauen U (2007):

Ischemia-reperfusion injury: processes in pathogenetic networks: a review

Transplant Proc 39, 481-484

Gubernatis G, Pichlmayr R, Lamesch P, Grosse H, Bornscheuer A, Meyer HJ, Ringe B, Farle M, Bretschneider HJ (1990):

HTK-solution (Bretschneider) for human liver transplantation. First clinical experiences

Langenbecks Arch Chir $\underline{375}$, 66-70

Gute DC, Ishida T, Yarimizu K, Korthuis R J (1998):

Inflammatory responses to ischemia and reperfusion in skeletal muscle

Mol Cell Biochem 179, 169-187

Hansen TN, Dawson PE, Brockbank KG (1994):

Effects of hypothermia upon endothelial cells: mechanisms and clinical importance Cryobiology $\underline{31}, 101-106$

Hauet T, Han Z, Doucet C, Ramella-Virieux S, Hadj Aissa A, Carretier M, Papadopoulos V (2003):

A modified University of Wisconsin preservation solution with high-NA+ low-K+ content reduces reperfusion injury of the pig kidney graft

Transplantation $\underline{76}, 18-27$

Hochachka PW (1986):

Defense strategies against hypoxia and hypothermia

Science 231, 234-241

Hoffmann RM, Stratta R J, D'Alessandro AM, Sollinger HW, Kalayoglu M, Pirsch JD, Southard JH, Belzer FO (1989):

Combined cold storage-perfusion preservation with a new synthetic perfusate Transplantation 47, 32-37 


\section{Huang H, Salahudeen AK (2002):}

Cold induces catalytic iron release of cytochrome P-450 origin: a critical step in cold storage-induced renal injury

Am J Transplant 2, 631-639

Isemer FE, Ludwig A, Schunck O, Bretschneider HJ, Peiper HJ (1988):

Kidney procurement with the HTK solution of Bretschneider

Transplant Proc $\underline{20}, 885-886$

Jamieson NV, Sundberg R, Lindell S, Claesson K, Moen J, Vreugdenhil PK, Wight DG, Southard JH, Belzer FO (1988):

Preservation of the canine liver for $24-48$ hours using simple cold storage with UW solution

Transplantation $\underline{46}, 517-522$

Junqueira LC, Carneiro J:

Histologie. 4. Auflage; Springer-Verlag, Berlin 1996, 506

Kakinoki K, Fujino Y, Suzuki Y, Li S, Yoshikawa T, Tanioka Y, Ku Y, Kuroda Y (2004):

Protection against ischemia/reperfusion injury by the cavitary two-layer method in canine small intestinal transplantation with reduction of reactive oxygen species

Surgery $\underline{135}$, 642-648

\section{Kapitza HG:}

Mikroskopieren von Anfang an. 2. Auflage; Carl Zeiss Verlag, Oberkochen 1994, 30

Karam G, Compagnon P, Hourmant M, Despins P, Duveau D, Noury D, Boudjema K (2005):

A single solution for multiple organ procurement and preservation

Transpl Int $\underline{18}, 657-663$

Kerkweg U, Li T, de Groot H, Rauen U (2002):

Cold-induced apoptosis of rat liver cells in University of Wisconsin solution: the central role of chelatable iron

Hepatology $\underline{35}, 560-567$ 
Kerkweg U, Jacob M, de Groot H, Mannherz HG, Rauen U (2003):

Cold-induced apoptosis of rat liver endothelial cells: contribution of mitochondrial alterations

Transplantation $\underline{76}$, 501-508

Kerkweg $\mathbf{U}$, de Groot $\mathbf{H}$, Rauen $\boldsymbol{U}$ in Essen: mündliche Mitteilung über Kälteschädigung von Zellen in der Zellkultur (2004)

Klyscz T, Junger M, Jung F, Zeintl H (1997):

Cap image - a new kind of computer-assisted video image analysis system for dynamic capillary microscopy

Biomed Tech 42, 168-175

Kozar RA, Schultz SG, Bick RJ, Poindexter BJ, Desoignie R, Moore FA (2004):

Enteral glutamine but not alanine maintains small bowel barrier function after ischemia/reperfusion injury in rats

Shock 21, 433-437

Kuroda Y, Sakai T, Suzuki Y, Tanioka Y, Matsumoto S, Kim Y, Fujita H, Hamano M, Hasegawa Y, Ku Y et al. (1996):

Small bowel preservation using a cavitary two-layer (University of Wisconsin solution/perfluorochemical) cold storage method

Transplantation $\underline{61}, 370-373$

Lee MA, McCauley RD, Kong SE, Hall JC (2002):

Influence of glycine on intestinal ischemia-reperfusion injury

JPEN J Parenter Enteral Nutr $\underline{26}$, 130-135

Lemasters JJ (2004):

Rusty notions of cell injury

J Hepatol 40, 696-698

Maathuis MH, Leuvenink HG, Ploeg RJ (2007):

Perspectives in organ preservation

Transplantation 우, 1289-1298 


\section{Mangino JE, Kotadia B, Mangino MJ (1996):}

Characterization of hypothermic intestinal ischemia-reperfusion injury in dogs. Effects of glycine

Transplantation $\underline{62}, 173-178$

Mangus R, Vianna R, Tector A (2009):

Intestinal transplantation: an overview

Minerva Chir $\underline{64}, 45-57$

Maroulis J, Kalfarentzos F (2000):

Complications of parenteral nutrition at the end of the century

Clin Nutr $\underline{19}$, 295-304

Marsh DC, Vreugdenhil PK, Mack VE, Belzer FO, Southard JH (1993):

Glycine protects hepatocytes from injury caused by anoxia, cold ischemia and mitochondrial inhibitors, but not injury caused by calcium ionophores or oxidative stress

Hepatology $\underline{17}, 91-98$

Marzi I, Knee J, Menger MD, Harbauer G, Buhren V (1991):

Hepatic microcirculatory disturbances due to portal vein clamping in the orthotopic rat liver transplantation model

Transplantation $\underline{52}, 432-436$

Massberg S, Messmer K (1998):

The nature of ischemia/reperfusion injury

Transplant Proc $\underline{30}$, 4217-4223

Massberg S, Gonzalez AP, Leiderer R, Menger MD, Messmer K (1998 a):

In vivo assessment of the influence of cold preservation time on microvascular reperfusion injury after experimental small bowel transplantation

Br J Surg 모, 127-133

Massberg S, Leiderer R, Gonzalez AP, Menger MD, Messmer K (1998 b):

Carolina rinse attenuates postischemic microvascular injury in rat small bowel isografts

Surgery $\underline{123}, 181-190$ 
Mazzoni MC, Borgstrom P, Intaglietta M, Arfors KE (1989):

Lumenal narrowing and endothelial cell swelling in skeletal muscle capillaries during hemorrhagic shock

Circ Shock $\underline{29}$, 27-39

McCord JM (1985):

Oxygen-derived free radicals in postischemic tissue injury

N Engl J Med 312, 159-163

Menasche P, Termignon JL, Pradier F, Grousset C, Mouas C, Alberici G, Weiss M, Piwnica A, Bloch G (1994):

Experimental evaluation of Celsior, a new heart preservation solution

Eur J Cardiothorac Surg $\underline{8}, 207-213$

Menger MD, Marzi I, Messmer K (1991):

In vivo fluorescence microscopy for quantitative analysis of the hepatic microcirculation in hamsters and rats

Eur Surg Res 23, 158-169

Menger MD, Pelikan S, Steiner D, Messmer K (1992):

Microvascular ischemia-reperfusion injury in striated muscle: significance of "reflow paradox"

Am J Physiol 263, 1901-1906

Monchik GJ, Russell PS (1971):

Transplantation of small bowel in the rat: technical and immunological considerations Surgery $\underline{70}, 693-702$

Nakao M, Taguchi T, Yanai K, Yamada T, Suita S (1997):

Energy metabolism during cold ischemia and reperfusion in rat small intestinal transplantation: comparison of jejunal and ileal grafts

J Pediatr Surg 32, 1675-1678

Nishimura Y, Lemasters JJ (2001):

Glycine blocks opening of a death channel in cultured hepatic sinusoidal endothelial cells during chemical hypoxia

Cell Death Differ $\underline{8}$, 850-858 
Nolte D, Zeintl H, Steinbauer M, Pickelmann S, Messmer K (1995):

Functional capillary density: an indicator of tissue perfusion?

Int J Microcirc Clin Exp 15, 244-249

Pedotti P, Cardillo M, Rigotti P, Gerunda G, Merenda R, Cillo U, Zanus G, Baccarani U, Berardinelli ML, Boschiero L et al. (2004):

A comparative prospective study of two available solutions for kidney and liver preservation

Transplantation $\underline{77}, 1540-1545$

Pegg DE (1986):

Organ preservation

Surg Clin North Am $\underline{66}, 617-632$

Peters SM, Rauen U, Tijsen MJ, Bindels RJ, van Os $\mathrm{CH}$, de Groot $\mathrm{H}$, Wetzels JF (1998):

Cold preservation of isolated rabbit proximal tubules induces radical-mediated cell injury

Transplantation $\underline{65}, 625-632$

Petrat F in Essen: mündliche Mitteilung von Befunden im Ratten-Tiermodell (2006)

Pisarenko OI, Rosenfeldt FL, Langley L, Conyers RA, Richards SM (1995):

Differing protection with aspartate and glutamate cardioplegia in the isolated rat heart Ann Thorac Surg $\underline{59}, 1541-1548$

Post S, Menger MD, Rentsch M, Gonzalez AP, Herfarth C, Messmer K (1992):

The impact of arterialization on hepatic microcirculation and leukocyte accumulation after liver transplantation in the rat

Transplantation $\underline{54}, 789-794$

Rauen U, de Groot H (1998):

Cold-induced release of reactive oxygen species as a decisive mediator of hypothermia injury to cultured liver cells

Free Radic Biol Med 24, 1316-1323 


\section{Rauen U, de Groot H (2002):}

Mammalian cell injury induced by hypothermia- the emerging role for reactive oxygen species

Biol Chem $\underline{383}, 477-488$

Rauen U, de Groot H (2004):

New insights into the cellular and molecular mechanisms of cold storage injury

J Investig Med 52, 299-309

Rauen U, de Groot H (2008):

Inherent toxicity of organ preservation solutions to cultured hepatocytes

Cryobiology $\underline{56}, 88-92$

Rauen U, Bruns W, de Groot $\mathbf{H}$ in Essen: mündliche Mitteilung über die Toxizität von Eisenchelatoren (2006)

Rauen U, Reuters I, Fuchs A, de Groot H (1997):

Oxygen-free radical-mediated injury to cultured rat hepatocytes during cold incubation in preservation solutions

Hepatology 26, 351-357

Rauen U, Polzar B, Stephan H, Mannherz HG, de Groot H (1999):

Cold-induced apoptosis in cultured hepatocytes and liver endothelial cells: mediation by reactive oxygen species

FASEB J $13,155-168$

\section{Rauen U, Petrat F, Li T, de Groot H (2000):}

Hypothermia injury/cold-induced apoptosis--evidence of an increase in chelatable iron causing oxidative injury in spite of low $\mathrm{O} 2-/ \mathrm{H} 2 \mathrm{O} 2$ formation

FASEB J $\underline{14}, 1953-1964$

Rauen U, Kerkweg U, de Groot H (2007 a):

Iron-dependent vs. iron-independent cold-induced injury to cultured rat hepatocytes: a comparative study in physiological media and organ preservation solutions Cryobiology $\underline{54}, 77-86$ 


\section{Rauen U, Klempt S, de Groot H (2007 b):}

Histidine-induced injury to cultured liver cells, effects of histidine derivatives and of iron chelators

Cell Mol Life Sci $\underline{64}, 192-205$

Rhoads JM, Wu G (2009):

Glutamine, arginine, and leucine signaling in the intestine

Amino Acids $\underline{37}, 111-122$

Rhoads JM, Liu Y, Niu X, Surendran S, Wu G (2008):

Arginine stimulates cdx2-transformed intestinal epithelial cell migration via a mechanism requiring both nitric oxide and phosphorylation of p70 S6 kinase

J Nutr $\underline{138}, 1652-1657$

Rice MJ, Southard JH, Hoffmann RM, Belzer FO (1985):

Effects of hypothermic kidney preservation on the isolated perfused kidney: a comparison of reperfusion methods

Cryobiology $\underline{22}, 161-167$

Richards DM, Deeks JJ, Sheldon TA, Shaffer JL (1997):

Home parenteral nutrition: a systematic review

Health Technol Assess 1, 1-59

Roels L, Coosemans W, Donck J, Maes B, Peeters J, Vanwalleghem J, Pirenne J, Vanrenterghem $Y$ (1998):

Inferior outcome of cadaveric kidneys preserved for more than $24 \mathrm{hr}$ in histidinetryptophan-ketoglutarate solution. Leuven Collaborative Group for Transplantation Transplantation $\underline{66}, 1660-1664$

Rosenfeldt FL, Korchazhkina OV, Richards SM, Fisher JL, Tong S, Pisarenko OI (1998):

Aspartate improves recovery of the recently infarcted rat heart after cardioplegic arrest

Eur J Cardiothorac Surg 14, 185-190 
Ross H, Marshall VC, Escott ML (1976):

72-hr canine kidney preservation without continuous perfusion

Transplantation $\underline{21}$, 498-501

Salahudeen AK, Huang H, Patel P, Jenkins JK (2000):

Mechanism and prevention of cold storage-induced human renal tubular cell injury

Transplantation $\underline{70}, 1424-1431$

Salehi P, Bigam DL, Ewaschuk JB, Madsen KL, Sigurdson GT, Jewell LD, Churchill TA (2008):

Alleviating intestinal ischemia-reperfusion injury in an in vivo large animal model: developing an organ-specific preservation solution

Transplantation $\underline{85}, 878-884$

Shiiya N, Paul M, Benvenuti C, Astier A, Ferrer MJ, Loisance D (1993):

A lactobionate-based extracellular-type solution for donor heart preservation

J Heart Lung Transplant 12, 476-483

Southard JH, van Gulik TM, Ametani MS, Vreugdenhil PK, Lindell SL, Pienaar BL, Belzer FO (1990):

Important components of the UW solution

Transplantation $\underline{49}, 251-257$

Springer TA (1990):

Adhesion receptors of the immune system

Nature $\underline{346}, 425-434$

Stojanovic T, Schlemminger R, Bedke J, Grone HJ, Heuser M, Leister I, Hecker M, Becker H, Markus PM (2000):

In vivo changes in acute rejection of rat small bowel allografts

Transplant Proc 32, 1247-1248

Stojanovic T, Bedke J, Grone HJ, Proudfoot AE, Becker H, Markus P, Hecker M (2002):

Met-RANTES inhibition of mucosal perfusion failure in acute intestinal transplant rejection - role of endothelial cell-leukocyte interaction

J Vasc Res $\underline{39}, 51-58$ 


\section{Sumimoto R, Kamada N, Jamieson NV, Fukuda Y, Dohi K (1991):}

A comparison of a new solution combining histidine and lactobionate with UW solution and eurocollins for rat liver preservation

Transplantation 51, 589-593

Tesi RJ, Jaffe BM, McBride G, Haque S (1996):

Human small bowel preservation injury in University of Wisconsin solution

Transplant Proc 료, 2609-2610

Testa G, Malago M, Nadalin S, Treptow B, Paul A, Frilling A, Broelsch CE (2003):

Histidine-tryptophan-ketoglutarate versus University of Wisconsin solution in living donor liver transplantation: results of a prospective study

Liver Transpl $\underline{9}$, 822-826

Turut H, Kurutas EB, Bulbuloglu E, Yasim A, Ozkaya M, Onder A, Imrek SS (2009):

Zinc aspartate alleviates lung injury induced by intestinal ischemia-reperfusion in rats

J Surg Res 151, 62-67

Urushihara T, Sumimoto R, Sumimoto K, Jamieson NV, Ito H, Ikeda M, Fukuda Y, Dohi K (1992):

A comparison of some simplified lactobionate preservation solutions with standard UW solution and Eurocollins solution for pancreas preservation

Transplantation $\underline{53}, 750-754$

Vianna RM, Mangus RS, Tector AJ (2008):

Current status of small bowel and multivisceral transplantation

Adv Surg 42, 129-150

Vollmar B, Menger MD (1998):

The use of intravital microscopy in surgical research.

Langenbecks Arch Surg $\underline{383}, 282-285$

Wahlberg JA, Southard JH, Belzer FO (1986):

Development of a cold storage solution for pancreas preservation

Cryobiology $\underline{23}, 477-482$ 


\section{Wattanasirichaigoon S, Menconi MJ, Delude RL, Fink MP (1999):}

Effect of mesenteric ischemia and reperfusion or hemorrhagic shock on intestinal mucosal permeability and ATP content in rats

Shock $\underline{12}, 127-133$

Weinberg JM, Venkatachalam MA, Garzo-Quintero R, Roeser NF, Davis JA (1990):

Structural requirements for protection by small amino acids against hypoxic injury in kidney proximal tubules

Faseb J $\underline{4}, 3347-3354$

Wicomb WN, Collins AB, Tokunaga Y, Esquivel C (1991):

Choice of cation in solutions for hypothermic storage of liver and heart. High-sodium versus high-potassium

Transplantation $\underline{51}, 281-282$

Wight JP, Chilcott JB, Holmes MW, Brewer N (2003):

Pulsatile machine perfusion vs. cold storage of kidneys for transplantation: a rapid and systematic review

Clin Transplant 17, 293-307

Wille T, de Groot H, Rauen U (2008):

Improvement of the cold storage of blood vessels with a vascular preservation solution. Study in porcine aortic segments

J Vasc Surg $\underline{47}, 422-431$

Wu K, Turk TR, Rauen U, Su S, Feldkamp T, de Groot H, Wiswedel I, Baba H A, Kribben A, Witzke O (2010):

Prolonged cold storage using a new histidine-tryptophan-ketoglutarate-based preservation solution in isogeneic cardiac mouse grafts

Eur Heart J doi:10.1093/eurheartj/ehq135

Wu S, Wohlschlaeger J, de Groot H, Rauen U (2009):

Evaluation of a modified HTK solution containing the new iron chelator LK 614 in an isolated rat liver perfusion model

J Invest Surg 22, 340-347 
Yoshikawa T, Suzuki Y, Fujino Y, Kakinoki K, Li S, Goto T, Tanaka T, Matsumoto I, Sakai T, Tanioka Y et al. (2005):

Detailed analysis of mucosal restoration of the small intestine after the cavitary twolayer cold storage method

Am J Transplant $\underline{5}, 2135-2142$

Zachariassen KE (1991):

Hypothermia and cellular physiology

Arctic Med Res 50 Suppl 6, 13-7

Zeintl H, Sack FU, Intaglietta M, Messmer K (1989):

Computer assisted leukocyte adhesion measurement in intravital microscopy

Int J Microcirc Clin Exp $\underline{8}$, 293-302

Zhong Z, Wheeler MD, Li X, Froh M, Schemmer P, Yin M, Bunzendaul H, Bradford B, Lemasters JJ (2003):

L-Glycine: a novel antiinflammatory, immunomodulatory, and cytoprotective agent Curr Opin Clin Nutr Metab Care $\underline{6}$, 229-40 


\section{Abbildungsverzeichnis}

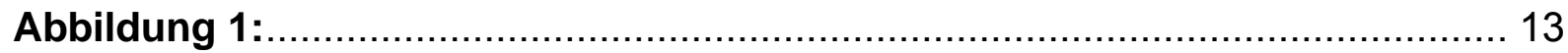

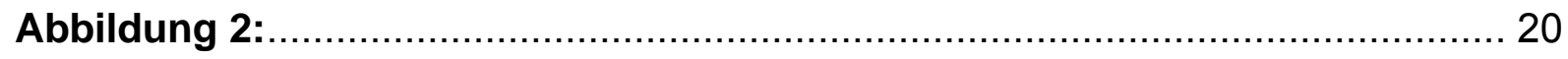

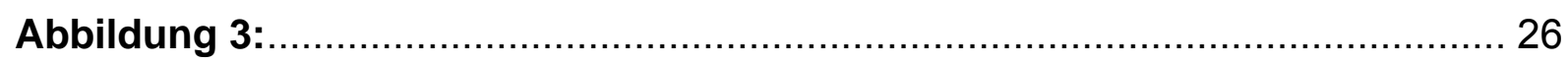

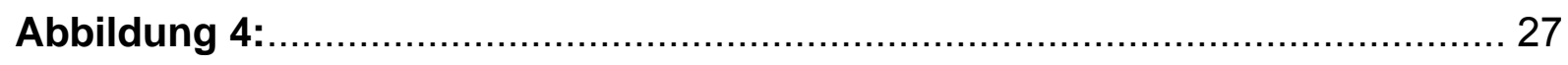

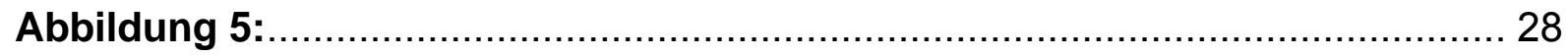

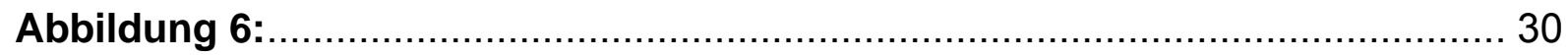

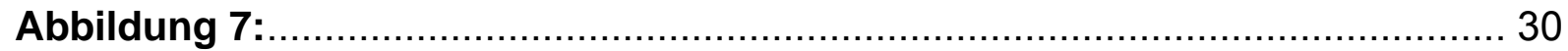

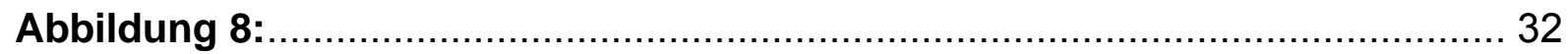

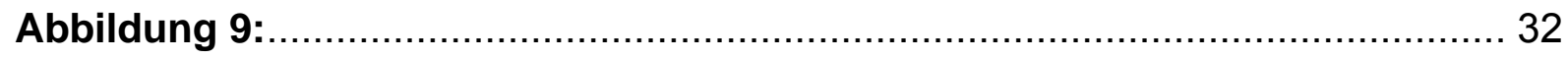

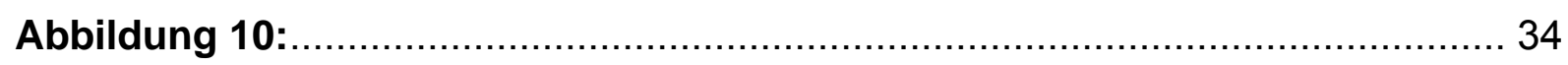

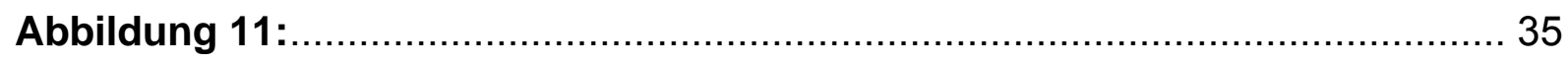

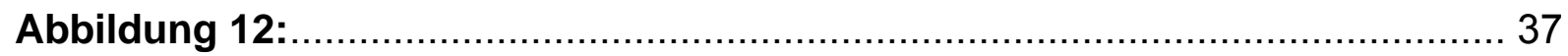

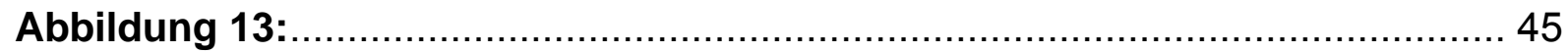

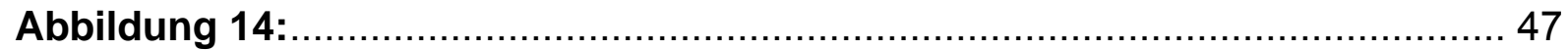

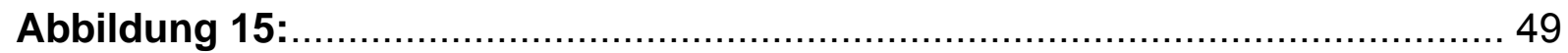

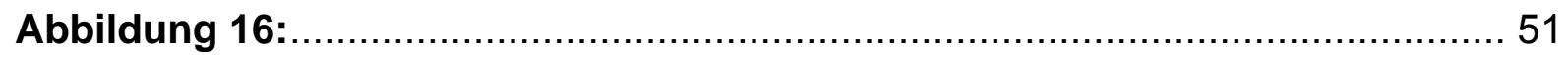

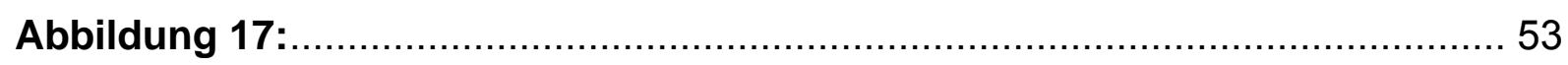

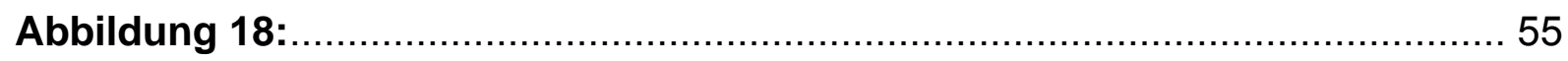

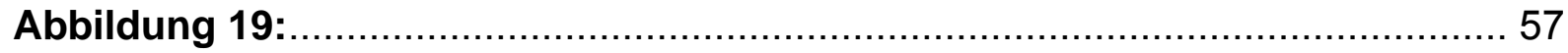

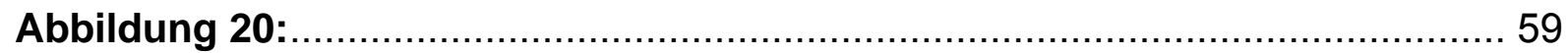

Abbildung 21:

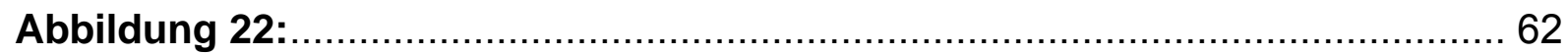

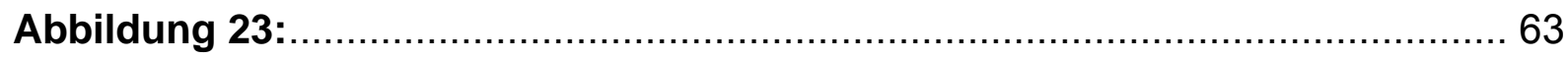




\section{Tabellenverzeichnis}

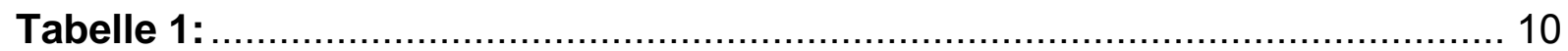

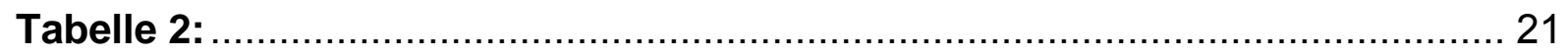

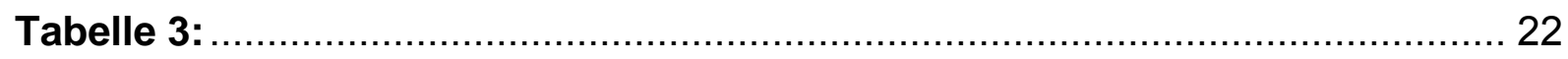

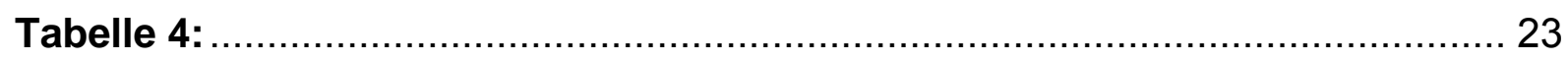

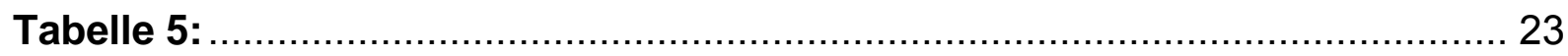




\section{Danksagung}

Herrn Prof. Dr. med. Dipl.-Phys. Friedrich-Albert Schöndube danke ich für die Unterstützung und Förderung, die die Durchführung der Versuche und die Erstellung dieser Arbeit ermöglicht haben.

Besonderen Dank entbiete ich Herrn PD Dr. med. Tomislav Stojanovic für die Überlassung des Themas dieser Arbeit sowie seine uneingeschränkte Unterstützung bei dieser Arbeit. Seine geduldige Anleitung zum eigenständigen wissenschaftlichen Arbeiten hat maßgeblich zu dem Gelingen dieser Arbeit beigetragen.

Herrn PD Dr. med. Peter Middel danke ich für die exzellente Unterstützung bei den histopathologischen Fragestellungen sowie der abschließenden Beurteilung der Gewebeschnitte.

Frau Prof. Dr. med. Ursula Rauen danke ich für die zur Verfügungstellung der Protektionslösungen sowie die Diskussion der Versuchsergebnisse.

Herrn Dr. med. Jens Bedke und Herrn Dr. med Lutz Scheele danke ich für die Einweisung in die Methode der Intravitalmikroskopie.

Frau Regina Waldmann-Beushausen danke ich für die Beratung und Unterstützung bei der Immunhistochemie sowie für die Anfertigung der immunhistochemischen Gewebeschnitte.

Frau Rosi Streich danke ich für ihre Hilfe bei der Herstellung der Gewebeschnitte. 